Florida International University FIU Digital Commons

$11-4-2011$

\title{
Endocrine Regulation of Dynamic Communication Signals in Gymnotiform Fish
}

Anna Goldina

Florida International University, agoldi01@fiu.edu

DOI: $10.25148 /$ etd.FI1 1120803

Follow this and additional works at: https://digitalcommons.fiu.edu/etd

\section{Recommended Citation}

Goldina, Anna, "Endocrine Regulation of Dynamic Communication Signals in Gymnotiform Fish" (2011). FIU Electronic Theses and Dissertations. 521.

https://digitalcommons.fiu.edu/etd/521 


\title{
FLORIDA INTERNATIONAL UNIVERSITY \\ Miami, Florida
}

\section{ENDOCRINE REGULATION OF DYNAMIC COMMUNICATION SIGNALS IN GYMNOTIFORM FISH}

\author{
A dissertation submitted in partial fulfillment of the \\ requirements for the degree of \\ DOCTOR OF PHILOSOPHY \\ in \\ BIOLOGY \\ by \\ Anna Goldina
}

2011 
To: Dean Kenneth G. Furton

College of Arts and Sciences

This dissertation, written by Anna Goldina, and entitled Endocrine Regulation of Dynamic Communication Signals in Gymnotiform Fish, having been approved in respect to style and intellectual content, is referred to you for judgment.

We have read this dissertation and recommend that it be approved.

Maureen Donnelly

Matthew Grober

Lidia Kos

Robert Lickliter

Philip K. Stoddard, Major Professor

Date of Defense: November 4, 2011

The dissertation of Anna Goldina is approved.

\begin{tabular}{r}
\hline Dean Kenneth G. Furton \\
College of Arts and Sciences \\
\hline Dean Lakshmi N. Reddi \\
University Graduate School
\end{tabular}

Florida International University, 2011 


\section{DEDICATION}

This dissertation is dedicated to my parents, Gregory and Emma Goldin, and my

husband, Dmitriy Krichevskiy. Without their love, support, and belief in my abilities, I would not have been able to complete this project. 


\section{ACKNOWLEDGMENTS}

I am so grateful to my committee members; Maureen Donnelly, Matthew Grober, Lidia Kos, Robert Lickliter and Philip Stoddard for their support, understanding, time, and guidance. Their expertise and constructive criticism has been essential to the success of this project. Especially, I would like to acknowledge my major professor, Philip K. Stoddard. From the beginning to the end of my graduate career, he has been an inspiration. In every conversation he conveyed the passion he has for science, mentorship and service. Through kindness, patience and a never-ending belief in my abilities, Phil gave me room to grow as a scientist and a teacher, helping me recognize my purpose along the way.

My labmates were instrumental in the completion of this project. Through all the successes and failures of graduate school, they made the graduate experience unforgettable. Especially, I would like to thank Dr. Michael Markham for his generous invitation to participate in what became chapter II of my dissertation. Without him this dissertation project would not exist. Vielka Salazar, Susan J. Allee, Justin Tackney, Christine Munoz, Sat Gavassa, Carol Curtis, Arthur Martin, and Jandouwe Villinger helped me learn new techniques, troubleshoot failed experiments, analyze data and edit manuscripts. The undergraduate students whom I've had the pleasure of training and working with; Christian Agudelo, Michael Helbig, James Roach, Juan Molina, Pedro Perez and Manny Gonzalez, taught me so much about mentorship and humility. 
I would also like to thank my fellow graduate students and faculty on the $2^{\text {nd }}$ floor of the HLS building. Their humor, support, and friendship made HLS always feel like a seond home.

My research has been supported by multiple funding sources, including NIHMBRS grant S06GM08205 and NSF grant IOS-0956603 (PKS) to Dr. Philip Stoddard, and NIH-K01 grant MH064550 to Dr. Michael R. Markham. I also received funding from the MBRS graduate fellowship, Sigma-Xi research society, and multiple travel and research grants from the FIU Graduate Student Association. 


\section{ABSTRACT OF THE DISSERTATION \\ ENDOCRINE REGULATION OF DYNAMIC COMMUNICATION SIGNALS IN GYMNOTIFORM FISH}

by

Anna Goldina

Florida International University, 2011

Miami, Florida

\section{Professor Philip K. Stoddard, Major Professor}

Communication signals are shaped by the opposing selection pressures imposed by predators and mates. A dynamic signal might serve as an adaptive compromise between an inconspicuous signal that evades predators and an extravagant signal preferred by females. Such a signal has been described in the gymnotiform electric fish, Brachyhypopomus gauderio, which produces a sexually dimorphic electric organ discharge (EOD). The EOD varies on a circadian rhythm and in response to social cues. This signal plasticity is mediated by the slow action of androgens and rapid action of melanocortins.

My dissertation research tested the hypotheses that (1) signal plasticity is related to sociality levels in gymnotiform species, and (2) differences in signal plasticity are regulated by differential sensitivity to androgen and melanocortin hormones. To assess the breadth of dynamic signaling within the order Gymnotiformes, I sampled 13 species from the five gymnotiform families. I recorded EODs to observe spontaneous signal oscillations after which I injected melanocortin hormones, saline control, or presented the fish with a conspecific. I showed that through the co-option of the ancient melanocortin 
pathway, gymnotiforms dynamically regulate EOD amplitude, spectral frequency, both, or neither.

To investigate whether observed EOD plasticities are related to species-specific sociality I tested four species; two territorial, highly aggressive species, Gymnotus carapo and Apteronotus leptorhynchus, a highly gregarious species, Eigenmannia cf. virescens, and an intermediate short-lived species with a fluid social system, Brachyhypopomus gauderio. I examined the relationship between the androgens testosterone and 11ketotestosterone, the melanocortin $\alpha-\mathrm{MSH}$, and their roles in regulating EOD waveform. I implanted all fish with androgen and blank silicone implants, and injected with $\alpha-\mathrm{MSH}$ before and at the peak of implant effect. I found that waveforms of the most territorial and aggressive species were insensitive to hormone treatments; maintaining a static, stereotyped signal that preserves encoding of individual identity. Species with a fluid social system were most responsive to hormone treatments, exhibiting signals that reflect immediate condition and reproductive state. In conclusion, variation in gymnotiform signal plasticity is hormonally regulated and seems to reflect species-specific sociality. 


\section{TABLE OF CONTENTS}

CHAPTER

PAGE

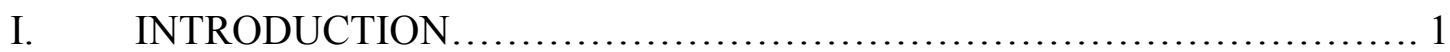

References........................................................ 11

II. MODULATION OF DYNAMIC COMMUNICATION SIGNALS

THROUGH DIFFERENTIAL MELANOCORTIN SENSITIVITY IN

GYMNOTIFORM ELECTRIC FISHES................................16

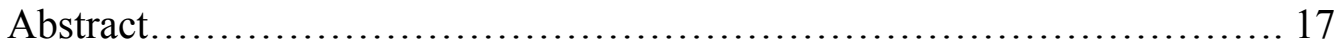

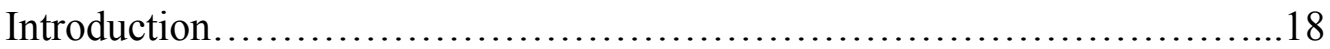

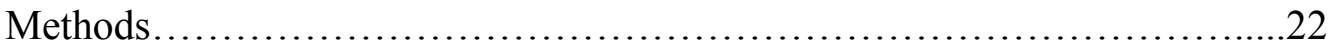

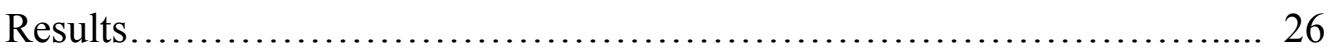

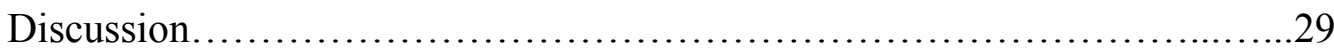

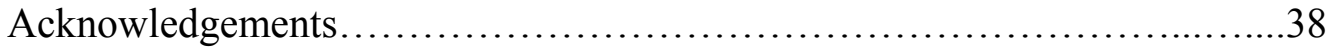

References.............................................................. 40

III. TESTOSTERONE AND 11-KETOTESTOSTERONE HAVE DIFFERENT REGULATORY EFFECTS ON ELECTRIC COMMUNICATION SIGNALS OF MALE BRACHYHYPOPOMUS GAUDERIO...................58

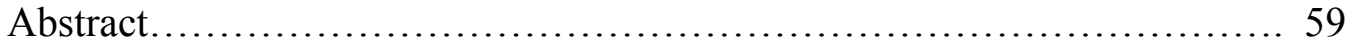

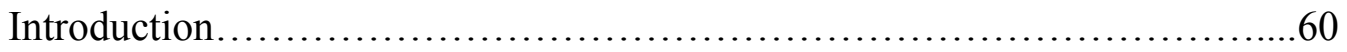

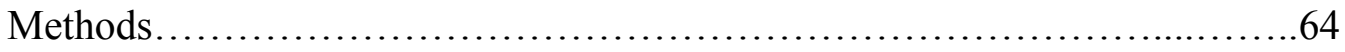

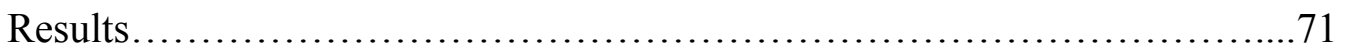

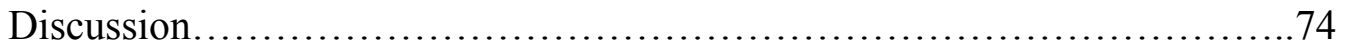

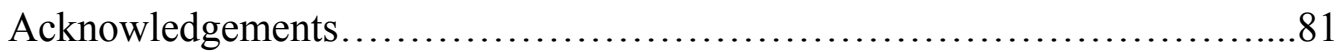

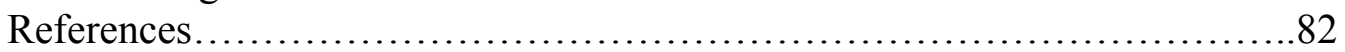

IV. HORMONALLY REGULATED SIGNAL PLASTICITY TRACKS

SOCIALITY ACROSS GYMNOTIFORM FISH..........................99

Abstract............................................................... 100

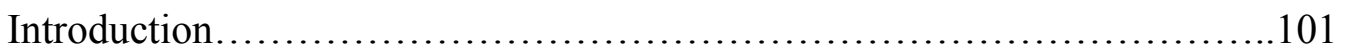

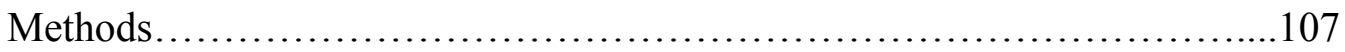

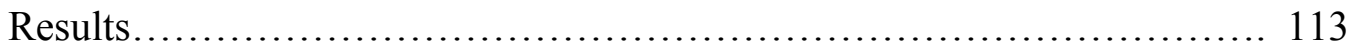

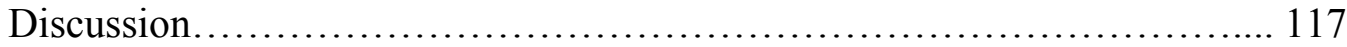

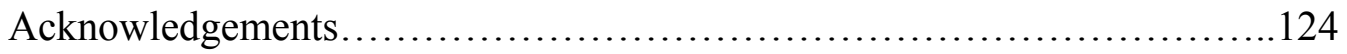

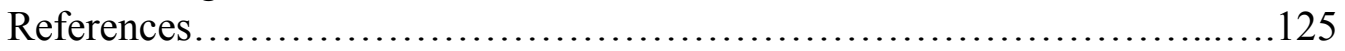

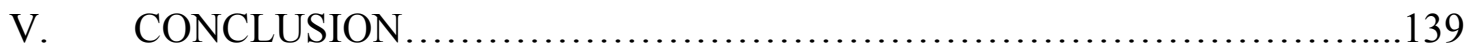

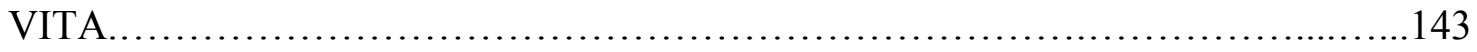




\section{LIST OF FIGURES}

FIGURE

PAGE

\section{Chapter II}

Fig. 1: EOD machine .50

Fig. 2: Day-night EOD modulations of select members of the order Gymnotiformes ....

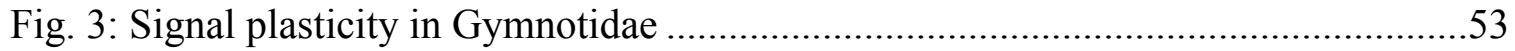

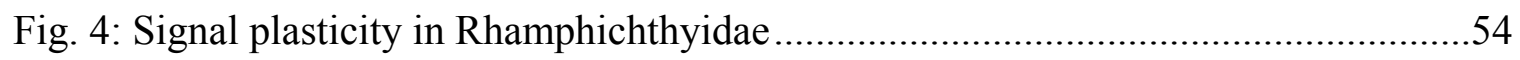

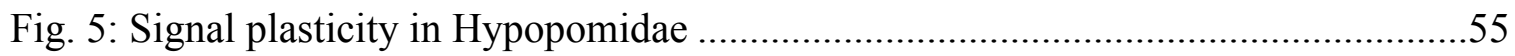

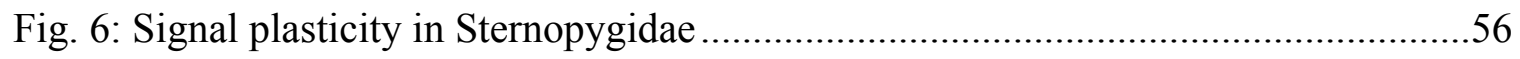

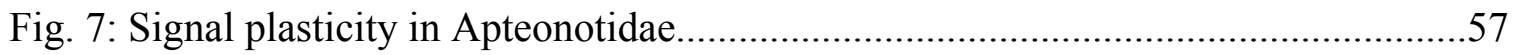

\section{Chapter III}

Figure 1. The EOD waveform of B. gauderio varies in peak-to-peak amplitude and in duration of the second phase (parameterized as $\tau_{\mathrm{p} 2}$ ) ...................................... 91

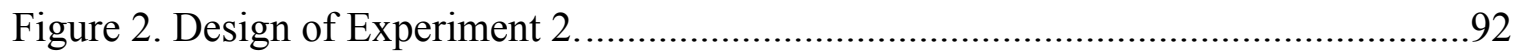

Figure 3. Effect of androgen implants on daytime and nighttime EOD ........................93

Figure 4. Effect of social challenge on the EOD waveform .......................................95

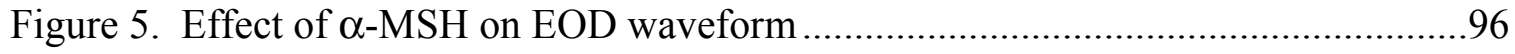

Figure 6. Androgen effect on EOD responsiveness to $\alpha-\mathrm{MSH}$ injections................97

Figure 7. Effect of social challenge on melanocortin responsiveness.................98

\section{Chapter IV}

Figure 1. Selected gymnotiform species and their respective EODs............................135

Figure 2. Effect of androgen implants on EOD amplitude and duration.......................136 
Figure 3. Effect of androgen implants on responsiveness of EOD amplitude and

duration to melanocortins ..........................................................................................137

Figure 4. EOD plasticity and stereotypy reflect endocrine integration and independence in gymnotiforms. .138 


\section{LIST OF TABLES}

TABLE

PAGE

\section{Chapter II}

Table 1: Species origin and weights (mean \pm S.E.)

Table 2: Change in EOD amplitude from day to night and in response to melanocortin (ACTH and MSH) injections and short-term social challenges.

\section{Chapter III}

Table 1. Androgen implants significantly elevated plasma T and 11-KT levels compared to blank implanted males

Table 2. Androgen implants and social challenge significantly enhanced EOD $\tau_{\mathrm{p} 2}$ and the effects of $\alpha$-MSH on $\tau_{\mathrm{p} 2}$

\section{Chapter IV}

Table 1. Summary of gymnotiform sociality forms

Table 2. Response of Gymnotus carapo to androgen and peptide hormone treatments. 


\section{LIST OF ABBREVIATIONS}

\begin{tabular}{|c|c|}
\hline $11-\mathrm{KT}$ & 11-ketotestosterone \\
\hline$\alpha-\mathrm{MSH}$ & alpha-melanocyte stimulating hormone \\
\hline ACTH & adrenocorticotropic hormone \\
\hline ANOVA & analysis of variance \\
\hline cAMP & cyclic adenosine monophasphate \\
\hline $\mathrm{DC}$ & direct current \\
\hline DHT & $5 \alpha$-dihydrotestosterone \\
\hline EIA & enzyme immunoassay \\
\hline EOD & electric organ discharge \\
\hline FFT & fast fourier transform \\
\hline GLM & general linear model \\
\hline JAR & jamming avoidance response \\
\hline $\mathrm{K}^{+}$ & potassium ions \\
\hline LTFE & long-term frequency elevation \\
\hline LSD & least significant difference \\
\hline MANCOVA & multiple analysis of covariance \\
\hline Matlab & matrix laboratory \\
\hline MC1-5R & melanocortin receptors \\
\hline $\mathrm{Na}^{+}$ & sodium ions \\
\hline P1-3 & EOD phases 1-3 \\
\hline PKA & protein kinase $\mathrm{A}$ \\
\hline $\mathrm{PMN}$ & pacemaker nucleus \\
\hline
\end{tabular}


POMC

SPSS

$\mathrm{T}$

$\tau_{\mathrm{p} 2}$ pro-opiomelanocortin

statistical package for the social sicences

testosterone

time constant of repolarization of phase 2 of the EOD 
CHAPTER I

INTRODUCTION 
Communication occurs in a complex network of receivers that include prospective mates, same-sex competitors, predators, and parasitoids (Dabelsteen, 2004). Collectively the different classes of receivers constitute a communication network (McGregor and Dabelsteen, 1996). Different participants in the network have different interests, often opposed to those of the signaler. The different classes of receivers act within the communication network to differentially shape the communication signal. For example, while predation pressure should favor evolution of cryptic communication signals that can elude detection (Maynard-Smith and Harper, 2003), intended receivers such as potential mates, should favor more conspicuous and expensive signals that serve as an index of quality. Opposing selection forces of these different audiences are thought to drive the evolution of compromise in signal structure (Bernal et al., 2007; Tuttle and Ryan, 1981). The resulting compromised communication signals attract both intended and unintended receivers at reduced efficiencies, though the degree of reduction can vary between receiver classes depending on sensory biases.

The established view is that predators constrain effectiveness of a communication signal while mates and competitors favor signal elaboration. Research on electric fish, however, has suggested that solutions to elude hostile eavesdroppers have led to novel signal adaptations that themselves have become the substrate for elaboration through sexual selection (Stoddard et al., 1999). Thus, the established view appears too restrictive to accurately ascribe the origins of signal structures and functions within communication networks. Indeed, another solution suggested by electric fish research is that the classic compromise between opposing interests can be resolved through dynamic 
communication signals that can be modified over time based on changing costs and benefits that follow from temporal changes in the interests and activities of the different audiences. Furthermore, since in a communication network individuals eavesdrop and are eavesdropped on, they might benefit from being able to modulate their signals based on content and presence of intended and unintended audience. For example, signals directed at a particular individual are invariably broadcast to predators, which can use these signals to localize prey. In the tungara frogs, complex "whine-chuck" calls attract not only females, but also predators and parasitoid flies, better than simple "whine" calls (Bernal et al., 2007). Thus, presence of predators would constrain signal elaboration potentially increasing the need for dynamic control of communication.

Through dynamic regulation of the signal an individual can increase its signal complexity or energetic content at times when these features can be most beneficial (e.g., in the presence of females), and decrease them when costs are high (e.g., when predators and eavesdroppers are around). Dynamic signal modulation would be favored in an environment where predators occupy similar niches as their prey species. However, animals living in stable social groups must be able to maintain a signature signal that is stereotyped enough to be identified by conspecifics and is an accurate representation of the individual's status at all times (Bond et al., 2003). While evidence of these dynamic signals is recorded in taxa ranging from fish to primates (Cheney and Seyfarth, 2005; Naguib, 2005; Peake, 2005), it is not clear how this plasticity evolved.

It is not known how can some species have infinitely plastic signals, while the signals of other species are immutable. The endocrine mechanisms that regulate these diverse communication signals are also unknown. My dissertation explores how 
gymnotiform electric fish dynamically alter their signals in accordance with the opposing interests created by the communication networks in which they live, and presumably with which they evolved. I examine the relationship between peptide and steroid hormones and their role in mediating dynamic signaling among species of gymnotiform electric fish that exhibit different social strategies. I use a comparative approach to answer two questions: 1) Is communication signal plasticity related to species-specific social strategies? 2) Have endocrine mechanisms evolved to generate the diversity seen in dynamics of signal plasticity?

\section{Electric fish are exemplary models to study dynamic signal evolution}

The ability to generate electric signals evolved independently in the African order Mormyriformes and the South American order Gymnotiformes about 100 million years ago (Alves-Gomes, 2001). The order Gymnotiformes is composed of five families with close to 200 species of weakly electric fish, widely distributed from southern Mexico to northern Argentina (Albert and Crampton, 2005). Gymnotiforms occupy diverse fresh water habitats varying in depths, temperatures, conductivity and oxygen content, flooding periods and vegetation (Albert and Crampton, 2005).

All gymnotiforms generate weakly electric organ discharges (EOD) that they use for electrolocation and communication (Alves-Gomes, 2001). The EODs are speciesspecific and convey information on status and sex, and play a key role in aggression, territoriality and mate assessment (Hopkins, 1988). Because all gymnotiforms are nocturnal and inhabit murky waters, the EOD is their primary mode of communication. However, since the EOD is also used for electrolocation it is constantly emitted even 
when the fish are inactive. This inability to shut down the EOD for prolonged periods of time makes gymnotiform weakly electric fish susceptible to electrosensory predators such as catfish and the electric eel, Electrophorus electricus (Stoddard, 1999; Westby, 1988). In Brachyhypopomus gauderio, a member of the Hypopomidae family, predation pressure probably selected for the evolution of a more complex, biphasic EOD that is less detectable by electroreceptive predators (Stoddard, 1999). The biphasic signal has further been modified by sexual selection, where male Brachyhypopomus gauderio enhance the duration and amplitude of the second phase of their waveform during nighttime to attract females (Curtis and Stoddard, 2003). Thus, in at least one species of weakly electric fish, a dynamic communication signal evolved through opposing selection pressures.

Most pulse gymnotiforms modify EOD rate and at least three families (Sternopygidae, Hypopomidae and Rhamphichthydae) modify the amplitude of their signals in a circadian pattern; enhancing their waveforms at night and decreasing them during the day (Moller, 1995; Stoddard et al., 2007). These increases coincide with nighttime activity onset, including foraging and social interactions. Weakly electric species also modulate various aspects of their EODs in a species-specific manner in the contexts of competition, aggression and mating. Members of the Apteronotidae family produce transient increases of their EOD frequencies known as chirps, that can be divided into 6 types based on duration, amount and type of frequency increase and decrease (Zupanc et al., 2006). Some of these chirps have been correlated with aggressive behavior observed in Apteronotus leptorhynchus and Apteronotus albifrons during escalated fights for shelter (Dunlap and Larkins-Ford, 2003; Serrano-Fernandez, 2003; Tallarovic and Zakon, 2002). 
Most gymnotiforms modify EOD rate during social interactions. Members of the Apteronotidae family and Eigenmannia cf. virescens from the Sternopygidae family, exhibit a jamming avoidance response (JAR) which prevents interference of electrolocation by fish with similar frequencies. During a JAR a fish shifts its own discharge frequency away from the jamming frequency of another fish allowing it to maintain electrosensory capabilities (Heiligenberg, 1986). Interestingly, the JAR response seems to correlate with different social structures of these species. Eigenmannia cf. virescens are believed to be a gregarious species (Hagedorn and Heiligenberg, 1985) and they normally die if isolated (personal observation). Correlated with this behavior, Eigenmannia can maintain a JAR for up to 6 hours, known as a long term frequency elevation (LTFE) and can shift its discharge frequencies upward and downward from the jamming frequencies of conspecifics; thus allowing them to maintain prolonged social interaction without affecting electrolocation ability (Oestreich and Zakon, 2005). Apteronotus, on the other hand, are much more aggressive and territorial and will fight until death to maintain sole control of a shelter (personal observation). Apteronotids can only shift their frequency upward during a JAR and exhibit a much weaker LTFE than E. virescens (Oestreich and Zakon, 2005). In fact, Apteronotus leptorhynchus intentionally jam rivals during aggressive interactions (Tallarovic and Zakon, 2005), yet another example of a dynamic control of communication signal. 


\section{The EOD is generated by a well-described neural circuit that is regulated by hormones}

Because of their structural simplicity, electric signals constitute good models for exploring dual hormone signal regulation and the implication of hormonal interplay for communication. The neural circuitry of electrocommunication and electrolocation has been well described. The EOD is produced by the summation of action potentials generated by electrically excitable cells of the electric organ (Szabo, 1974). EOD is regulated by the pacemaker cells, which synapse on each other and on adjoining relay cells in the pacemaker nucleus (PMN) in the medulla. Relay cells further innervate the electromotoneurons in the spinal cord, which synapse on electrocytes. The electrocytes of all weakly electric fish, except Apteronotids, are myogenically derived (in Apteronotidae, electrocytes are an extension of electromotorneurons (Bennett, 1971)). Because cells of the PMN are intrinsically oscillating and spontaneously active, and because of their extensive connections to each other and relay cells, the frequency of the EOD is determined by the firing frequency of the PMN. The waveform is modulated by the ion channel properties of the electrocytes (Zakon, 1999).

The EOD is regulated centrally and peripherally by steroid hormones. Androgens masculinize the EOD waveform by increasing the firing rate of the PMN and broadening electrocyte action potential (Few and Zakon, 2001). Andrognes masculinize, while estrogens feminize the waveforms of most gymnotiforms (Dunlap and Zakon, 1998; Few and Zakon, 2001; Hagedorn and Carr, 1985). Increased 11-ketotestosterone levels in members of Apteronotidae family are positively correlated with increased chirp rate, but 
androgen implants stimulate chirp production only in Apteronotus leptorhynchus, not in A. albifrons (Dunlap, 2002a, b; Dunlap and Larkins-Ford, 2003).

While androgens affect EOD waveform on an intermediate timescale of days to months, serotonin and melanocortin hormones such as Adrenocorticotropic hormone (ACTH) and $\alpha$-Melanocyte Stimulating Hormones ( $\alpha-\mathrm{MSH})$ induce rapid changes in the EOD within minutes-hours of injection (Markham and Stoddard, 2005; Smith and Combs, 2008; Stoddard et al., 2003; Stoddard et al., 2006). Serotonin regulates the EOD centrally and has no effect on the waveform when applied directly on electrocytes (Allee et al., 2008; Stoddard et al., 2003). Serotonin effects on the waveform are likely exhibited through the activation of the hypothalamus-pituitary interrenal axis, stimulating melanocortin release at the periphery (Markham and Stoddard, 2005; Stoddard et al., 2003).

The melanocortin system is highly conserved across vertebrates (Metz et al., 2006). Derived from the posttranslational modification of pro-opiomelanocortin (POMC), the melanocortin peptide hormones act through a series of 7-transmembrane Gprotein-coupled receptors (MC1R-MC5R) to regulate a diverse array of physiological and behavioral processes (Ducrest et al., 2008; Hadley and Haskell-Luevano, 1999). The POMC and melanocortin receptors are widely expressed throughout the body, including the central and peripheral nervous systems, skin, and reproductive tract (Ducrest et al., 2008). Melanocortins regulate a wide suite of traits including social communication, learning, grooming, appetite, lipolysis, melanin production, inflammation, glucocorticosteroid release, sexual performance, and aggressive and sexual behaviors (Brain and Evans, 1977; Ducrest et al., 2008; Gonzalez et al., 1996; Wikberg et al., 
2000). In Brachyhypopomus gauderio injections of adrenocorticotropic hormone (ACTH) increase amplitude and second phase duration of the EOD by differentially modulating the action potentials of the two excitable membranes of the electrocytes (Markham and Stoddard, 2005). Peripheral injections of ACTH or $\alpha-M S H$ induce changes in the waveform comparable to those observed during social interactions, suggesting a possible mechanism for dynamic EOD regulation (Markham and Stoddard, 2005; Stoddard et al., 2006).

All studies examining the effects of hormones on EOD modulations have focused on 5 select gymnotiform species; Apteronotus leptorhynchus, Eigenmannia cf. virescens and Sternopygus macrurus (testosterone, cortisol and 11-ketotestosterone, serotonin), and Gymnotus carapo (testosterone, 1 study), and Brachyhypopomus gauderio (DHT, ACTH, $\alpha-\mathrm{MSH}$, serotonin). These studies are instrumental in increasing our knowledge of the proximate mechanisms involved in EOD modulation and set the stage for this dissertation, using a comparative approach to examine the role of communication behaviors and social strategy in the evolution of neuroendocrine mechanisms of animal sociality.

In chapter II of this dissertation, I examine the extent of dynamic signaling in representative species of the order Gymnotiformes. I measure EOD waveform modulations from day to night, in response to short-term social challenges and melanocortin (ACTH and $\alpha-\mathrm{MSH})$ injections. In chapter III, I measure whether shortterm signal plasticity of Brachyhypopomus gauderio is driven by activational effects of the androgens testosterone (T) and 11-ketotestosterone (11-KT). Furthermore, I examine if androgens enhance the effects of melanocortins on signal waveform. Finally, in chapter 
IV I compare 4 gymnotiform species (Gymnotus carapo, Brachyhypopomus gauderio, Eigenmannia cf. virescens, and Apteronotus leptorhynchus) with varying degrees of sociality and signal plasticity. I examine whether the different degrees of dynamic signaling in these four species are driven by differential sensitivity to androgens and $\alpha$ MSH. 


\section{References}

Albert, J.S., Crampton, W.G.R., 2005. Diversity and phylogeny of neotropical electric fishes (Gymnotiformes), in: Hopkins, C.D., Bullock, T.H., Fay, R.R., Popper, A.N. (Eds.), Electroreception, 1 ed. Springer, pp. 360-409.

Allee, S., Markham, M.R., Salazar, V.L., Stoddard, P.K., 2008. Opposing actions of 5HT1A and 5HT2-like serotonin receptors on modulations of the electric signal waveform in the electric fish Brachyhypopomus pinnicaudatus. Hormones and Behavior $53,481-488$.

Alves-Gomes, J.A., 2001. The evolution of electroreception and bioelectrogenesis in teleost fish: a phylogenetic perspective. Journal of Fish Biology 58, 1489-1511.

Bennett, M.V.L., 1971. Electric organs, in: Hoar, W.S., Randall, D.J. (Eds.), Fish Physiology. Academic Press, London, pp. 347-491.

Bernal, X.E., Page, R.A., Rand, S.A., Ryan, M.J., 2007. Cues for eavesdroppers: do frog calls indicate prey density and quality? The American Naturalist 169, 409-415.

Bond, A.B., Kamil, A.C., Balda, R.P., 2003. Social complexity and transitive inference in corvids. Animal Behaviour 65, 479-487.

Brain, P.F., Evans, A.E., 1977. Acute influences of some ACTH-related peptides on fighting and adrenocortical activity in male laboratory mice. Pharmacology Biochemistry \& Behavior 7, 425-433.

Cheney, D.L., Seyfarth, R.M., 2005. Social complexity and the information acquired during eavesdropping by primates and other animals, in: McGregor, P.K. (Ed.), Animal communication networks. Cambridge University Press, pp. 583-603.

Curtis, C.C., Stoddard, P.K., 2003. Mate preference in female electric fish, Brachyhypomus pinnicaudatus. Animal Behaviour 66, 329-336.

Dabelsteen, T., 2004. Strategies that facilitate or counter eavesdropping on vocal interactions in songbirds. Annals of the Brazilian Academy of Sciences 76, 274-278. 
Ducrest, A.L., Keller, L., Roulin, A., 2008. Pleiotropy in the melanocortin system, coloration and behavioural syndromes. Trends in Ecology and Evolution 23, 502-510.

Dunlap, K.D., 2002a. Hormonal and body correlates of electrocommunication behavior during dyadic interactions in a weakly electric fish, Apteronotus leptorhynchus. Hormones and Behavior 41, 187-194.

Dunlap, K.D., Larkins-Ford, J., 2003. Diversity in the structure of electrocommunication signals with a genus of electric fish, Apteronotus. Journal of Comparative Physiology A 189, 153-161.

Dunlap, K.D., Pelczar, Patricia L., Knapp, Rosemarry, 2002b. Social interactions and cortisol treatment increase the production of aggressive electrocommunication signals in male electric fish, Apteronotus leptorynchus. Hormones and Behavior 42, 97-108.

Dunlap, K.D., Zakon, H.H., 1998. Behavioral actions of androgens and androgen receptor expression in the electrocommunication system of an electric fish, Eigenmannia virescens. Hormones and Behavior 3, 30-38.

Few, W.P., Zakon, H.H., 2001. Androgens alter electric organ discharge pulse duration despite stability in electric organ discharge frequency. Hormones and Behavior 40, 434442.

Gonzalez, M.I., Vaziri, S., Wilson, C.A., 1996. Behavioral effects of alpha-MSH and $\mathrm{MCH}$ after central administration in the female rat. Peptides 17, 171-177.

Hadley, M., Haskell-Luevano, C., 1999. The proopiomelanocortin system. Annals of New York Academy of Sciences 885, 1-21.

Hagedorn, M., Carr, C., 1985. Single electrocytes produce a sexually dimorphic signal in South American electric fish, Hypopomus occidentalis (Gymnotiformes, Hypopomidae). Journal of Comparative Physiology A 156, 511-523.

Hagedorn, M., Heiligenberg, W., 1985. Court and spark:electric signals in the courtship and mating of gymnotid fish. Animal Behaviour 33, 254-265.

Heiligenberg, W., 1986. Jamming avoidance responses: model systems for neuroethology, in: Bullock, T.H., Heiligenberg, W. (Eds.), Electroreception. John Wiley \& Sons, New York, pp. 613-649. 
Hopkins, C.D., 1988. Neuroethology of electric communication. Annual Reviews in Neuroscience 11, 497-535.

Markham, M.R., Stoddard, P.K., 2005. Adrenocorticotropic hormone enhances the masculinity of an electric communication signal by modulating the waveform and timing of action potentials within individual cells. Journal of Neuroscience 25, 8746-8754.

Maynard-Smith, J., Harper, D., 2003. Animal Signals. University Press, Oxford.

McGregor, P.K., Dabelsteen, T., 1996. Communication Networks, in: Kroodsma, D.E., Miller, E.H. (Eds.), Ecology and evolution of acoustic communication in birds. Cornell University Press, Ithaca, pp. 401-425.

Metz, J.R., Peters, J.J.M., Flik, G., 2006. Molecular biology and physiology of the melanocortin system in fish: a review. General and Comparative Endocrinology.

Moller, P., 1995. Locomotor and electric organ discharge rhythms, Electric fishes: history and behavior. Chapman \& Hall, London, pp. 345-360.

Naguib, M., 2005. Singing interactions in songbirds: implications for social relations and territorial settlement, in: McGregor, P.K. (Ed.), Animal Communiation Networks. University Press, Cambridge, pp. 300-341.

Oestreich, J., Zakon, H.H., 2005. Species-specific differences in sensorimotor adaptation are correlated with differences in social structure. Journal of Comparative Physiology A $191,845-856$.

Peake, T.M., 2005. Eavesdropping in communication networks, in: K, M.P. (Ed.), Animal Communication Networks. Cambridge University Press, Cambridge, pp. 13-37.

Serrano-Fernandez, P., 2003. Gradual frequency rises in interacting black ghost knifefish, Apteronotus albifrons. Journal of Comparative Physiology A 189, 685-692.

Smith, G.T., Combs, N., 2008. Serotonergic activation of 5HT1A and 5HT2 receptor modulates sexually dimorphic communicaiton signals in the weakly electric fish Apteronotus leptorhynchus. Hormones and Behavior 54, 69-82.

Stoddard, P.K., 1999. Predation enhances complexity in the evolution of electric fish signals. Nature 400, 254-256. 
Stoddard, P.K., Markham, M.R., Salazar, V.L., 2003. Serotonin modulates the electric waveform of the gymnotiform electric fish, Brachyhypopomus pinnicaudatus. Journal of Experimental Biology 206, 1353-1362.

Stoddard, P.K., Markham, M.R., Salazar, V.L., Allee, S., 2007. Circadian rhythms in electric waveform structure and rate in the electric fish Brachyhypopomus pinnicaudatus. Physiology \& Behavior 90, 11-20.

Stoddard, P.K., Rasnow, B., Assad, C., 1999. Electric organ discharges of the gymnotiform fishes: III. Brachyhypopomus. Journal of Comparative Physiology A 184, 609-630.

Stoddard, P.K., Zakon, H.H., Markham, M.R., McAnelly, L., 2006. Regulation and modulation of electric waveforms in gymnotiform electric fish. Journal of Comparative Physiology A 192, 613-624.

Szabo, T., 1974. Anatomy of the specialized lateral line organs of electroreception, in: Fessard, A. (Ed.), Handbook of Sensory Physiology. Springer-Verlag, Berlin, pp. 13-58.

Tallarovic, S.K., Zakon, H.H., 2002. Electrocommunication signals in female brown ghost electric knifefish, Apteronotus leptorhynchus. Journal of Comparative Physiology A $188,649-657$.

Tallarovic, S.K., Zakon, H.H., 2005. Electric organ discharge frequency jamming during social interactions in brown ghost knifefish, Apteronotus leptorhynchus. Animal Behaviour 70, 1355-1365.

Tuttle, M.D., Ryan, M.J., 1981. Bat predation and the evolution of frog vocalizations in the neotropics. Science 214, 677.

Westby, G.W.M., 1988. The ecology, discharge diversity and predatory behaviour of gymnotiforme electric fish in the coastal streams of French Guiana. Behavioral Ecology and Sociobiology 22, 341-354.

Wikberg, J.E.S., Muceniece, R., Mandrika, I., Prusis, P., Lindblom, J., Post, C., Skottner, A., 2000. New aspects on the melanocortins and their receptors. Pharmacological Research 42, 393-420. 
Zakon, H.H., McAnelly, L., Smith, G. T., Dunlap, K., Lopreato, G., Oestreich, J., Few, W. P., 1999. Plasticity of the electric organ discharge: implications for the regulation of ionic currents. The Journal of Experimental Biology 202, 1409-1416.

Zupanc, G.K.H., Sirbulescu, R.F., Nichols, A., Ilies, I., 2006. Electric interactions through chirping behavior in the weakly electric fish, Apteronotus leptorhynchus. Journal of Comparative Physiology A 192, 159-173. 


\section{CHAPTER II}

MODULATION OF DYNAMIC COMMUNICATION SIGNALS THROUGH DIFFERENTIAL MELANOCORTIN SENSITIVITY IN GYMNOTIFORM ELECTRIC

FISHES 


\begin{abstract}
Dynamic communication signals allow individuals to adapt to the opposing interests imposed by mates and predators. Such plasticity is present in Brachyhypopomus gauderio, a weakly electric gymnotiform that oscillates its electric organ discharges (EODs) on a circadian rhythm and during social interactions. Signal plasticity is modulated by melanocortin hormones (ACTH and $\alpha-\mathrm{MSH})$, which mimic waveform changes that occur during staged social interactions. While all gymnotiforms generate EODs for communication and electrolocation, the taxonomic breadth of dynamic signal regulation is not known. I explored the presence of circadian and melanocortin-induced EOD plasticity within the Neotropical order Gymnotiformes. I continuously recorded 72 $\mathrm{h}$ of EODs from 13 species from each of the five gymnotiform families (at least 2 species/family) to observe spontaneous oscillations of the EOD, after which I injected (i) ACTH, (ii) $\alpha-\mathrm{MSH}$, or (iii) saline control, (iv) or presented the fish with a conspecific. I found that signal plasticity in weakly electric fish included modulations in EOD amplitude, spectral frequency, both, or neither. My results show that members of the Hypopomidae can modulate amplitude and spectral frequency of their signals, while Apteronotidae don't modulate either parameter. In Sternopygidae, Sternopygus macrurus can change EOD amplitude and spectrum, while Eigenmannia cf. virescens can only modulate amplitude. In Gymnotidae, all modulations types are present. The phylogenetic pattern of differences in signal modulation suggests that melanocortin-based EOD waveform plasticity evolved at the base of the gymnotiform clade and was lost independently in the family Apteronotidae, which produces EODs through a derived neural electric organ. The gymnotiform electric fish appear to have evolved a dynamic
\end{abstract}


control of their electric waveform through co-option of the ancient melanocortin hormone pathway. Widespread response to the same modulator suggests taxonomic differences in modulation patterns that probably result from derived differences in the voltage-gated ion channels of the electrocytes.

Keywords: Gymnotiformes, adrenocorticotropic hormone (ACTH), alpha-melanocyte stimulating hormone ( $\alpha-\mathrm{MSH})$, electric communication signals, plasticity, EOD

\section{Introduction}

Communication signals can reflect individual quality, sex, developmental stage, identity, and condition. In most species, traits such as sex, condition and genetic quality are static; they cannot be changed rapidly and may not reflect current environmental or social conditions. Static signals may include deer antlers (Alcock, 2001), beetle horns (Emlen et al., 2006), chucks of frogs (Ryan et al., 1982) and bird plumage (Karubian et al., 2011). The call of male midshipman fish conveys reproductive strategy; territorial nesting males produce "grunts," and "hums," while subordinate, sneaker males typically do not vocalize. These call types are static, as are the male morphs (Grober and Bass, 2002). Furthermore, in species that use multiple signals or signaling modalities to communicate, dynamic signaling might be costlier for the signalers and less informative to the receivers that rely on multiple messages for effective information transfer (BroJorgensen, 2009; Rand and Ryan, 1981).

Traits that convey social status and quality are dynamic, reflecting short-term environmental and social changes. Dynamic signals change rapidly, yet might be energetically expensive to generate and maintain. For animals restricted to a single 
communication mode or that possess a limited repertoire, dynamic signal modulation can allow quick adjustments to sudden environmental and social changes. Examples of dynamic traits include rapid color change in chameleons (Stuart-Fox and Moussalli, 2008) and fish (Burmeister et al., 2005), soft vascularized parts in birds (Karubian et al., 2011), and acoustic signals such as advertisement calls of frogs (Emerson, 2001).

Most animals use multiple sensory modalities to communicate, making examination of the role of any one signal in communication logistically difficult (BroJorgensen, 2009). Weakly electric fishes are a great model system to study communication signal plasticity because their signals contain both static and dynamic components. In addition, most electric fish use their electric sense as the main communication modality, thus reducing the possible effects of multiple sensory modalities on evolution of communication signals.

The South American order Gymnotiformes is composed of five families with over 250 species of weakly electric fish distributed from southern Mexico to northern Argentina (Crampton, 2011). Electric fish occupy diverse fresh water habitats varying in depths, temperatures, conductivity, oxygen content, flood period, and vegetation (Albert and Crampton, 2005). While all gymnotiforms generate electric organ discharges (EODs) for electrolocation and communication; the signal waveforms are species-specific conveying information on sex and social status (Alves-Gomes, 2001; Hopkins, 1988).

Gymnotiforms are mostly nocturnal, making the EOD their primary mode of communication. Because the EOD is also used for electrolocation it is constantly emitted even when the fish are inactive, making gymnotiforms susceptible to electrosensory predators such as catfish and the electric eel, Electrophorus electricus (Stoddard, 1999; 
Westby, 1988). Electroreceptive predators use the ampullary system, which is narrowly tuned to direct current and to $0-50 \mathrm{~Hz}$ frequency range; the range at which muscle cells depolarize, to detect their prey (Bradbury and Vehrencamp, 1998).The ancestral EODs are believed to be monophasic signals, as in Brachyhypopomus genus and in Gymnotus cylindricus, with most of the energy concentrated in the lower frequencies and highly conspicuous to predators (Stoddard, 1999). This predation pressure probably selected for the evolution of more complex, multiphasic EODs that are less dectectable to electroreceptive predators (Stoddard, 1999; 2002). Complex signals with equal amounts of energy above and below $0 \mathrm{~V}$ of direct current are less conspicuous to electroreceptive eavesdroppers because the signals balance the amount of energy around $0 \mathrm{~V}$ of direct current, nulling the DC component that is so attractive to predators (Stoddard and Markham, 2008). While both electroceptive predators and electrogenic fish possess the ampullary system, gymnotiforms and the African mormyriforms evolved tuberous electroreceptors which are broadly tuned to the individual's own, high-frequency component signal (Zupanc and Bullock, 2005). The high-frequency signals cannot be detected by electroreceptive predators (Stoddard, 1999). The presence of the tuberous system allowed electric fish to develop a private communication channel, and the presence of both ampullary and tuberous receptor systems set the stage for the evolution of dynamic communication signals.

In the hypopomids and the African mormyrid genus Macrusenius a biphasic signal has been further modified by sexual selection, where males increase EOD amplitude and duration of the second phase at night, particularly while challenging other males and courting females (Curtis and Stoddard, 2003; Franchina et al., 2001; Machnik 
and Kramer, 2008). EOD modification made both groups more conspicuous to electroreceptive predators by increasing energy in the ampullary-sensitive region of the spectrum (Hanika and Kramer, 1999, 2000; Stoddard, 1999). Thus, in at least one of gymnotiform and one mormyriform group of weakly electric fish, the EOD signal appears to have been shaped by classic opposition of natural and sexual selection pressures.

The EOD is produced by the composite action potentials of electrocytes, myogenically derived cells of the electric organ. While the discharge rate is regulated by the pacemaker nucleus in the brain (Few and Zakon, 2001; Mills and Zakon, 1991), waveform shape is regulated peripherally by the electrocytes (Szabo, 1974). It was believed that the EOD is a static signal, constrained by the biophysical properties of the ion channels on the electrocyte membranes (Bennett, 1971). However, in the genus Brachyhypopomus (Hypopomidae), the EOD changes on multiple timescales. Long-term changes occur during development and seasonally (Franchina, 1997), and are driven by steroid hormones (Meyer, 1983; Mills and Zakon, 1991; Zakon, 1993). Rapid changes, on the other hand, ranging from minutes to hours, occur during the onset of nighttime activity and social interactions (Franchina et al., 2001; Franchina and Stoddard, 1998; Hagedorn, 1995; Stoddard et al., 2007). Recently, the melanocortins alpha-melanocyte stimulating hormone ( $\alpha-\mathrm{MSH})$ and adrenocorticotropic hormone (ACTH) were found to be involved in the modulation of EODs in Brachyhypopomus gauderio, a member of the Hypopomidae family (Markham et al., 2009a; Markham and Stoddard, 2005). Within minutes of injection, $\mathrm{ACTH}$ and $\alpha-\mathrm{MSH}$ induce rapid changes in the signal waveform of B. gauderio that resemble changes seen during social interactions (Franchina et al., 2001; 
Goldina et al., 2011). Additionally, in B. gauderio, prolonged social isolation causes a decline in EOD amplitude and duration that can be partially reversed with melanocortins (Franchina et al., 2001; Franchina and Stoddard, 1998; Stoddard et al., 2007).

Currently, the taxonomic breadth of short-term signal plasticity is unknown. While multiple gymnotiform species can rapidly modulate EOD discharge rate (Zakon and Smith, 2009; Zupanc et al., 2006), dynamic waveform modulation has only been described in the genus Brachyhypopomus and in Sternopygus macrurus (Sternopygidae) (Hagedorn, 1995; Markham et al., 2009b; Stoddard et al., 2006). Yet, the ability to alter a communication signal quickly has many potential benefits ranging from reduction of energetic costs of signal production during times of inactivity (i.e., during the day, in the absence of potential mates) to decreasing detection by predators and competitors.

In this study I survey representative species across the order Gymnotiformes to characterize the extent of EOD plasticity and its hormonal regulation (Fig. 2). I examine whether EOD amplitude and spectra within the ampullary range vary (i) from day to night, (ii) during short-term social interactions and, where present, (iii) if this plasticity is driven my the melanocortins $\mathrm{ACTH}$ and $\alpha-\mathrm{MSH}$ as in B. gauderio.

\section{Methods}

\section{Animals}

I sampled at least two representative species from each of the five Gymnotiform families (Table 1). Except for Brachyhypopomus gauderio, Gymnotus cylindricus, and Rhamphichthys marmoratus, all animals were purchased through various fish importers (Ruineman's Aquarium, Inc., Ornamental Fish, Segrest Farms and World Wide Scientific 
Animals). Brachyhypopomus gauderio, originally obtained from Colombia/Argentina, was sampled from a captive-reared F14 breeding colony at Florida International University, Gymnotus cylindricus was captured in Costa Rica by colleagues, and Rhamphichthys marmoratus was a generous gift from Troy Smith.

All fish were kept either in our aquarium facility, in a 12D:12L, in tanks with temperatures ranging between $26-28^{\circ} \mathrm{C}$ and conductivities between $100-200 \mu \mathrm{S} / \mathrm{cm}$, or in an outdoor facility in 450 liter pools covered with water hyacinths, Eichhornia crassipes. Except Electrophorus electricus, which was fed frozen smelt, all fish were fed oligochaete blackworms (Gulfstream Tropical Aquaria, Dania, Florida) 3x weekly. Fish were housed depending on their aggression and sociality levels. Aggressive species from the Gymnotidae and Apteronotidae families were housed individually. Conspecifics from the remaining families were housed in groups. Fish were brought indoors and placed individually in 284 liter aquaria for data collection (see EOD recording). This study was conducted within the guidelines outlined by the National Institute of Health's 'Guide for the Care and Use of Laboratory Animals (DHEW Publication 80-23, revised 1985 ) and all protocols were approved by the FIU IACUC (protocol approval no. 08$023)$.

\section{EOD recording}

Changes in fish EODs were monitored using an automated EOD machine (Fig. 1) (Stoddard et al., 2003). The EOD machine is an automated system that consists of 12 tanks, $120 \mathrm{~cm} \times 44 \mathrm{~cm} \times 44 \mathrm{~cm}$, covered with copper shielding. The tanks are in a light $(12 \mathrm{D}: 12 \mathrm{~L})$ and temperature $\left(27 \pm 2{ }^{\circ} \mathrm{C}\right)$ controlled room. Each tank is divided into three 
compartments by two plastic grids covered in mesh. An electrically transparent, unglazed ceramic tube connects the two partitions via two plastic funnels that guide fish into the tube. The tank is equipped with two pairs of nichrome electrodes, one pair on top of the ceramic tube (tube electrodes) and the other pair on the opposite ends of the tank (tank electrodes). When the tube electrodes register that a fish is centered in the ceramic tube, the tank electrodes record approximately nine consecutive EODs every minute, which are then digitized. The recorded EODs are amplified 500X and low-pass filtered at 10kHz. To record the high-voltage signals of Electrophorus electricus without damaging our equipment, we connected a $1 \mathrm{k} \Omega: 31 \mathrm{k} \Omega$ voltage divider to the tube electrodes thereby decreasing the voltage being recorded and digitized. The amplifier was lowered to a gain of $1 \mathrm{X}$.

\section{Experimental design}

Fish weights were measured prior to being placed in the EOD machine tanks. In the recording tanks, we measured EODs of all the individuals for at least 72 hours to obtain baseline recordings and to monitor for day-night signal oscillations. Following baseline recordings, animals were injected with $\alpha-\mathrm{MSH}, \mathrm{ACTH}(25 \mathrm{uM} / \mathrm{g}$ of fish, i.m.) and saline. The following concentrations of ACTH and $\alpha-\mathrm{MSH}$ were chosen based on previous studies showing that this concentration fully enhances the EOD in Brachyhypooomus gauderio (Markham and Stoddard, 2005). Finally, to examine whether melanocortins mimic the EOD response to a social challenge, I placed a conspecific into the middle compartment of the test tanks, where the intruder was able to interact electrically but not physically with the resident individual. The social challenge lasted 45- 
60 minutes. Order of all treatments was randomized. Most individuals received all of the treatments (1) ACTH, (2) $\alpha-\mathrm{MSH}$, (3) Saline and (4) Social challenge.

\section{Injections}

Alpha-Melanocyte stimulating hormone ( $\alpha-\mathrm{MSH})$ and adrenocorticotropic hormone (ACTH) (Sigma, M4135 and A2227, respectively) were dissolved in physiological saline: $\mathrm{NaCl} 114 \mathrm{mmol} \mathrm{1}^{-1}, \mathrm{KCl} 2 \mathrm{mmol} \mathrm{1}^{-1}, \mathrm{CaCl} 2.2 \mathrm{H} 2 \mathrm{O} 4 \mathrm{mmol} \mathrm{1}^{-1}$, $\mathrm{MgCl} 2.6 \mathrm{H} 2 \mathrm{O} 2 \mathrm{mmol}^{-1}$, Hepes $2 \mathrm{mmol}^{-1}$, $\mathrm{pH}$ adjusted to 7.2 with $\mathrm{NaOH}$ for a final concentration of $25 \mathrm{uM}$. Aloquats were frozen until and diluted to $25 \mathrm{uM}$ on the day of injection. Physiological saline was used to control for handling and injection. Experimental and control solutions were injected at $1 \mathrm{ul} \mathrm{g}^{-1}$ of fish intramuscularly using a Hamilton syringe fitted with a disposable 31.5 gauge needle. All injections were done between 11:00 and 14:00.

\section{Data analysis}

\section{Signal analysis}

Spectral analysis with a Hanning-windowed FFT was used to examine changes in peak-to peak amplitude and power spectra within the ampullary range $(0-50 \mathrm{~Hz})$ because of treatment. Analyses were performed in Matlab. I measured the EOD amplitude and power spectra in the low-frequency range $(0-50 \mathrm{~Hz})$ immediately before treatment and at the peak of the response following treatment. In cases where no response was evident, as in response to a saline injection or in species that are insensitive to melanocortins, the EOD was measured 45 minutes after treatment. In species sensitive to melanocortins, it 
takes about 45 minutes for melanocortins to reach peak effect (Markham and Stoddard, 2005; Stoddard et al., 2006). Changes in day-night signal variation were measured by sampling the EODs midday, around noon and during the night when the EOD amplitude as at its highest. The time when night amplitude peaked varied between species.

\section{Statistical analysis}

We tried to minimize the number of treatments the individuals were subjected to if the animals appeared very fragile or stressed. In such cases the four different treatments (saline, ACTH, $\alpha-\mathrm{MSH}$, and social challenge) were split between individuals where one individual might have received a saline and ACTH injections, while another individual was treated with saline and $\alpha-\mathrm{MSH}$. While I tried to have at least 6 individuals per representative species because of import regulations, unpredictability of fish importers and increased mortality rate resulting from prolonged handling stress, certain groups have fewer than 6 individuals (i.e., Electrophorus electricus).

Responses to melanocortin injections were compared to saline responses using paired t-tests. In cases where no significant differences were found between ACTH and $\mathrm{MSH}$ responses, data were pooled to increase statistical power. Paired t-tests were also used to measure differences between day and night amplitude, as well as pre and postsocial challenge responses. Where data did not meet normality assumptions, Wilcoxon signed rank test was used. Analyses were performed using SPSS (version 14.0), $\alpha=0.05$ two tailed. 


\section{Results}

\section{Day-Night EOD changes}

EOD amplitudes increased from day to night in members of the Rhamphichthyidae, Hypopomidae and Sternopygidae. Within Rhamphicthyidae, amplitude increased at night in Rhamphichthys marmoratus $(\mathrm{t}=-2.06, \mathrm{df}=18, \mathrm{p}=0.05)$, but not in Gymnorhamphichthys rondoni $(\mathrm{t}=-1.09, \mathrm{df}=7, \mathrm{p}=0.31)$. Of the three Hypopomidae species tested, nighttime amplitude increase in B. gauderio was the greatest (25.19 $\pm 7.97 \%)$, followed by S. elegans $(15.12 \pm 3.12 \%)$ and B. bennetti (10.9 $\pm 2.15 \%$; Table 2). In both Sternopygidae species, nighttime amplitude was significantly higher than daytime amplitude $(E$. cf. virescens $; \mathrm{t}=-2.81, \mathrm{df}=10, \mathrm{p}=0.02 ; S$. macrurus; $\mathrm{Z}=-2.51, \mathrm{~N}=15, \mathrm{p}=0.01$, Table 2). In Gymnotidae and Apteronotidae, EOD amplitudes were invariant (Table 2).

Nighttime onset did not affect the low-frequency end of the power spectrum $(<50 \mathrm{~Hz})$ in members of Gymnotidae or Apteronotidae (Table 2), while causing a significant enhancement in all three Hypopomidae species, and in $R$. marmoratus. Interestingly, neither $S$. macrurus nor $E$. cf. virescens exhibited a change in the ampullary range of the EOD spectra during the night (Table 2).

\section{Effect of melanocortins on EOD}

Compared to saline, injections of the melanocortin $\alpha-\mathrm{MSH}$, but not ACTH significantly enhanced EOD amplitudes in the Gymnotidae (G. cylindricus $\alpha-\mathrm{MSH}: \mathrm{t}=-$ 3.38, $\mathrm{df}=7, \mathrm{p}=0.01$; G. carapo $\alpha-\mathrm{MSH}: \mathrm{Z}=-3.26, \mathrm{~N}=24, \mathrm{p}<0.01)$, Rhamphichthyidae $(G$. rondoni $\alpha-\mathrm{MSH}: \mathrm{t}=-3.15, \mathrm{df}=7, \mathrm{p}=0.02)$, and Hypopomidae $($ B. bennetti $\alpha-\mathrm{MSH}: \mathrm{t}=-$ 
21.38, $\mathrm{df}=4, \mathrm{p}<0.01 ;$ B. gauderio $\alpha-\mathrm{MSH}$ : $\mathrm{t}=-2.72, \mathrm{df}=7, \mathrm{p}=0.03$ ). From previous studies we know that ACTH can increase EOD amplitude by up to 26\% (Markham and Stoddard, 2005), suggesting that our lack of statistical significance (B. gauderio ACTH: $\mathrm{t}=-6.26$, $\mathrm{df}=6, \mathrm{p}=0.06$ ) might be confounded by a small sample size. In $S$. elegans, ACTH enhanced EOD amplitude to a greater extent than $\alpha-\mathrm{MSH}$ (ACTH: $\mathrm{t}=-5.45$, $\mathrm{df}=8, \mathrm{p}<0.01$; $\alpha$-MSH: $\mathrm{t}=-2.15, \mathrm{df}=9, \mathrm{p}=0.06$ ). There was no difference between ACTH and $\alpha-\mathrm{MSH}$ response in Sternopygidae, (S. macrurus: $\mathrm{t}=-0.80, \mathrm{df}=12, \mathrm{p}=0.44$, E. cf. virescens: $\mathrm{t}=0.52$, $\mathrm{df}=9, \mathrm{p}=0.61$ ), and both melanocortins increased EOD amplitude (S. macrurus: $\mathrm{Z}=-3.30$, $\mathrm{N}=14, \mathrm{p}<0.01 ;$. cf virescens: $\mathrm{t}=-4.59, \mathrm{df}=9, \mathrm{p}<0.01)$. Neither melanocortin had any effect on A. leptorhynchus ( $\alpha-\mathrm{MSH}: \mathrm{Z}=-0.68, \mathrm{~N}=6, \mathrm{p}=0.5$; ACTH: $\mathrm{Z}=-0.06, \mathrm{~N}=9$, $\mathrm{p}=0.95$ ) or A. albifrons $(\alpha-\mathrm{MSH}: \mathrm{t}=-0.29, \mathrm{df}=3, \mathrm{p}=0.79$; ACTH: $\mathrm{t}==1.08, \mathrm{df}=7, \mathrm{p}=0.32)$ amplitudes.

Within the Gymnotidae, $\alpha$-MSH increased EOD spectra within the ampullary range only in G. cylindricus $(\mathrm{t}=-4.87, \mathrm{~d}=7, \mathrm{p}<0.01)$. Neither melanocortin treatment had any effect on the EOD spectra of the remaining species in Gymnotidae, Apteronotidae, or Rhamphichthyidae (Table 2). Within Hypopomidae, $\alpha$-MSH, but not ACTH increased signal spectrum in S. elegans $(\alpha-\mathrm{MSH}: \mathrm{t}=-7.02, \mathrm{df}=9, \mathrm{p}<0.01$; ACTH: $\mathrm{t}=-2.02, \mathrm{df}=8$, $\mathrm{p}=0.08)$ and B. gauderio $(\alpha-\mathrm{MSH}: \mathrm{t}=-6.08, \mathrm{df}=7, \mathrm{p}<0.01 ;$ ACTH: $\mathrm{t}=0.67, \mathrm{df}=6, \mathrm{p}=0.53$ ), while neither melanocortin had any effect on $B$. bennetti $(\alpha-\mathrm{MSH}$ : $\mathrm{t}=-1.81, \mathrm{df}=4, \mathrm{p} 0.15$; ACTH: $\mathrm{t}=-6.00, \mathrm{df}=4, \mathrm{p}=0.58$ ). Within Stenopygidae, both melanocortins increased signal spectrum in $S$. macrurus $(\mathrm{Z}=-2.67, \mathrm{~N}=13, \mathrm{p}<0.01)$, but had no effect on $E$.cf. virescens $(\mathrm{t}=1.97, \mathrm{df}=9, \mathrm{p}=0.08)$. 


\section{Effect of short-term social challenges on EOD}

Social challenges had no effect on peak-to-peak amplitudes of Gymnotidae, Rhamphichthyidae or Apteronotidae species (Table 2). Only $S$. elegans $(\mathrm{t}=-2.49, \mathrm{df}=6$, $\mathrm{p}=0.05)$ and $B$. bennetti $(\mathrm{t}=-2.90, \mathrm{df}=4, \mathrm{p}=0.04)$ within Hypopomidae, and $S$. macrurus $(\mathrm{Z}=-2.95, \mathrm{~N}=11, \mathrm{p}<0.01)$ within Sternopygidae increased amplitudes during social challenges (Table 2).

Social challenges significantly increased the energy within the low-frequency rage of $S$. macrurus $(\mathrm{Z}=-2.82, \mathrm{~N}=12, \mathrm{p}<0.01)$ and decreased it in A. leptorhynchus $(\mathrm{Z}=-$ 2.02, $\mathrm{N}=5, \mathrm{p}=0.04)$. The spectra of all other species remained unaffected (Table 2).

\section{Discussion}

\section{EOD waveform plasticity varies across gymnotiform families}

I observed three patterns of EOD modulations in gymnotiform species examined; amplitude modulation, spectral modulation, combined amplitude and spectral modulation, and absence of waveform modulation entirely. In general, neither species in Apteronotidae or Gymnotidae seem to express dynamic waveform modulation (although individual species, and individuals in the non-modulating species showed some degree of amplitude and/or spectrum plasticity). In the Apteronotidae, both $A$. leptorhynchus and $A$. albifrons do not modulate their amplitudes from day to night, during social challenges or in response to melanocortins (Table 2, Fig. 7). Interestingly, in response to a social challenge, A. leptorhynchus increased the amount of energy present within the lowfrequency range of the power spectrum (Table 2, Fig. 7C), but neither melanocortin treatment was able to mimic this response. Within Gymnotidae, neither species exhibited 
day-night or social challenge-induced modulation of EOD amplitude or spectra (Table 2, Fig. 3). However, G. carapo and G. cylindricus increased EOD amplitude in response to $\alpha$-MSH, but not ACTH. This differential melanocortin response was also observed in $G$. rondoni (Rhamphichthyidae, Table 2) and in B. gauderio (Hypopomidae, Table 2). In $B$. gauderio, ACTH has been shown to significantly enhance signal amplitude (Markham and Stoddard, 2005), suggesting that lack of statistically significant ACTH effect might be a confound of small sample size rather than absence of a biologically significant melanocortin effect (Fig. 5). Furthermore, short-term social challenges had no effect on either amplitude or power spectra of B. gauderio EOD. I have previously shown that short-term social challenge can enhance signal amplitude (Franchina et al., 2001; Goldina et al., 2011); I am not sure why these effects were not observed in this study. In previous studies, the social challenges administered consisted of size-matched same-sex male opponents, inducing a large amplitude increase (Franchina et al., 2001; Goldina et al., 2011). However, because I was unsure of the sex of the other species in this study, I used male and female same-sex social challenges. Compared to males, female B. gauderio do not exhibit as large nightly amplitude increases (Franchina and Stoddard, 1998; Stoddard et al., 2007), nor do they respond to same-sex social challenges (Allee et al., 2009). However, no sex difference was apparent in my statistical analyses (data not shown). I observed amplitude modulation in E. cf. virescens of Sternopygidae in response to melanocortins and nighttime onset, but not to social challenges (Table 2). Neither of these treatments increased energy in the ampullary region of the EOD power spectrum (Fig. 6D). It is possible that in E. cf. virescens, melanocortins drive the day-night rhythms, but not social communication. 
Plasticity in amplitude and power spectra was present in several species within the gymnotiform families. Sternopygus macrurus of Sternopygidae increased signal amplitude and boosted energy in the ampullary-sensitive region of the spectrum in response to melanocortins and social challenges (Fig. 6A). Nighttime onset increased amplitude without affecting the power spectra (Fig. 6B). Conversely, R. marmoratus (Rhamphichthyidae) increased amplitude and spectral energy during nighttime, but not in response to melanocortins or social challenges (Table 2, Fig. 2A,B). Finally, members of the Hypopomidae exhibited the most plastic signals; enhancing EOD amplitudes in response to every treatment (except B. gauderio, see above). All four species tested boosted energy in the low-frequency region of the spectrum, a phenomenon that was mimicked by $\alpha-\mathrm{MSH}$ but not ACTH injections in S. elegans and B. gauderio (Table 2, Fig. 5).

In summary, it seems that members of the Apteronotidae and Gymnotidae exhibit most static signals, Sternopygidae and Rhamphichthyidae mainly modulate amplitude, while Hypopomidae have the most dynamic signals, varying amplitude and power spectrum. I examined too few species, especially from the Rhamphichthyidae, Sternopygidae and Apteronotidae, to be confident that the patterns I observed can be extended to the rest of the family members. Therefore, in the rest of this paper I interpret my results with caution, hoping to stimulate discussion and more experiments using the less popular, but not less fascinating gymnotiform species. 


\section{Proximate differences in signal production may account for differences in EOD plasticity}

The observed species and family differences in signal plasticity may be attributed to electric organ heterogeneity, as well as the differential expression of ion channels on

the electrocyte membranes. Additionally, differential sensitivity to melanocortins may be the product of (1) differential melanocortin receptor expression on electrocytes or (2) differential melanocortin sensitivity of downstream effectors that regulate signal waveform.

Electric organs differ between species in electrocyte shape, quantity, number of excitable faces, patterns of innervation by motoneurons, as well as presence of accessory organs (Bennett, 1971). All of these differences contribute to species-specific waveforms, including differences in EOD phase number, pulse shape, and duration. For example, the 34 recognized species within the family Gymnotidae, possess highly variable EODs ranging from monophasic (E. electricus and G. cylindricus) to multiphasic signals $(G$. carapo and G. ucamara) (Lovejoy et al., 2010). In G. carapo different phases of the waveform are generated by distinct parts of the electric organ; the abdominal and central portion of the electric organ have doubly innervated electrocytes allowing it to produce an EOD waveform with four faces (Caputi et al., 2005; Trujilo-Cenoz and Echague, 1989). In several gymnotids, S. elegans (Hypopomidae) and rhamphichthyds (Rhamphichthyidae) accessory organs contribute additional phases to the waveforms (Crampton and Albert, 2006). However, while the electric eel (E. electricus) has three electric organs, Main, Hunter's and Sachs, only Sachs and posterior portion of the Hunter's organ are used in low-voltage signaling for communication and electrolocation 
(Main and anterior portion of Sachs generate the high-voltage EODs used to stun prey (Bennett, 1971; Zupanc and Bullock, 2005)). In E. electricus melanocortins increased overall signal amplitude (Fig. 3A); however, I could not tell which organ was discharging. It is possible that Sachs and Hunter's organ are differentially sensitive to melanocortins, affecting communication, hunting or both behaviors.

Unlike the rest of the gymnotiforms whose electric organs are myogenically derived, the electric organs of apteronotids are an extension of the electromotoneurons (Bennett, 1971). Apteronotids have a myogenically derived larval electric organ, that is replaced by a neurogenic organ during development (Unguez and Zakon, 1998; Zakon and Unguez, 1999). Neurogenically derived electrocytes allow apteronotids to produce EODs of the highest frequency in the entire order. However, the ability to generate a dynamic waveform might have been lost along with the loss of myogenically derived electric organ. Alternatively, the neurogenic organ might lack melanocortin receptor expression in electrocytes and is thus insensitive to melanocortins. Examining whether melanocortin sensitivity and amplitude modulation is present throughout larval and juvenile stages, and is lost when the juvenile myogenic organ is replaced by the adult neurogenic one would be a good test of this hypothesis.

Dynamic signaling might also be a result of species-specific co-option of the melanocortin hormone pathway. Short-term amplitude modulations in B. gauderio and $S$. macrurus are regulated by melanocortins through the activation of the cAMP/PKA pathway (Markham and Stoddard, 2005; McAnelly et al., 2003; Stoddard et al., 2006), which in turn promotes exocytosis of preformed voltage-gated $\mathrm{Na}+$ and inward rectifying $\mathrm{K}+$ channels into the electrocyte membrane. Increasing the number of ion channels in the 
membranes causes EOD amplitude increase (Markham et al., 2009b). Furthermore, if melanocortin receptors are differentially expressed throughout the electric organ of a species with either a heterogeneous organ, as in gymnotids, or with accessory organs, as in rhamphichthyids or Steatogenys, then different phases of the waveforms can be independently modulated, increasing signal plasticity. Plasticity might also be a result of differential expression of melanocortin receptors. Of the five melanocortin receptors (MC1-5R), MC2R is specific for ACTH, MC1R and MC4R have equally high affinities for $\alpha-\mathrm{MSH}$ and $\mathrm{ACTH}$, and MC3R has the highest affinities for $\alpha-\mathrm{MSH}$ and lowest for ACTH (Gantz and Fong, 2003). It is possible that differential responses to ACTH and $\alpha-$ MSH I observed in G. cylindricus, G. carapo, R. marmoratus, G. rondoni and B. gauderio reflect differential expression of the melanocortin receptors within the electric organs of these species. However, while melanocortin system is highly conserved across vertebrates (Metz et al., 2006), it is not known whether the receptor affinities described in other teleosts reflect melanocortin receptor affinities in gymnotiforms. Furthermore, it is currently not known if gymnotiform electrocytes express melanocortin receptors. Preliminary studies suggest that B. gauderio electrocytes express MC-5R (Villinger and Stoddard, unpublished observations), a receptor associated with aggressive and sexual behaviors in rodents (Caldwell and Lepri, 2002; Morgan and Cone, 2006; Morgan et al., 2004).

Finally, signal plasticity may be generated through secondary melanocortin effects. ACTH regulates testicular steroidogenesis and glucocorticoid release and promotes testosterone production during fetal mouse development (Ducrest et al., 2008; Haskell-Luevano and Hadley, 1999; O'shaughnessy et al., 2003). In gymnotiforms, 
androgens masculinize the waveform (Allee et al., 2009; Hagedorn and Carr, 1985; Silva et al., 2002), and in B. gauderio, androgens enhance $\alpha$-MSH amplitude rise (Goldina et al., 2011), further increasing sexual dimorphism of the waveform. Androgens also enhance $\alpha$-MSH amplitude response of E. cf. virescens, but not of $G$. carapo or $A$. leptorhynchus (Goldina and Stoddard, unpublished observations). Interestingly, all four species are sensitive to androgens (Dunlap et al., 1998; Dunlap and Zakon, 1998; Silva et al., 2002). These findings suggest that signal plasticity is regulated through differential melanocortin sensitivity, while steroid hormones activate these effects possibly by inducing changes in electrocytes observed during sexual differentiation (Bass and Volman, 1987).

\section{Behavioral explanations for observed signal differences}

EODs are energetically expensive to generate (Salazar and Stoddard, 2008) and it would make sense to restrict signaling to situations where benefits (i.e., mate attraction) can outweigh the energetic costs. Dynamic signaling can thus serve as an adaptive strategy for species that share habitats with multiple predators. Hypopomids have the most dynamic signals (Table 2, Fig. 5), increasing signal amplitude and power at night, when courting females and during social interactions (Franchina et al., 2001; Franchina

and Stoddard, 1998). They are often found in the same habitats as gymnotids, whose diet at least partially consists of electric fish, including B. gauderio (Crampton and Albert, 2006; Miranda et al., 2008).

Within the Gymnotidae, E. electricus has been reported to prey on G. carapo and possibly other electric species in the wild (Westby, 1988). Through natural selection for 
multiphasic signals gymnotiforms might have decreased their conspicuousness to electroreceptive predators (Stoddard 1999), maintenance of such signals is energetically expensive when predators are absent. In Gymnotus, the multiphasic state is ancestral with multiple lineages losing phases independently. Thus, the monophasic waveform of $G$. cylindricus is a derived condition (Lovejoy et al., 2010). Gymnotus cylindricus inhabits freshwaters in Central America that are devoid of electrorecetive predators such as catfish, stingrays and electric eels (Lovejoy et al., 2010). Thus, G. cylindricus does not incur the potential costs of enhancing the amplitude and energy in the low frequency region of the power spectrum (Table 2). The monophasic waveform of $B$. bennetti seems to encode sex, and males in breeding condition produce signals twice as large as that of females (Crampton and Albert, 2006). Of all the gymnotiforms I tested, B. bennetti exhibits the greatest increase in the low-frequency end of the spectrum during nighttime and social challenges (Table 2), making it highly conspicuous to electroreceptive predators. It has been suggested that the $B$. bennetti is a batesian mimic of the electric eel and its large discharge is often mistaken by scientists for this sympatric predator's EOD (Stoddard, 1999). Whether B. bennetti males experience greater predation rates than females or if they manage to escape predation because they are mistaken for predators themselves remains to be tested. Currently, no studies examine whether the melanocortin-induced waveform enhancements reflect actual signal modulations used by this species and whether, as seen in hypopomids and mormyrids (Machnik and Kramer, 2008; Stoddard, 1999), greater signal amplitude is preferred by females.

In wave fishes (Apteronotidae and Sternopygidae), EOD frequency is typically very stable, sexually dimorphic and conveys social status. Short-term frequency 
modulations of wave species are often used during courtship and aggressive interactions (Hagedorn and Heiligenberg, 1985; Zakon and Smith, 2002). EOD waveform and frequency are highly variable across apteronotid species and might be used in species recognition (Turner et al., 2007). The function of amplitude modulation, however, is not clear. Since wave type waveforms are symmetrical above and below 0 volts DC, their waveforms are generally not attractive to predators. The absence of any amplitude and spectral modulation in the apteronotid species might be attributed to the need to maintain a stable, stereotypical signal that is recognizable by territorial conspecifics. Since most apteronotids are highly aggressive and territorial, keeping waveform amplitudes and spectra constant may convey information about individual identity and serve as a signature signal. Alternatively, since most apteronotids are confined to deep river channels (Crampton and Albert, 2006), fast flowing waters might inhibit effective transmission of amplitude-modulated signals. Another explanation for the relative stability of EOD amplitude in apteronotids is that amplitude modulation might be reserved for electroreception, enhacing object detectability used in scan-swimming (Crampton and Albert, 2006). Therefore, dynamic amplitude modulation in the context of communication, in addition to amplitude modulations during scan-sampling, might be too energetically expensive.

Similarly, amplitude modulation in Sternopygidae might reflect their more social nature. Since E. virescens adjust their EOD frequencies to avoid jamming conspecifics within their social groups (Oestreich and Zakon, 2005), they maintain a stable amplitude during social challenges to convey identity and status (Table 2, Fig. 6C). On the other hand, the less social $S$. macrurus does not form shoals and does not have a means to 
avoid being electrically jammed by conspecifics, changes amplitude during social challenges (Table 2, Fig. 6A) to possibly convey changes in motivation.

\section{Conclusions}

In gymnotiforms, electric organ heterogeneity within and between individuals may serve as a substrate for the evolution of signal plasticity and dynamic communication signals via the co-option of the ancient melanocortin hormone pathway. Most likely, this melanocortin driven plasticity is mediated through differential modulation of the voltage-gated ion channels.

To date, very little is known about the behaviors and significance of signal modulations in most gymnotiforms. Without the basic knowledge of their natural history, it is impossible to propose the value of signal modulations in communication of a given species. Furthermore, without understanding the behavioral repertoires of the different species, including the environmental pressures they are under, one cannot fully understand the proximate or ultimate reasons for dynamic signaling in gymnotiforms. I hope that my findings will stimulate further studies examining EOD plasticity of multiple poorly described gymnotiform species in their natural environments.

\section{Acknowledgements}

Financial support and equipment were provided by NIH grants MBRS S06GM08205 (PKS), NIH K01MH64550 (MRM) and MBRS graduate fellowship, Sigma Xi research grant, and Graduate Student Association Research Grant (AG). I thank Scott Chormanski, Joel Baez, Michael Helbig, Christian Agudelo, James Roach 
and Susan Allee for help with fish care. Special gratitude goes to Maureen Donnelly and Ralph Saporito for obtaining G. cylindricus from La Selva, Panama and Troy Smith for kindly donating R. marmoratus. Finally, Arie and Arijon de Zwart from Ruineman's Aquarium, Inc. provided invaluable advice on fish care, disease diagnosis and treatment. 


\section{References}

Albert, J.S., Crampton, W.G.R., 2005. Diversity and phylogeny of neotropical electric fishes (Gymnotiformes), in: Hopkins, C.D., Bullock, T.H., Fay, R.R., Popper, A.N. (Eds.), Electroreception, 1 ed. Springer, pp. 360-409.

Alcock, J., 2001. Animal Behavior: An Evolutionary Approach, 7th ed. Sinauer Associates, Inc., Sunderland, Massachusetts.

Allee, S.J., Markham, M.R., Stoddard, P.K., 2009. Androgens enhance plasticity of an electric communication signal in female knifefish, Brachyhypopomus pinnicaudatus. Hormones and Behavior 56, 264-273.

Alves-Gomes, J.A., 2001. The evolution of electroreception and bioelectrogenesis in teleost fish: a phylogenetic perspective. Journal of Fish Biology 58, 1489-1511.

Bass, A.H., Volman, S.F., 1987. From behavior to membranes: testosterone-induced changes in action potential duration in electric organs. Proc.Natl. Acad. Sci. U.S.A. 84, 9295-9298.

Bennett, M.V.L., 1971. Electric organs, in: Hoar, W.S., Randall, D.J. (Eds.), Fish Physiology. Academic Press, London, pp. 347-491.

Bradbury, J.W., Vehrencamp, S.L., 1998. Chapter 11. Electroreception, Principles of Animal Communication. Sinauer Associates, Inc., Sunderland, Massachusetts, pp. 319350 .

Bro-Jorgensen, J., 2009. Dynamics of multiple signalling systems: animal communication in a world of flux. Trends in Ecology and Evolution 25, 292-299.

Burmeister, S.S., Jarvis, E.D., Fernald, R., 2005. Rapid behavioral and genomic responses to social opportunity. PLOS Biology 3, 1-9.

Caldwell, H.K., Lepri, J.J., 2002. Disruption of the fifth melanocortin receptor alters the urinary excretion of aggression-modifying pheromones in male house mice. Chem. senses 27, 91-94.

Caputi, A.A., Carlson, B.A., Macadar, O., 2005. Electric organs and their control, in: Bullock, T.H., Hopkins, C.D., Popper, A.N., Fay, R.R. (Eds.), Electroreception. Springer, New York, pp. 411-451. 
Crampton, W.G.R., 2011. An ecological perspective on diversity and distributions, in: Albert, J.S., Reis, R.E. (Eds.), Historical biogeography of neotropical freshwater fishes. Uniersity of California Press, Berkeley, pp. 165-189.

Crampton, W.G.R., Albert, J.S., 2006. Evolution of electric signal diversity in gymnotiform fishes, in: Ladich, F., Collin, S.P., Moller, P., Kapoor, B.G. (Eds.), Communication in fishes. Science Publishers, Enfield, NH, pp. 647-731.

Curtis, C.C., Stoddard, P.K., 2003. Mate preference in female electric fish, Brachyhypomus pinnicaudatus. Animal Behaviour 66, 329-336.

Ducrest, A.L., Keller, L., Roulin, A., 2008. Pleiotropy in the melanocortin system, coloration and behavioural syndromes. Trends in Ecology and Evolution 23, 502-510.

Dunlap, K.D., Thomas, P., Zakon, H.H., 1998. Diversity of sexual dimorphism in electrocommunication signals and its androgen regulation in a genus of electric fish, Apteronotus. Journal of Comparative Physiology A 183, 77-86.

Dunlap, K.D., Zakon, H.H., 1998. Behavioral actions of androgens and androgen receptor expression in the electrocommunication system of an electric fish, Eigenmannia virescens. Hormones and Behavior 3, 30-38.

Emerson, S.B., 2001. Male advertisement calls, in: Ryan, M.J. (Ed.), Anuran communication. Smithsonian Institution Press, Washington, pp. 36-44.

Emlen, D.J., Szafran, Q., Corley, L.S., Dworkin, I., 2006. Insulin patterning and limbpatterning: candidate pathways for the origin and evolutionary diversification of beetle 'horns'. Heredity 97, 179-191.

Few, W.P., Zakon, H.H., 2001. Androgens alter electric organ discharge pulse duration despite stability in electric organ discharge frequency. Hormones and Behavior 40, 434442.

Franchina, C.R., 1997. Ontogeny of the electric organ discharge and the electric organ in the weakly electric pulse fish Brachyhypopomus pinnicaudatus (Hypopomidae, Gymnotiformes). Journal of Comparative Physiology A 181, 111-119.

Franchina, C.R., Salazar, V.L., Volmar, C.-H., Stoddard, P.K., 2001. Plasticity of the electric organ discharge waveform of male Brachyhypopomus pinnicaudatus. II. Social effects. Journal of Comparative Physiology A 187, 45-52.

Franchina, C.R., Stoddard, P.K., 1998. Plasticity of the electric organ discharge waveform of the electric fish Brachyhypopomus pinnicaudatus I. Quantification of daynight changes. Journal of Comparative Physiology A 183, 759-768. 
Gantz, I., Fong, T.M., 2003. The melanocortin system. Am. J. Physiol. Endocrinol. Metab. 284, E468-E474.

Grober, M., Bass, A.H., 2002. Life history, neuroendocrinology, and behavior in fish, in: Pfaff, D., Arnold, A., Etgen, A., Fahrbach, S., Rubin, R., Frank, L. (Eds.), Hormones, Brain and Behavior. Academic Press, New York.

Hagedorn, M., 1995. The electric fish Hypopomus occidentalis can rapidly modulate the amplitude and duration of its electric organ discharges. Animal Behavior 49, 1409-1413.

Hagedorn, M., Carr, C., 1985. Single electrocytes produce a sexually dimorphic signal in South American electric fish, Hypopomus occidentalis (Gymnotiformes, Hypopomidae). Journal of Comparative Physiology A 156, 511-523.

Hagedorn, M., Heiligenberg, W., 1985. Court and spark:electric signals in the courtship and mating of gymnotid fish. Animal Behaviour 33, 254-265.

Hanika, S., Kramer, B., 1999. Electric organ discharges of mormyrid fish as a possible cue for predatory catfish. Naturwissenschaften $86,286-288$.

Hanika, S., Kramer, B., 2000. Electrosensory prey detection in the African sharptooth catfish, Clarias gariepinus (Clariidae), of a weakly electric mormyrid fish, the bulldog (Marcusenius macrolepidotus). Behavioral Ecology and Sociobiology 48, 218-228.

Haskell-Luevano, C., Hadley, M., 1999. The melanocortin receptors. Drug news perspectives 12, 197-205.

Hopkins, C.D., 1988. Neuroethology of electric communication. Annual Reviews in Neuroscience 11, 497-535.

Karubian, J., Lindsay, W.R., Schwabl, H., Webster, M.S., 2011. Bill coloration, a flexible signal in a tropical passerine bird is regulated by social environment and androgens. Animal Behavior 81, 795-800.

Lovejoy, N.R., Lester, K., Crampton, W.G.R., Marques, F.P.L., Albert, J.S., 2010. Phylogeny, biogeography, and electric signal evolution of Neotropical knifefishes of the genus Gymnotus (Osteichthyes: Gymnotidae). Molecular phylogenetics and evolution 54, $278-290$.

Machnik, P., Kramer, B., 2008. Female choice by electric pulse duration: attractiveness of the males' communication signal assessed by female bulldog fish, Marcusenius pongolensis (Mormyridae, Teleostei). The Journal of Experimental Biology 211, 19691977. 
Markham, M.R., Allee, S., Goldina, A., Stoddard, P.K., 2009a. Melanocortins regulate the electric waveforms of gymnotiform electric fish. Hormones and Behavior 55, 306313.

Markham, M.R., McAnelly, L.M., Stoddard, P.K., Zakon, H.H., 2009b. Circadian and social cues regulate ion channel trafficking. PLOS Biology 7, 1-14.

Markham, M.R., Stoddard, P.K., 2005. Adrenocorticotropic hormone enhances the masculinity of an electric communication signal by modulating the waveform and timing of action potentials within individual cells. Journal of Neuroscience 25, 8746-8754.

McAnelly, L.M., Silva, A., Zakon, H.H., 2003. Cyclic AMP modulates electrical signaling in a weakly electric fish. Journal of Comparative Physiology A 189, 273-282.

Metz, J.R., Peters, J.J.M., Flik, G., 2006. Molecular biology and physiology of the melanocortin system in fish: a review. General and Comparative Endocrinology.

Meyer, J.H., 1983. Steroid influences upon the discharge frequencies of a weakly electric fish. Journal of Comparative Physiology 153, 29-37.

Mills, A., Zakon, H.H., 1991. Chronic androgen treatment increases action potential duration in the electric organ of Sternopygus. Journal of Neuroscience 11, 2349-2361.

Miranda, M., Silva, A.C., Stoddard, P.K., 2008. Use of space as an indicator of social behavior and breeding systems in the gymnotiform electric fish Brachyhypopomus pinnicaudatus. Environmental Biology of Fishes 82, 379-389.

Morgan, C., Cone, R., 2006. Melanocortin-5 receptor deficiency in mice blocks a novel pathway influencing pheromone-induced aggression. Behavior Genetics 36, 291-300.

Morgan, C., Thomas, R.E., Ma, W., Novotny, M.V., Cone, R., 2004. Melanocortin-5 receptor deficiency reduces a pheromonal signal for aggression. Chem. senses 29, 111115.

O'shaughnessy, P., Fleming, L., Jackson, G., Hochgeschwender, U., Reed, P., Baker, P., 2003. Adrenocorticotropic hormone directly stimulates testosterone production by the fetal and neonatal mouse testis. Endocrinology 144, 3279-3284.

Oestreich, J., Zakon, H.H., 2005. Species-specific differences in sensorimotor adaptation are correlated with differences in social structure. Journal of Comparative Physiology A 191, 845-856.

Rand, S.A., Ryan, M.J., 1981. The adaptive significance of a complex vocal repertoire in a neotropical frog. Tierpsychology 57, 209-214. 
Ryan, M.J., Tuttle, M.D., Rand, S.A., 1982. Bat predation and sexual advertisement in a neotropical anuran. American Naturalist 119, 136-139.

Salazar, V.L., Stoddard, P.K., 2008. Sex differences in energetic costs explain sexual dimorphism in the circadian rhythm modulation of the electrocommunication signal of the gymnotiform fish Brachyhypopomus pinnicaudatus. Journal of Experimental Biology 211, 1012-1020.

Silva, A., Quintana, L., Ardanaz, J.L., Macadar, O., 2002. Environmental and hormonal influences upon EOD waveform in gymnotiform pulse fish. Journal of Physiology-Paris 96, 473-484.

Stoddard, P.K., 1999. Predation enhances complexity in the evolution of electric fish signals. Nature 400, 254-256.

Stoddard, P.K., 2002. The evolutionary origins of electric signal complexity. Journal of Physiology-Paris 96, 485-491.

Stoddard, P.K., Markham, M.R., 2008. Signal cloaking in electric fish. BioScience 58, 415-425.

Stoddard, P.K., Markham, M.R., Salazar, V.L., 2003. Serotonin modulates the electric waveform of the gymnotiform electric fish, Brachyhypopomus pinnicaudatus. Journal of Experimental Biology 206, 1353-1362.

Stoddard, P.K., Markham, M.R., Salazar, V.L., Allee, S., 2007. Circadian rhythms in electric waveform structure and rate in the electric fish Brachyhypopomus pinnicaudatus. Physiology \& Behavior 90, 11-20.

Stoddard, P.K., Zakon, H.H., Markham, M.R., McAnelly, L., 2006. Regulation and modulation of electric waveforms in gymnotiform electric fish. Journal of Comparative Physiology A 192, 613-624.

Stuart-Fox, D., Moussalli, A., 2008. Selection for social signalling drives the evolution of chameleon colour change. PLOS Biology 6, 22-29.

Szabo, T., 1974. Anatomy of the specialized lateral line organs of electroreception, in: Fessard, A. (Ed.), Handbook of Sensory Physiology. Springer-Verlag, Berlin, pp. 13-58.

Trujilo-Cenoz, O., Echague, J.A., 1989. Waveform generation of the electric organ discharge in Gymnotus carapo. Journal of Comparative Physiology A 165, 343-351.

Turner, C.R., Derylo, M., de Santana, C.D., Alves-Gomes, J.A., Smith, G.T., 2007. Phylogenetic comparative analysis of electric communication signals in ghost knifefishes (Gymnotiformes: Apteronotidae). Journal of Experimental Biology 210, 4104-4122. 
Unguez, G.A., Zakon, H.H., 1998. Phenotypic conversion of distinct muscle fiber populations to electrocytes in a weakly electric fish. Journal of Comparative Neurology 399, 20-34.

Westby, G.W.M., 1988. The ecology, discharge diversity and predatory behaviour of gymnotiforme electric fish in the coastal streams of French Guiana. Behavioral Ecology and Sociobiology 22, 341-354.

Zakon, H.H., 1993. Weakly electric fish as model systems for studying long-term steroid action on neural circuits. Brain Behavior and Evolution 42, 242-251.

Zakon, H.H., Smith, G.T., 2002. Weakly electric fish: neurobiology, and neuroendocrinology. Hormones, Brain and Behavior 2, 349-374.

Zakon, H.H., Smith, G.T., 2009. Weakly electric fish: behavior, neurobiology, and neuroendocrinology, in: Pfaff, D., Arnold, A., Etgen, A., Fahrbach, S., Rubin, R. (Eds.), Hormones, brain and behavior, 2 ed. Academic press, Amsterdam, pp. 611-638.

Zakon, H.H., Unguez, G.A., 1999. Development and regeneration of the electric organ. Journal of Experimental Biology 202, 1427-1434.

Zupanc, G.K.H., Bullock, T.H., 2005. From electrogenesis to electroreception: an overview, in: Bullock, T.H., Hopkins, C.D., Popper, A.N., Fay, R.R. (Eds.), Electroreception. Springer, New York, pp. 5-46.

Zupanc, G.K.H., Sirbulescu, R.F., Nichols, A., Ilies, I., 2006. Electric interactions through chirping behavior in the weakly electric fish, Apteronotus leptorhynchus. Journal of Comparative Physiology A 192, 159-173. 
Table 1. Species origin and weights (mean \pm S.E.).

\begin{tabular}{|l|c|c|}
\hline $\begin{array}{l}\text { Family } \\
\text { Species }\end{array}$ & Origin & $\begin{array}{c}\text { Weight (g) } \\
\text { Mean } \pm \text { SD }\end{array}$ \\
\hline Gymnotidae & & \\
\hline Electrophorus electricus & Brazil & $1098 \pm 710$ \\
\hline Gymnotus cylindricus & Costa Rica & $7.53 \pm 2.99$ \\
\hline Gymnotus carapo & Colombia / Peru & $30.3 \pm 17.3$ \\
\hline Gymnotus ucamara & Peru & $11.8 \pm 4.38$ \\
\hline Rhamphichthyidae & Colombia & $28.8 \pm 18.8$ \\
\hline Rhamphichthys marmoratus & Peru & $4.5 \pm 0.7$ \\
\hline Gymnorhamphichthys rondoni & & \\
\hline Hypopomidae & Peru & $9.96 \pm 4.09$ \\
\hline Steatogenys elegans & Ecuador & $10 \pm 3.2$ \\
\hline Brachyhpopomus bennetti & Colombia / Argentina & $9.6 \pm 1.3$ \\
\hline Brachyhypopomus gauderio & Ecuador & $26.2 \pm 15.2$ \\
\hline Sternopygidae & Guyana / Colombia & $9.85 \pm 4.16$ \\
\hline Sternopygus macrurus & & \\
\hline Eigenmannia cf. virescens & Brazil & $18 \pm 3.83$ \\
\hline Apteronotidae & Colombia & $14.1 \pm 8.4$ \\
\hline Apteronotus albifrons & & \\
\hline Apteronotus leptorhynchus & & \\
\hline
\end{tabular}

Beyond country, I was unable to find out the detailed locations from which the different species were obtained, because except for B. gauderio and G. cylindricus, all individuals were purchased from multiple tropical fish importers. Since most of the above species occupy multiple habitat types (Albert and Crampton, 2005), it was not possible to differentiate the effect of habitat or presence of heterospecifics on signal plasticity within any one species. Also, because most of the tested species are not sexually dimorphic in morphology or their signals, I do not know the sex of most individuals used in this study. 
Table 2. Change in EOD amplitude from day to night and in response to melanocortin (ACTH and MSH) injections and shortterm social challenges.

\begin{tabular}{|c|c|c|c|c|c|c|c|}
\hline Species & & \multicolumn{3}{|c|}{$\%$ Relative amplitude change } & \multicolumn{3}{|c|}{$\begin{array}{l}\text { \% Relative change in ampullary range } \\
(<50 \mathrm{~Hz}) \text { of the spectrum }\end{array}$} \\
\hline E. electricus & $\mathbf{N}$ & Mean \pm SE & Statistic & p-value & Mean \pm SE & t statistic & p-value \\
\hline Day-Night & 2 & $-12.80 \pm 5.30$ & ----- & ----- & $1517.7 \pm 297.0$ & ----- & ----- \\
\hline MSH & 2 & $11.5 \pm 4.30$ & ----- & ----- & $-768.7 \pm 306.0$ & ----- & ----- \\
\hline \multicolumn{8}{|l|}{ G. cylindricus } \\
\hline Day-Night & 16 & $-1.27 \pm 1.11$ & $t=-0.06$ & 0.95 & $80.50 \pm 42.70$ & $\mathrm{t}=1.84$ & 0.09 \\
\hline MSH & 8 & $2.30 \pm 0.58$ & $\mathrm{t}=-3.38$ & $0.01 *$ & $-118.27 \pm 48.1$ & $\mathrm{t}=-4.87$ & $<0.01 *$ \\
\hline $\mathrm{ACTH}$ & 8 & $-1.10 \pm 0.44$ & $\mathrm{t}=-0.90$ & 0.40 & $14.05 \pm 28.32$ & $\mathrm{t}=-1.48$ & 0.18 \\
\hline Social challenge & 12 & $0.74 \pm 0.62$ & $t=-0.65$ & 0.53 & $-25.28 \pm 22.18$ & $\mathrm{t}=-1.08$ & 0.30 \\
\hline \multicolumn{8}{|l|}{ G. carapo } \\
\hline Day-Night & 29 & $-1.47 \pm 4.36$ & $Z=-1.80$ & 0.07 & $9.65 \pm 6.43$ & $Z=-0.81$ & 0.42 \\
\hline $\mathrm{MSH}$ & 24 & $8.47 \pm 4.11$ & $Z=-3.26$ & $<0.01 *$ & $-1.81 \pm 4.38$ & $Z=-1.26$ & 0.21 \\
\hline $\mathrm{ACTH}$ & 9 & $-0.04 \pm 0.95$ & $Z=-0.42$ & 0.68 & $29.06 \pm 48.80$ & $Z=-1.01$ & 0.31 \\
\hline Social challenge & 9 & $-0.46 \pm 3.60$ & $\mathrm{Z}=0.00$ & 1.00 & $109.1 \pm 88.0$ & $Z=-0.30$ & 0.77 \\
\hline \multicolumn{8}{|l|}{ G. ucamara } \\
\hline Day-Night & 8 & $-3.71 \pm 2.34$ & $\mathrm{t}=1.40$ & 0.20 & $-9.70 \pm 10.06$ & $\mathrm{t}=-1.32$ & 0.23 \\
\hline $\mathrm{MSH}$ & 8 & $1.94 \pm 1.96$ & $\mathrm{t}=-1.43$ & 0.20 & $8.02 \pm 6.52$ & $\mathrm{t}=1.28$ & 0.24 \\
\hline $\mathrm{ACTH}$ & 8 & $6.41 \pm 7.66$ & $\mathrm{t}=-1.09$ & 0.31 & $-11.0 \pm 10.67$ & $\mathrm{t}=-0.92$ & 0.39 \\
\hline Social challenge & 8 & $7.02 \pm 10.48$ & $\mathrm{t}=-0.41$ & 0.69 & $5.27 \pm 10.10$ & $\mathrm{t}=0.02$ & 0.98 \\
\hline \multicolumn{8}{|l|}{ R. marmoratus } \\
\hline Day-Night & 19 & $17.64 \pm 8.98$ & $Z=-2.42$ & $0.02 *$ & $-9.53 \pm 6.18$ & $Z=-1.93$ & $0.05 *$ \\
\hline $\mathrm{MSH}+\mathrm{ACTH}$ & 19 & $18.76 \pm 6.40$ & $Z=-1.69$ & 0.09 & $1.79 \pm 6.86$ & $Z=-0.28$ & 0.78 \\
\hline Social challenge & 8 & $5.95 \pm 6.74$ & $Z=-0.17$ & 0.87 & $-134.20 \pm 129.1$ & $Z=0.00$ & 1.00 \\
\hline \multicolumn{8}{|l|}{ G. rondoni } \\
\hline Day-Night & 8 & $22.5 \pm 16.90$ & $\mathrm{t}=-1.09$ & 0.31 & $-4.3 \pm 16.10$ & $\mathrm{t}=0.48$ & 0.65 \\
\hline $\mathrm{MSH}$ & 8 & $40.2 \pm 13.8$ & $t=-3.15$ & $0.02 *$ & $-7.1 \pm 21.70$ & $\mathrm{t}=-0.83$ & 0.43 \\
\hline ACTH & 8 & $6.8 \pm 3.50$ & $\mathrm{t}=0.68$ & 0.52 & $1.1 \pm 9.80$ & $t=-0.74$ & 0.49 \\
\hline Social challenge & 8 & $5.0 \pm 6.50$ & $\mathrm{t}=0.39$ & 0.71 & $5.8 \pm 15.40$ & $\mathrm{t}=-0.22$ & 0.83 \\
\hline S. elegans & $\mathbf{N}$ & Mean \pm SE & Statistic & p-value & Mean \pm SE & t statistic & p-value \\
\hline
\end{tabular}




\begin{tabular}{|c|c|c|c|c|c|c|c|}
\hline Day-Night & 14 & $15.12 \pm 3.12$ & $t=-3.24$ & $<0.01 *$ & $-35.25 \pm 9.75$ & $\mathrm{t}=-3.38$ & $<0.01 *$ \\
\hline $\mathrm{MSH}$ & 10 & $35.87 \pm 14.14$ & $t=-2.15$ & 0.06 & $-65.50 \pm 5.00$ & $\mathrm{t}=-7.02$ & $<0.01 *$ \\
\hline $\mathrm{ACTH}$ & 9 & $12.47 \pm 2.19$ & $t=-5.45$ & $<0.01 *$ & $-17.11 \pm 8.58$ & $\mathrm{t}=-2.02$ & 0.08 \\
\hline Social challenge & 7 & $2.26 \pm 0.89$ & $\mathrm{t}=-2.49$ & $0.05^{*}$ & $11.80 \pm 18.70$ & $\mathrm{t}=0.50$ & 0.63 \\
\hline \multicolumn{8}{|l|}{ B. bennetti } \\
\hline Day-Night & 5 & $10.9 \pm 2.15$ & $\mathrm{t}=-4.24$ & $0.01 *$ & $-1736.43 \pm 2398.4$ & $\mathrm{t}=-5.55$ & $<0.01 *$ \\
\hline $\mathrm{MSH}$ & 5 & $37.12 \pm 1.45$ & $t=-21.38$ & $<0.01 *$ & $-489.0 \pm 375.80$ & $\mathrm{t}=-1.81$ & 0.15 \\
\hline $\mathrm{ACTH}$ & 5 & $17.54 \pm 2.92$ & $\mathrm{t}=-6.26$ & $<0.01 *$ & $-1712.3 \pm 2691.5$ & $\mathrm{t}=-6.00$ & 0.58 \\
\hline Social challenge & 5 & $1.11 \pm 0.35$ & $t=-2.90$ & $0.04 *$ & $-1736.43 \pm 2398.4$ & $\mathrm{t}=-2.51$ & 0.07 \\
\hline \multicolumn{8}{|l|}{ B. gauderio } \\
\hline Day-Night & 8 & $25.19 \pm 7.97$ & $t=-5.49$ & $<0.01 *$ & $-56.7 \pm 4.65$ & $\mathrm{t}=-8.45$ & $<0.01 *$ \\
\hline $\mathrm{MSH}$ & 8 & $14.50 \pm 7.67$ & $\mathrm{t}=-2.72$ & $0.03 *$ & $-63.1 \pm 10.20$ & $t=-6.07$ & $<0.01 *$ \\
\hline $\mathrm{ACTH}$ & 7 & $9.32 \pm 7.53$ & $t=-2.26$ & 0.06 & $-47.25 \pm 9.02$ & $\mathrm{t}=0.67$ & 0.53 \\
\hline Social challenge & 7 & $4.02 \pm 3.02$ & $\mathrm{t}=-1.34$ & 0.23 & $-12.4 \pm 8.53$ & $\mathrm{t}=-1.27$ & 0.25 \\
\hline \multicolumn{8}{|l|}{ S. macrurus } \\
\hline Day-Night & 15 & $9.63 \pm 2.91$ & $Z=-2.51$ & $0.01 *$ & $1.90 \pm 2.83$ & $Z=-0.74$ & 0.46 \\
\hline $\mathrm{MSH}+\mathrm{ACTH}$ & 14 & $64.76 \pm 7.25$ & $Z=-3.30$ & $<0.01 *$ & $-6.95 \pm 1.60$ & $Z=-2.67$ & $<0.01 *$ \\
\hline Social challenge & 12 & $13.91 \pm 4.08$ & $Z=-2.95$ & $<0.01 *$ & $-2.05 \pm 2.35$ & $Z=-2.82$ & $<0.01 *$ \\
\hline \multicolumn{8}{|l|}{ E. cf. virescens } \\
\hline Day-Night & 11 & $17.88 \pm 5.50$ & $\mathrm{t}=-2.81$ & $0.02 *$ & $1.41 \pm 2.21$ & $\mathrm{t}=0.51$ & 0.62 \\
\hline $\mathrm{MSH}+\mathrm{ACTH}$ & 11 & $65.13 \pm 11.70$ & $\mathrm{t}=-4.59$ & $<0.01^{*}$ & $-5.41 \pm 2.14$ & $t=1.97$ & 0.08 \\
\hline Social challenge & 5 & $42.11 \pm 35.40$ & $\mathrm{t}=-1.47$ & 0.22 & $1.94 \pm 1.68$ & $t=1.14$ & 0.32 \\
\hline \multicolumn{8}{|l|}{ A. albifrons } \\
\hline Day-Night & 8 & $-0.71 \pm 1.65$ & $\mathrm{t}=0.41$ & 0.69 & $1.53 \pm 1.15$ & $\mathrm{t}=1.16$ & 0.28 \\
\hline MSH & 4 & $-3.07 \pm 3.06$ & $t=-0.29$ & 0.79 & $2.35 \pm 1.34$ & $\mathrm{t}=2.50$ & 0.09 \\
\hline ACTH & 8 & $2.60 \pm 2.24$ & $\mathrm{t}=-1.08$ & 0.32 & $-2.30 \pm 2.76$ & $\mathrm{t}=0.20$ & 0.85 \\
\hline Social challenge & 6 & $2.96 \pm 0.98$ & $t=-2.04$ & 0.10 & $-2.58 \pm 1.36$ & $\mathrm{t}=-1.87$ & 0.12 \\
\hline \multicolumn{8}{|l|}{ A. leptorhynchus } \\
\hline Day-Night & 11 & $-2.10 \pm 2.36$ & $Z=-0.31$ & 0.76 & $0.26 \pm 2.21$ & $Z=-0.27$ & 0.79 \\
\hline MSH & 6 & $-2.50 \pm 7.21$ & $Z=-0.68$ & 0.50 & $-2.54 \pm 0.95$ & $Z=-1.35$ & 0.18 \\
\hline $\mathrm{ACTH}$ & 9 & $-0.52 \pm 2.74$ & $Z=-0.06$ & 0.95 & $-2.65 \pm 1.73$ & $Z=-0.06$ & 0.95 \\
\hline
\end{tabular}


Numbers represent sample size $(\mathrm{N})$, mean and standard deviation of $\%$ relative amplitude change and the p-value from statistical analyses. Asterisks represent statistically significant differences $(p<0.05)$. Melanocortin responses were compared to saline responses, day amplitude was compared to nighttime increase, and response to social challenge was compared to EOD amplitude during solitary condition (i.e. day vs. night, pre vs. peak-social challenge effects). Because I only had two Electrophorus electricus, no statistical analyses were run; the data are presented strictly for comparative purpose. 


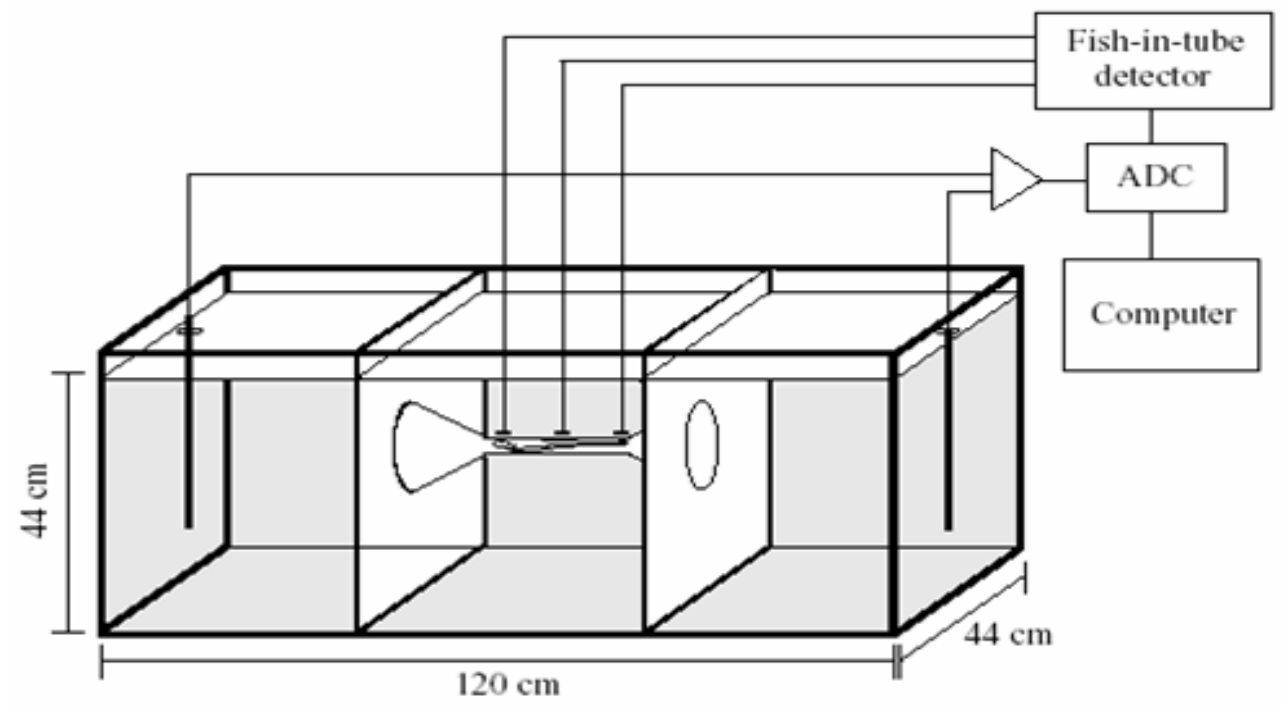

Figure 1. EOD machine. Allows around the clock recording and tracking of electric signals, following social and pharmacological challenges. 


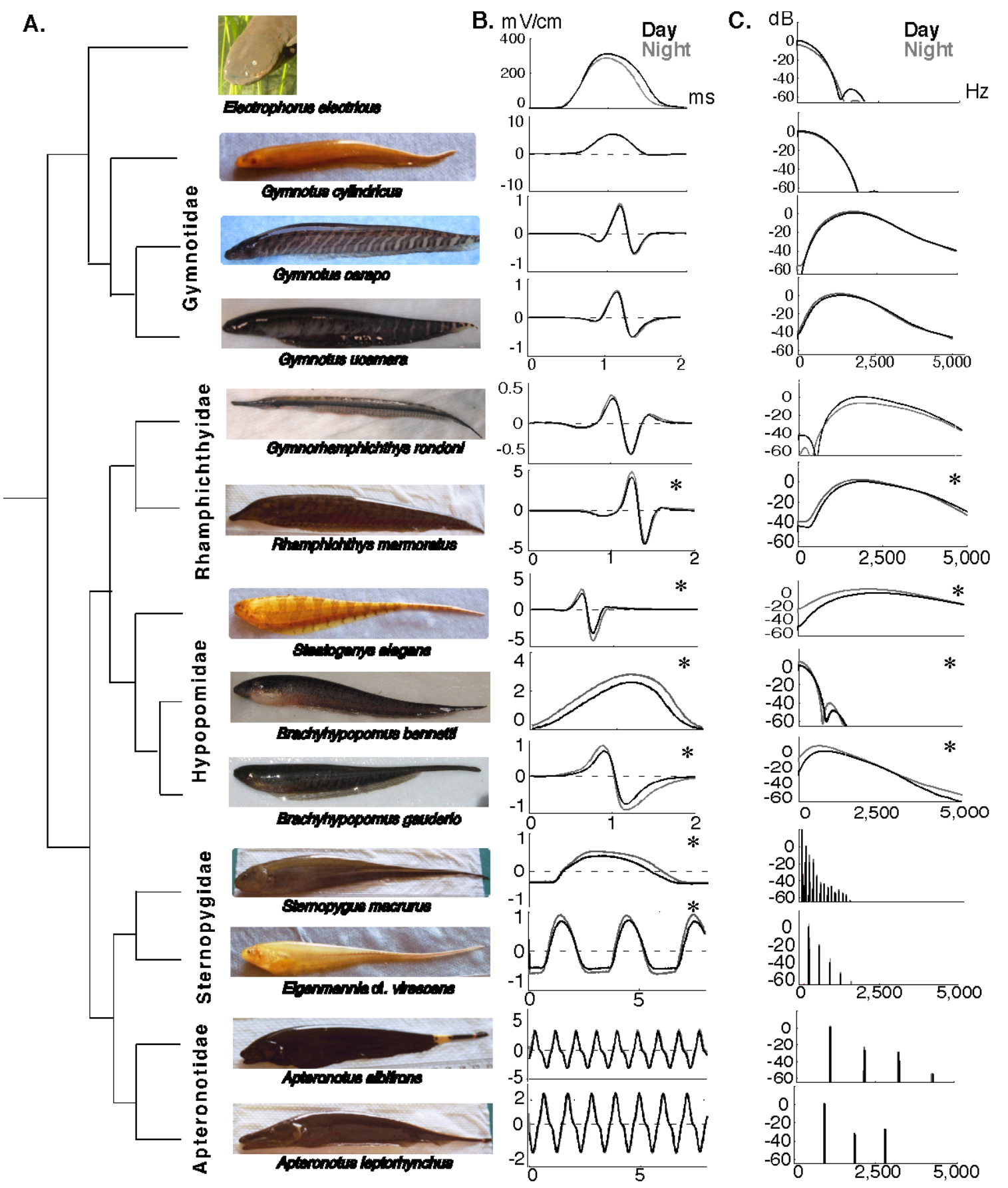

Figure 2. Day-night EOD modulations of select members of the order

Gymnotiformes. (A) Pictures of the select species used in this study. Phylogeny adapted from Crampton (2011). (B) EOD waveforms change from day (black) to 
night (gray) in members of the Hypopomidae, Sternopygidae and Rhamphichthyidae, but not in Gymnotidae or Apteronotidae. (C) Nighttime onset increases the amount of energy present in the ampullary range of the power spectra of Hypopomidae and $R$. marmoratus of Rhamphichthyidae. The spectra of remaining species are unchanged. Asterisks indicate significant day-night differences $(\mathrm{p}<0.05)$. 
A. Electrophorus electricus

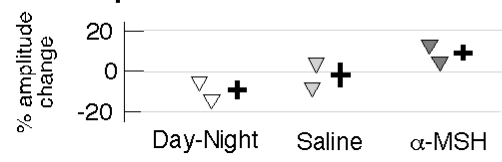

B. Gymnotus cylindricus

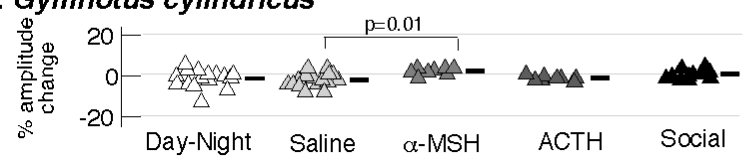

C. Gymnotus carapo

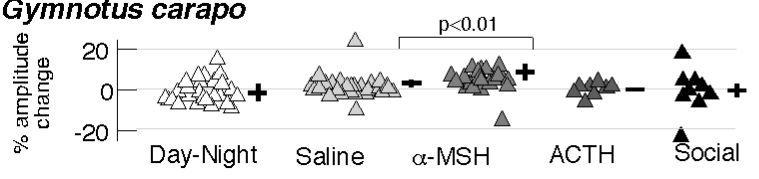

D. Gymnotus ucamara

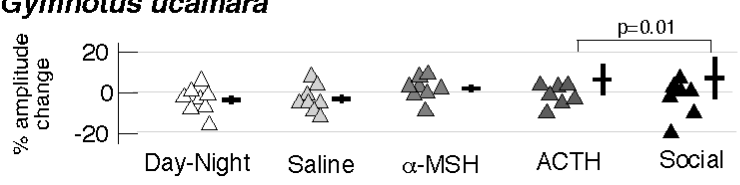

B. Electrophorus electricus

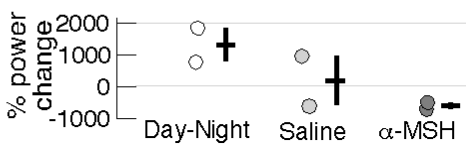

D. Gymnotus cylindricus

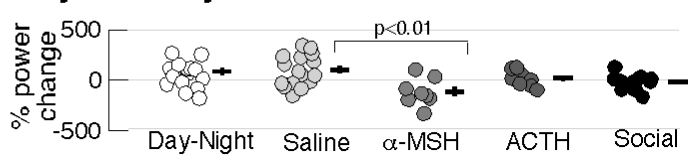

F. Gymnotus carapo

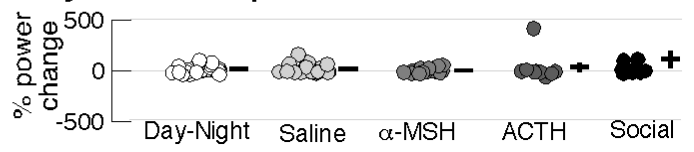

H. Gymnotus ucamara

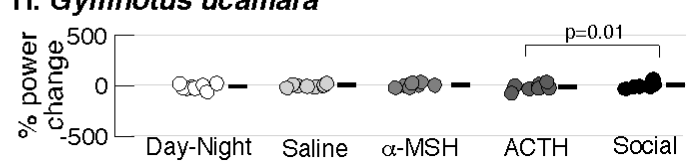

Figure 3. Signal plasticity in Gymnotidae. In general, members of the Gymnotidae do not change EOD amplitude (triangle; A, B, C, D) or energy in the low-frequency region of the signal spectrum (circles; B, D, F, H). A decrease in relative power change means an increase in energy of the low-frequency region of the EOD power spectrum. Symbols represent individual data points represented as relative change.

Horizontal and vertical bars depict mean and SEM, respectively. Significant differences between treatments are indicated by brackets, $p$-values reflect results from paired t-tests or Wilcoxon signed-rank test between treatments. 
A. Gymnorhamphichthys rondoni

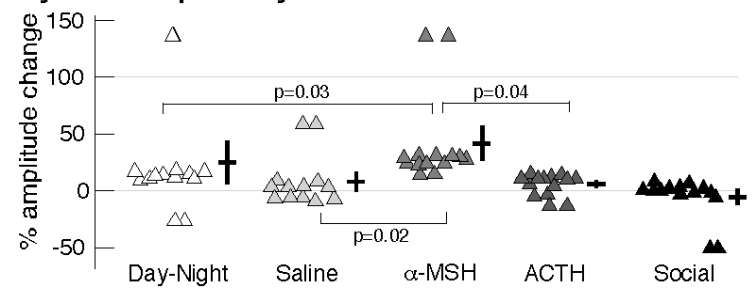

C. Rhamphichthys marmoratus

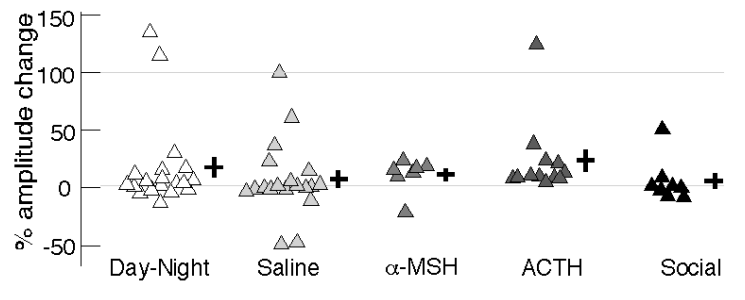

B. Gymnorhamphichthys rondoni

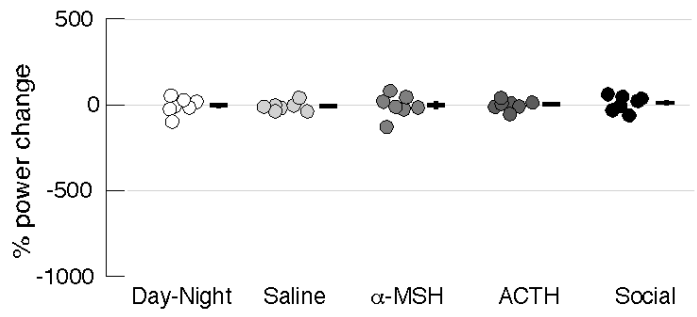

D. Rhamphichthys marmoratus

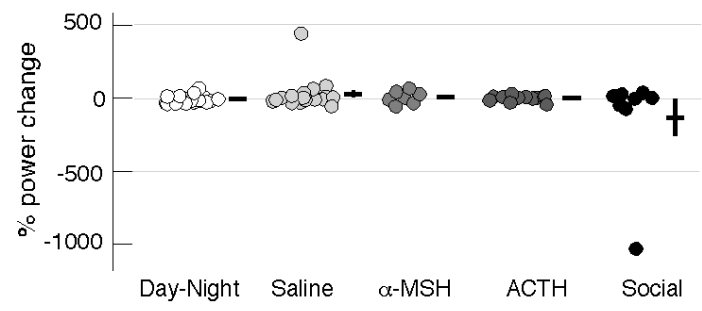

Figure 4. Signal plasticity in Rhamphichthyidae. Only G. rondoni increased signal amplitude in response to $\alpha$-MSH injections and during the night (A). Neither species modified its power spectrum $(\mathbf{B}, \mathbf{D})$. 


\section{A. Steatogenys elegans}

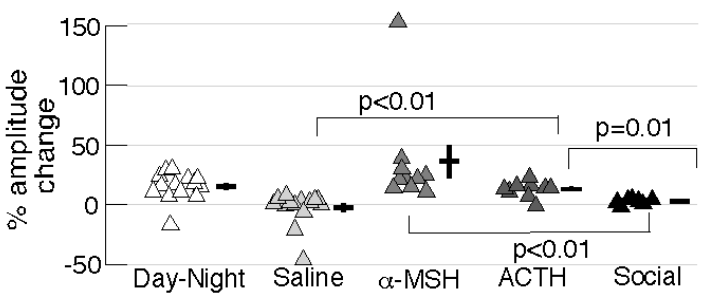

C. Brachyhypopomus bennetti

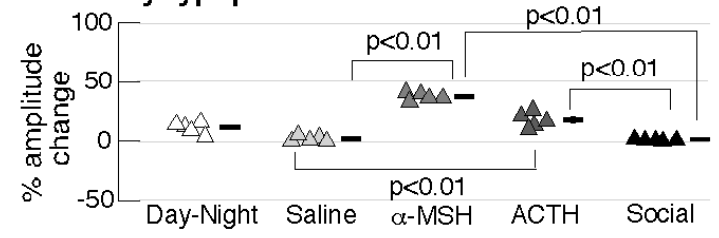

E. Brachyhypopomus gauderio

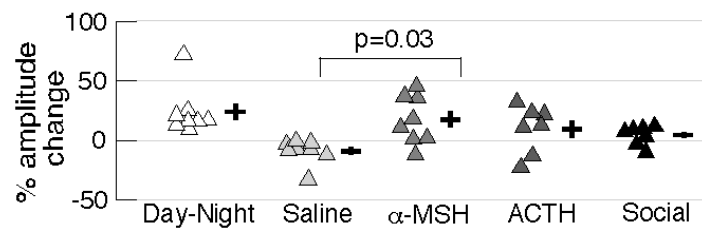

B. Steatogenys elegans

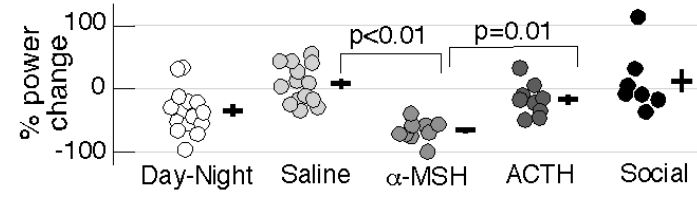

D. Brachyhypopomus bennetti

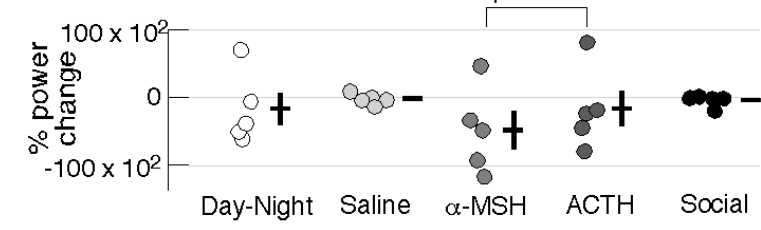

F. Brachyhypopomus gauderio

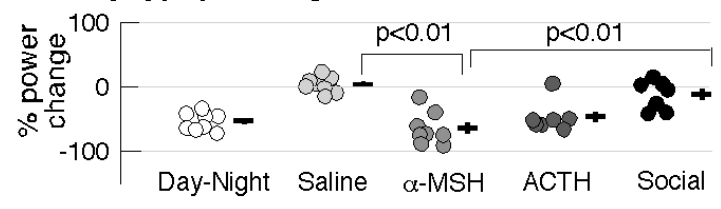

Figure 5. Signal plasticity in Hypopomidae. Members of the Hypopomidae have the most dynamic signals; changing both EOD amplitude $(\mathbf{A}, \mathbf{C}, \mathbf{E})$ and spectrum $(\mathbf{B}, \mathbf{D}$, F). The extent of plasticity ranges between species. 


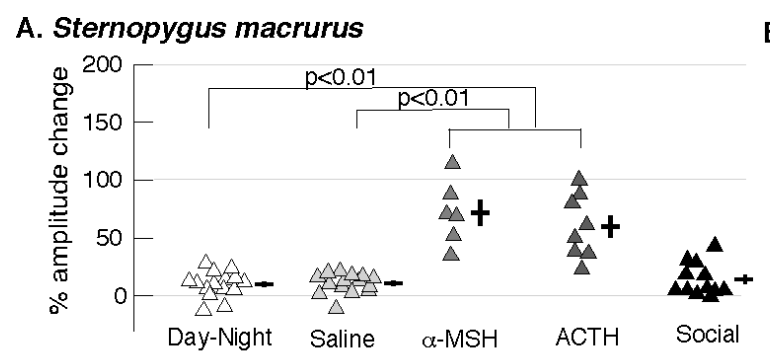

B. Sternopygus macrurus

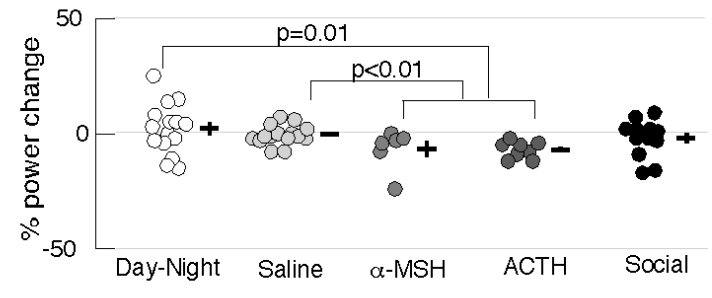

C. Eigenmannia cf. virescens

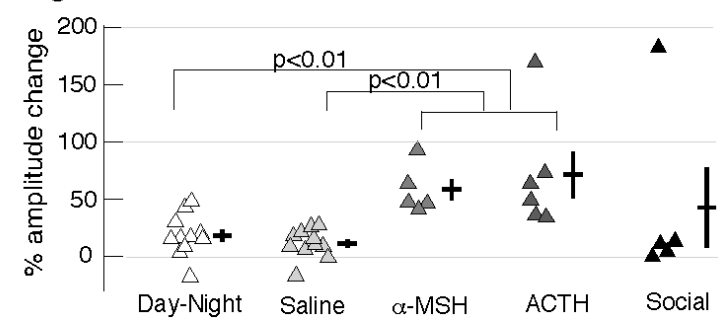

D. Eigenmannia cf. virescens

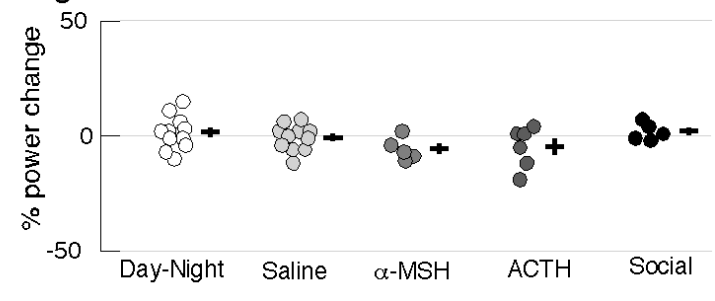

Figure 6. Signal plasticity in Sternopygidae. S. macrurus increases its amplitude

(A) and signal spectrum (B), while E. cf. virescens only modifies its signal

(B) amplitude (C). 


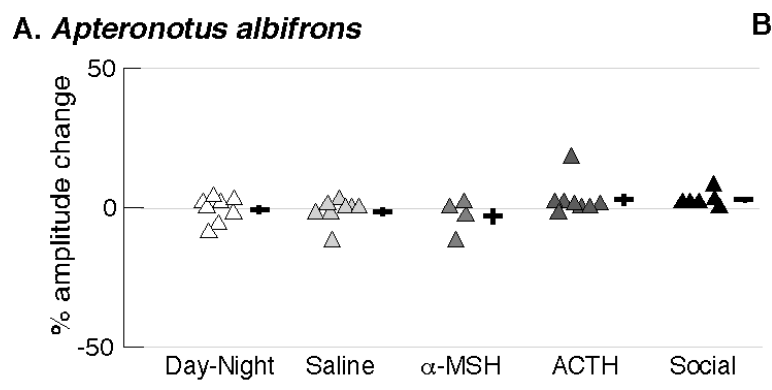

B. Apteronotus albifrons

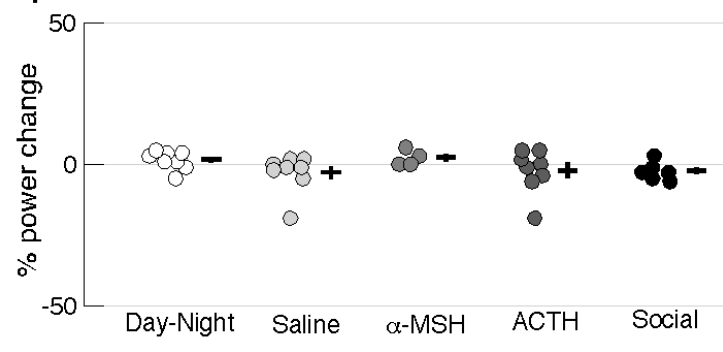

C. Apteronotus leptorhynchus

D. Apteronotus leptorhynchus
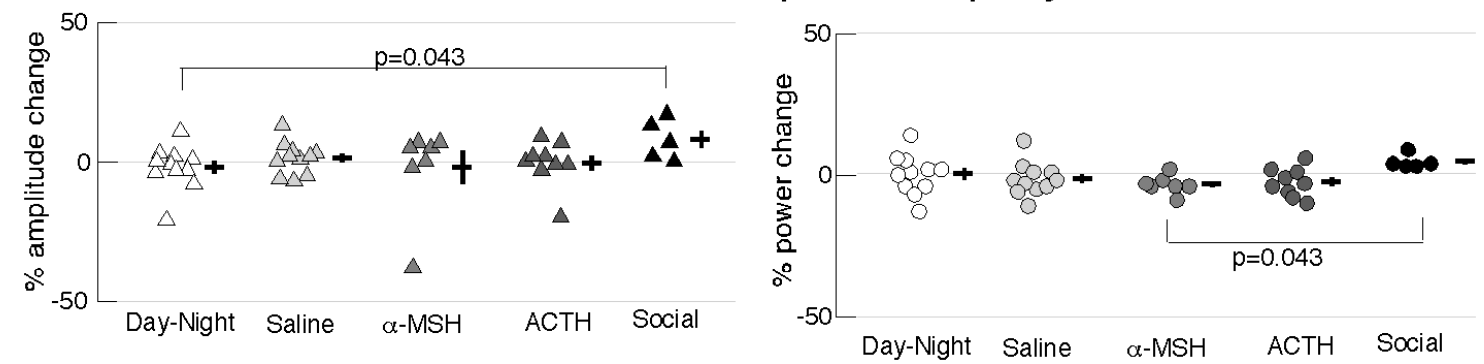

Figure 7. Signal plasticity in Apteronotidae. Apteronotids have highly stable signals, keeping amplitude and spectrum stable from day to night and in response to melanocortins. 


\title{
CHAPTER III
}

\author{
TESTOSTERONE AND 11-KETOTESTOSTERONE HAVE DIFFERENT \\ REGULATORY EFFECTS ON ELECTRIC COMMUNICATION SIGNALS OF MALE \\ BRACHYHYPOPOMUS GAUDERIO
}

As published in Hormones and Behavior

May 2011

Volume 60, Pages 139-147

Copyright $($ Elsevier 


\begin{abstract}
The communication signals of electric fish can be dynamic, varying between the sexes on a circadian rhythm and in response to social and environmental cues. In the gymnotiform fish Brachyhypopomus gauderio waveform shape of the electric organ discharge (EOD) is regulated by steroid and peptide hormones. Furthermore, EOD amplitude and duration change on different timescales and in response to different social stimuli, suggesting that they are regulated by different mechanisms. Little is known about how androgen and peptide hormone systems interact to regulate signal waveform. We investigated the relationship between the androgens testosterone (T) and 11ketotestosterone (11-KT), the melanocortin peptide hormone $\alpha-\mathrm{MSH}$, and their roles in regulating EOD waveform of male $B$. gauderio. Males were implanted with androgen (T, 11-KT, or blank), and injected with $\alpha-\mathrm{MSH}$ before and at the peak of androgen effect. We compared the effects of androgen implants and social interactions by giving males a size-matched male stimulus with which they could interact electrically. Social stimuli and both androgens increased EOD duration, but only social stimuli and 11-KT elevated amplitude. However, no androgen enhanced EOD amplitude to the extent of a social stimulus, suggesting that a yet unidentified hormonal pathway regulates this signal parameter. Additionally, both androgens increased response of EOD duration to $\alpha-\mathrm{MSH}$, but only 11-KT increased response of EOD amplitude to $\alpha-\mathrm{MSH}$. Social stimuli had no effect on EOD response to $\alpha-\mathrm{MSH}$. The finding that EOD amplitude is preferentially regulated by $11-\mathrm{KT}$ in $B$. gauderio may provide the basis for independent control of amplitude and duration.
\end{abstract}


Keywords: 11-ketotestosterone (11-KT); alpha-melanocyte stimulating hormone ( $\alpha$ MSH); androgen; communication signal; electric fish, electric organ discharge (EOD; gymnotiform; plasticity; Testosterone (T).

\section{Introduction}

Hormones co-regulate reproductive condition, behaviors, and, in many cases, the structure of communication signals (Adkins-Regan, 2005; Wilczynski and Chu, 2001). Hormonally mediated correlations between behavior, body condition, and signal structure may enable a receiver to infer the signaler's neuroendocrine state from the signal, and thus predict aggressive response or reproductive performance (Ketterson et al., 2009; McGlothlin et al., 2008; McGlothlin and Ketterson, 2008; Oliveira, 2005). Animals integrate social and physical stimuli in the environment and commonly respond by secreting fast-acting peptide hormones, which rapidly modulate behavior and steroid secretion. While steroid hormones overlap with peptides in these roles, they modulate physical phenotype and behavior over longer time periods through genomic action. The potential interplay between fast-acting peptides and slow-acting steroids enables greater behavioral flexibility over varying temporal ranges and social conditions. Thus, the extent to which steroid hormones may prime or inhibit the actions of peptide hormones can generate versatile behaviors that are best adapted to the individual's environment (Adkins-Regan, 2005). The electric communication signals of gymnotiform fish are regulated by melanocortin peptide hormones and by sex steroids on short and long time horizons, respectively (Stoddard et al., 2006). Because of their structural simplicity, 
electric signals constitute good models for exploring dual hormone signal regulation and the implication of hormonal interplay for communication.

The weakly electric gymnotiform species Brachyhypopomus gauderio (Giora and Malabara, 2009), southern sister species to B. pinnicaudatus, produces a sexually dimorphic electric organ discharge (EOD) for electrolocation and communication. The neural circuitry of electrocommunication and electrolocation has been well described (Heiligenberg, 1991; Hopkins, 1995; 1999; Metzner, 1999; Zupanc and Maler, 1997). The EOD pulse rate is regulated centrally in the pacemaker nucleus of the medulla, while waveform amplitude and duration are regulated peripherally (Few and Zakon, 2001; Mills and Zakon, 1991) by the electrocytes, electrically excitable cells of the electric organ (Szabo, 1974). The near simultaneous electric discharge of the anterior and posterior membranes of each electrocyte in B. gauderio produces a biphasic signal that varies in amplitude and duration (Fig. 1A). The durations of both phases are nearly equal in females, while males exhibit a longer duration of the second phase (referred to as $\tau_{\mathrm{p} 2}$ ) (Franchina, 1997; Hopkins et al., 1990).

The EOD is a dynamic signal that varies on a circadian rhythm, increasing in amplitude and $\tau_{\mathrm{p} 2}$ at night and during social interactions (Franchina et al., 2001; Stoddard et al., 2007) (Fig. 1). This signal plasticity is driven by the slow, genomic action (daysweeks) of steroid hormones (Allee et al., 2009; Dunlap et al., 1998; Stoddard et al., 2006; Zakon, 1993; Zakon and Smith, 2002) and by the rapid, non-genomic (minutes-hours) action of monoamine and peptide hormones (Markham et al., 2009a; Markham and Stoddard, 2005; Stoddard et al., 2003). Androgens masculinize the gymnotiform EOD by increasing waveform duration in peripheral electrocytes (Allee et al., 2009; Bass and 
Hopkins, 1984; Bass and Volman, 1987; Few and Zakon, 2001; Silva et al., 2002) and altering discharge frequency in the central pacemaker nucleus (Dunlap et al., 1998; Meyer, 1983).

Weakly electric species modulate EOD parameters in a species-specific manner in the contexts of competition, aggression, and mating. In B. occidentalis, winners of agonistic interaction have lower peak-power frequency and larger amplitude signals than losers. DHT, but not estrogen implants, masculinize these signal parameters, mimicking waveforms of dominant individuals (Hagedorn and Carr, 1985; Hagedorn and Zelick, 1989). Similarly, in B. gauderio social competition elevates circulating androgen (T and 11-KT) levels (Salazar and Stoddard, 2009) while in mormyriform electric fish Brienomyrus brachyistius, dominant males have the highest 11-KT levels (Carlson et al., 2000). In Apteronotus leptorhynchus, another gymnotiform species, 11-KT levels are correlated with aggressive EOD modulations, which can be induced by $11-\mathrm{KT}$ implants (Dunlap, 2002; Dunlap et al., 1998).

While androgens masculinize EOD waveform on a long-term timescale of days to months, melanocortins such as adrenocorticotropic hormone (ACTH) and $\alpha$-melanocyte stimulating hormone ( $\alpha-\mathrm{MSH})$ induce similar changes in the EOD waveform within minutes (Markham et al., 2009a). Melanocortins and their receptors are highly conserved across vertebrates (Metz et al., 2006) and regulate a diverse array of physiological and behavioral processes including social communication, learning, glucocorticosteroid release, and aggressive and sexual behaviors (Brain and Evans, 1977; Ducrest et al., 2008; Gonzalez et al., 1996; Wikberg et al., 2000). In B. gauderio, injections of ACTH or $\alpha$-MSH activate the cAMP/PKA pathway, which extends the $2^{\text {nd }}$ phase of the EOD 
$\left(\tau_{\mathrm{p} 2}\right)$ by extending action potential duration, and increases EOD amplitude by differentially modulating the timing of action potentials of the two excitable membranes of the electrocytes (Markham and Stoddard, 2005). These waveform changes are comparable to those observed during social interactions, suggesting a mechanism for social regulation of EOD (Franchina et al., 2001; Markham et al., 2009a; Markham and Stoddard, 2005; Stoddard et al., 2006). Additionally, in B. gauderio, prolonged social isolation causes a decline in EOD amplitude and $\tau_{\mathrm{p} 2}$ that can be partially reversed with melanocortins (Franchina et al., 2001; Franchina and Stoddard, 1998; Stoddard et al., 2007).

The interaction between androgens and melanocortins (and thus the interaction between long-term and rapid EOD modulators) has been less clear. Studies have suggested a bidirectional relationship between steroids and melanocortins, where $\alpha-\mathrm{MSH}$ enhances the effects of gonadal steroids centrally and peripherally and steroids upregulate melanocortin receptors, increasing sexual and aggressive behavior in rodents (Ducrest et al., 2008; Wikberg et al., 2000). In B. gauderio females, $5 \alpha$-dihydrotestosterone (DHT) implants enhance $\tau_{\mathrm{p} 2}$ response to injections of either serotonin or ACTH with little effect on EOD amplitude (Allee et al., 2009). Since both $\mathrm{T}$ and 11-KT are important for the development of secondary sexual characteristics and the accompanying sex-specific reproductive behaviors in teleost fish (Oliveira et al., 2005), it is possible that the EOD waveform is differentially regulated by the actions of aromatizable $\mathrm{T}$ and the nonaromatizable 11-KT, as is the case in teleost species with alternative reproductive strategies (Bass, 2008; Lee and Bass, 2005; Perry and Grober, 2003; Remage-Healey and Bass, 2006) . Subsequently, the absence of amplitude modulation by non-aromatizable 
DHT observed in a prior study (Allee et al., 2009) could be because amplitude is regulated by aromatizable $\mathrm{T}$.

In this study we test the hypothesis that circulating androgens regulate melanocortin actions on electric signal waveform. To that end, we explored the interactions between $\alpha-\mathrm{MSH}, \mathrm{T}$, and $11-\mathrm{KT}$ in generating communication signal plasticity in B. gauderio.

\section{Methods}

\section{Animals}

We randomly selected sexually mature male Brachyhypopomus gauderio (total length $=17.9 \pm 1.9 \mathrm{~cm}$, weight $=8.7 \pm 2.9 \mathrm{~g}$ ) from our outdoor breeding colony at Florida International University. These captive-reared 15-17th generation fish were maintained in 450-liter outdoor pools, in mixed-sex groups of 5-10 individuals. The water surface was covered with water hyacinths, Eichhornia crassipes. Water conductivity was maintained at $70-100 u \mathrm{~S} \mathrm{~cm}^{-1}$. For data collection, fish were brought indoors and placed individually in 284-liter aquaria. Aquaria were kept in a light- and temperaturecontrolled room on a 12:12 L:D light cycle. Water temperature and conductivity were maintained at $27-28^{\circ} \mathrm{C}$ and $70-100 u \mathrm{~S} \mathrm{~cm}^{-1}$, respectively. Fish were fed oligochaete "blackworms" ad libitum every other day. The EOD data collection was continuous from the time each fish was placed into the recording tank until it was removed at the end of the experiment. Experiments were conducted during the breeding season, May-Sep 2008 \& 2009. Experiments complied with the National Institutes of Health Guide for the Care and Use of Laboratory Animals (DHEW Publication 80-23, revised 1985) and were approved by the FIU IACUC (protocol approval no. 08-023). 


\section{Data collection}

EODs were recorded in an automated, calibrated recording system described in detail elsewhere (Franchina et al., 2001; Stoddard et al., 2003). Briefly, the recording system consists of 12 automated aquaria, $120 \times 44 \times 44 \mathrm{~cm}$, in an environmentally controlled room. Each aquarium is divided into thirds by plastic mesh screening with plastic mesh funnels. The funnels direct fish through an unglazed ceramic tube that joins the outer two compartments. To obtain repeatable measurements, EODs are amplified and digitized from nichrome wire electrodes at opposite ends of the tank only when the fish is in the ceramic tube, and thus centered in the tank. Electrodes on top of the ceramic tube register when the fish is geometrically centered in the tank, and trigger the computer to record EODs from electrodes on the tank ends.

To quantify the effects of androgens and $\alpha-\mathrm{MSH}$ on the waveform, we measured changes in the peak-to-peak amplitude and $\tau_{\mathrm{p} 2}$, the time constant of an inverse exponential function fitted to the decay segment of the second EOD phase (Fig. 1).

\section{Experimental design}

\section{Experiment 1: Effect of androgens on EOD waveform}

To verify that testosterone and 11-ketotestosterone modulate EOD waveform (amplitude and $\tau_{\mathrm{P} 2}$ ) in $B$. gauderio, 18 sexually mature males were placed in EOD recording tanks and isolated for 10 days. Social isolation causes a decline in EOD amplitude baseline and $\tau_{\mathrm{p} 2}$, stabilizing by the end of the first week (Franchina et al., 2001). At the end of the isolation period, males were randomly divided into three 
implant groups ( $\mathrm{n}=6$ per group), removed from their respective tanks and implanted with silicone implants containing either testosterone (T), 11-ketotestosterone (11-KT), or a blank (see implant protocol below). Fish were returned to the recording tanks and their EODs were monitored for seven days for changes in response to the implant, and to determine the time when the androgen effects peak, for a subsequent experiment. We discarded data from one male in the T-implanted group because he exhibited an anomalously reversed circadian rhythm, so that group had only 5 males.

\section{Experiment 2: Effect of androgens on melanocortin responsiveness}

Males were randomly assigned to one of three implant groups (11-KT, T, or blank) with 6 individuals per group. All males were placed into individual EOD recording tanks and isolated for 6 days (Fig. 2). During this time their EODs were recorded and monitored. On days 7 and 8 of social isolation, before steroid treatment, each fish was injected with either $25 \mu \mathrm{M} \mathrm{g}^{-1}$ body weight $\alpha$-MSH or saline control, in counterbalanced random order. This concentration of $\alpha$-MSH was chosen based on previous studies showing that $25 \mu \mathrm{M} \mathrm{g}^{-1}$ fully enhances the EOD (Markham et al., 2009a; Markham and Stoddard, 2005). On the ninth day of recording, individuals were removed from their recording tanks, implanted with silicone implants (T, 11-KT, or blank), and quickly returned to their tanks to resume recording.

The effect of androgen implants on EOD amplitude was monitored daily. When the EOD amplitude reached a maximum, determined by the lack of increase for 24 hours (usually 2-4 days after the implant), fish were re-injected with $25 \mu \mathrm{M} \alpha$-MSH and saline, as explained above. To verify that androgen implants elevated circulating androgen 
levels, all fish were bled 4-5 days post-implant for hormone analyses at a later time (see Blood collection and analyses below). Fish were returned to recording tanks and monitored for another three days to ensure full recovery before returning to outdoor pools.

\section{Experiment 3: Effect of a social interaction on melanocortin responsiveness}

We used a social challenge treatment for comparison purposes to examine whether androgen implants fully mimic the effect of a social companion on waveform recovery from social isolation. Eight males were isolated for 6 days and implanted with blank implants on day 9, as in Experiment 2. The following day, a size-matched male was placed into the middle compartment of each recording tank to serve as a social stimulus. This placement allowed electrical interaction between the experimental and stimulus males but not physical contact. A PVC hiding tube was placed in the middle compartment, oriented perpendicularly to the ceramic tube of the experimental male to reduce signal interference from the social stimulus. As in Experiment 2, males were injected with saline and $\alpha$-MSH prior to implants (days 7 and 8 ) and then re-injected 2 and 3 days after the beginning of the social challenge.

\section{Implants}

11-ketotestosterone (Sigma, K8250) and testosterone (Sigma, T6147) were each mixed with silicone (Dow Corning 3140 MIL-A-461 45 RTV coating) in a 1:4 ratio and shaped into thin lines. The mixtures were allowed to cure for about a week and the implant concentrations were recalculated to adjust for mass lost through evaporation. The 
resulting implants release all of the steroids contents within 2-4 days, which is evident by the steady decline in EOD amplitude and $\tau_{\mathrm{p} 2} 5$ days after implanting (unpublished observations). Implants were custom cut for each fish based on its weight, for a final concentration of $0.05 \mathrm{mg}$ of $11-\mathrm{KT}$ or $\mathrm{T}$ per 10 grams of fish. This concentration was based on previous studies (Allee et al., 2009)

To place the implants, we anesthetized the fish by immersion in a $0.075 \%$ solution of 2-phenoxyethanol (Sigma, P-1126FD) or 0.008\% clove oil (80 $\mathrm{mg} \mathrm{l}^{-1}$ eugenol, Sigma, E51791). We used an 18-gauge needle to cut a small hole through the skin into the fatty area on the trunk dorsal to the anal fin rays into which we inserted an implant. The incision was closed with surgical glue and the fish was returned to the recording tank. EOD amplitude and duration were monitored for any changes.

\section{MSH injections}

We dissolved $\alpha$-melanocyte stimulating hormone ( $\alpha$-MSH) (Sigma, M4135) in physiological saline: $\mathrm{NaCl} 114 \mathrm{mM} \mathrm{l}^{-1}, \mathrm{KCl} 2 \mathrm{mmol}^{-1}, \mathrm{CaCl}_{2} \cdot 2 \mathrm{H}_{2} \mathrm{O} 4 \mathrm{mM} 1^{-1}$, $\mathrm{MgCl}_{2} \cdot 6 \mathrm{H}_{2} \mathrm{O} 2 \mathrm{mM} \mathrm{l}^{-1}$, HEPES $2 \mathrm{mM} \mathrm{l}^{-1}, \mathrm{pH}$ adjusted to 7.2 with $\mathrm{NaOH}$ (modified from Ferrari and Zakon, 1993), for a final concentration of $100 \mu \mathrm{M}$. Aliquots were frozen until day of use and then diluted with saline to $25 \mu \mathrm{M}$ prior to injection. Physiological saline injections controlled for handling and injection. Experimental and control solutions were injected at $1 \mathrm{ul} \mathrm{g}^{-1}$ of fish intramuscularly using a Hamilton syringe fitted with a disposable 31.5 gauge needle. All injections were administered between 11:00 and 14:00. 


\section{Blood collection and analysis}

Males were removed from the recording tanks, anesthetized by immersion in 0.075\% 2-phenoxyethanol and bled from the subvertebral sinus. Blood was collected into $1 \mathrm{ml}$ polypropylene tube containing $5 \mu \mathrm{l}$ of 10\% EDTA and centrifuged for 15

minutes at $7000 \mathrm{rpm}$ at $-4^{\circ} \mathrm{C}$. Plasma samples were separated and transferred into a separate polypropylene tube and stored at $-20^{\circ} \mathrm{C}$ until steroid extraction and analysis. Plasma samples were extracted according to a steroid extraction protocol validated for this species (Salazar and Stoddard, 2009). Briefly, $250 \mu 1$ plasma samples were extracted using a mixture of hexane:ethyl acetate (90:10 for 11-KT and 70:30 for T) and resuspended in the phosphate buffer provided in the enzyme immunoassays (EIA) kits (Cayman Chemical, Inc.). Concentrations were quantified in duplicate according to the specification of the T and 11-KT EIA kits.

The detection limits of the EIA kits were $1.3 \mathrm{pg} / \mathrm{ml}$ for $11-\mathrm{KT}$ and $6 \mathrm{pg} / \mathrm{ml}$ for T. To verify extraction recovery, 11-KT and T EIA kit standards were extracted using $5 \mathrm{ml}$ of hexane:ethyl acetate alongside the plasma samples. Extraction efficiency was assessed by comparing kit standards for each hormone with the standards that have been extracted using hexane:ethyl acetate. All plasma samples were run in two 11-KT and T assays. For $11-\mathrm{KT}$, the intra-assay coefficients of variation were $4.04 \%$ and $8.16 \%$, while the interassay coefficient of variation was $1.44 \%$. For $\mathrm{T}$, the intra-assay coefficient of variation was $3.17 \%$ and $10.75 \%$ and the inter-assay coefficient of variation was $2.78 \%$. 


\section{Data treatment and analyses}

In B. gauderio, all treatment effects are superimposed on the individual's circadian rhythm (Franchina and Stoddard, 1998). To isolate the effects of treatments (implants, social challenge, and injections) from circadian oscillations, we used a previously described MATLAB (Mathworks, Natick, MA) data analysis program (Stoddard et al., 2003) to fit a smoothing spline function (MATLAB Spline Toolbox) to minute-by-minute EOD parameter data. We used the resulting functions to extract treatment effects. To examine the effect of androgen implants and social challenge on the waveform amplitude and $\tau_{\mathrm{p} 2}$, we measured the daytime minima and nighttime maxima before and after the treatment and then calculated a relative change in both parameters. To isolate the effects of $\alpha-\mathrm{MSH}$ and saline injections from circadian oscillations, we fit the smoothing spline function to the data one more time, but this time omitting the effects

of the injections, which are clearly visible in the data. We took the difference between the two fit lines (with and without injection effects) to represent the effects of injections on the waveform, independent of circadian oscillations. We assessed the effect of implants and social challenges on $\alpha-\mathrm{MSH}$ response by calculating the difference in $\alpha-\mathrm{MSH}$ injection effects before and after implant/social treatment.

\section{Statistical analyses}

We combined data from the first two experiments to examine the effect of androgen implants on EOD waveform. We used a two-way MANCOVA (GLM multivariate procedure in SPSS 14.0, Model III) with two fixed factors: (1) treatment [11KT, T, blank] and (2) Year [2008 (Expt. 1), 2009 (Expt. 2)]. To account for the possible 
influence of body size on the response to steroid treatment and year, we used body weight and length as covariates. To examine the effects of androgen implants on $\alpha-\mathrm{MSH}$ responsiveness (Expt. 2), we compared the differences in the magnitude of amplitude and $\tau_{\mathrm{p} 2}$ response to $\alpha-\mathrm{MSH}$ injection between the three implant groups using one-way MANCOVA (GLM multivariate procedure in SPSS 14.0, Model III) with implant [11$\mathrm{KT}$, T, blank] as a fixed factor and body weight and length as covariates. Paired t-tests analyzed the effects of a social challenge on amplitude and $\tau_{\mathrm{p} 2}$, as well as on $\alpha$-MSH responsiveness (Expt. 3). We log-transformed plasma steroid levels to meet the assumptions of normality and analyzed using one-way ANOVA. Where MANCOVA differences were significant $(p<0.05)$, we used the protected LSD post hoc analysis to determine significant pairwise differences. Data are reported as mean \pm SEM. All analyses were performed using MATLAB and SPSS (version 14.0), $\alpha=0.05$ two tailed.

\section{Results}

\section{Androgen effects on blood levels}

Androgen implants elevated plasma levels only for the particular androgen implanted and did not alter levels of the other androgen (ANOVA T: $\mathrm{F}_{2,11}=22.09$, $\left.\mathrm{p}<0.01 ; 11-\mathrm{KT} \mathrm{F}_{2,11}=6.42, \mathrm{p}=0.01\right)$ (Table 1). For example, even though $\mathrm{T}$ is a precursor for biosynthesis of 11-KT, the T implants only elevated plasma $\mathrm{T}$ levels, without affecting plasma 11-KT, which did not differ between $\mathrm{T}$ and blank implanted males $(\mathrm{p}=0.78)$. 


\section{Effect of androgens on EOD waveform}

Androgen implants increased $\tau_{\mathrm{p} 2}$ both in the day (Fig. $3 \mathrm{~A}$ and $\mathrm{B}$ ) and at night (Fig. 3C and D) relative to blank implanted males (LSD post-hoc: $\mathrm{T}$ day $\mathrm{p}<0.01$; T night $\mathrm{p}<0.01 ; 11-\mathrm{KT}$ day $\mathrm{p}<0.01 ; 11-\mathrm{KT}$ night $\mathrm{p}<0.01) .11-\mathrm{KT}$ had a larger effect than $\mathrm{T}$ on $\tau_{\mathrm{p} 2}$ at night (Fig. 3C), but not during the day (Fig. 3A; post-hoc LSD; day $p=0.31$; night $\mathrm{p}<0.01$ ). However, only 11-KT elevated EOD amplitude at night (Fig. 3D; post-hoc LSD: $\mathrm{T} p=0.23 ; 11-\mathrm{KT} p=0.02$ ), while neither androgen changed daytime amplitude (Fig. 3B; post-hoc LSD: $\mathrm{T} p=0.51 ; 11-\mathrm{KT} \mathrm{p}=0.97)$. Body length, but not weight, significantly predicted daytime $\tau_{\mathrm{p} 2}$, but not amplitude (univariate between-subject tests; daytime $\tau_{\mathrm{p} 2}$ $\mathrm{p}=0.02$, amplitude $\mathrm{p}=0.70)$.

Baseline EOD amplitude differed between the two years of the study (GLM multivariate tests: $\left.F_{4,24}=4.99 \mathrm{p}<0.01\right)$. Pre-implant day and night EOD amplitudes of the fish sampled in 2009 were significantly higher than those in 2008 (univariate betweensubjects tests: day amplitude $\mathrm{p}=0.02$; night amplitude $\mathrm{p}=0.03$ ). Pre-implant day and night $\tau_{\mathrm{p} 2}$, however, did not differ between years (univariate between-subjects tests: day $\tau_{\mathrm{p} 2}$ : $\mathrm{p}=0.85$; night $\tau_{\mathrm{p} 2}: \mathrm{p}=0.90$ ). The interaction between implants and year was not significant for any of the EOD parameters tested (GLM multivariate tests: $F_{8,50}=1.86, p=0.09$ ). Neither body weight nor body length differed between the two years (GLM multivariate tests: weight $\mathrm{F}_{4,24}=0.52, \mathrm{p}=0.72$; length $\mathrm{F}_{4,24}=1.15, \mathrm{p}=0.36$ ).

\section{Effect of social stimuli on EOD waveform}

Addition of a conspecific male to the tank significantly increased EOD amplitude of the focal male both by day and night (Fig. 4b) (paired t-test: day t: $p=0.01$; night 
$\mathrm{p}=0.01$ ). However, social stimulation only increased $\tau_{\mathrm{p} 2}$ during the night (Fig. 4a; paired t-test: day $\mathrm{t}=0.09, \mathrm{p}=0.93$; night $\mathrm{t}=-8.73, \mathrm{p}<0.01$ ).

\section{Androgen effects on $\alpha-M S H$ challenge}

As reported previously (Stoddard et al., 2006), $\alpha-\mathrm{MSH}$ enhanced both $\tau_{\mathrm{p} 2}$ (Fig.5b; $\mathrm{t}=3.23, \mathrm{df}=25, \mathrm{p}<0.01$ ) and amplitude (Fig. $5 \mathrm{c} ; \mathrm{t}=8.87, \mathrm{df}=25, \mathrm{p}<0.01$ ). Overall, 11-KT imparted the most pronounced increase in EOD waveform responsiveness to $\alpha-\mathrm{MSH}$, while $\mathrm{T}$ only enhanced responsiveness of $\tau_{\mathrm{p} 2}$ (Fig. 6). Neither body length nor weight predicted the magnitude of $\alpha$-MSH injection response to implant treatments (GLM multivariate tests: weight $\mathrm{F}_{2,12}=0.41, \mathrm{p}=0.67$; length $\mathrm{F}_{2,12}=0.16, \mathrm{p}=0.86$ ). Implant type had a significant effect on EOD response to $\alpha$-MSH (GLM multivariate tests, $F_{4,26}=4.05$, $\mathrm{p}=0.01$ ) While both androgen implants increased $\tau_{\mathrm{p} 2}$ response to $\alpha$-MSH (Fig. 6a; posthoc LSD; 11-KT $\mathrm{p}<0.01$; and $\mathrm{T} \mathrm{p}=0.03$ ), only $11-\mathrm{KT}$ increased amplitude responsiveness to $\alpha$-MSH (Fig. 6b; post-hoc LSD: 11-KT $p=0.02 ; \mathrm{T} p=0.78$ ). Social interactions had no effect on response to $\alpha-\mathrm{MSH}$ for either EOD parameter (Fig. 7; amplitude $\mathrm{t}=-0.19$, $\mathrm{df}=7$, $\left.p=0.86 ; \tau_{p 2} t=-1.21, d f=7, p=0.27\right)$.

The combined 11-KT and $\alpha-\mathrm{MSH}$ treatments enhanced the waveform multiplicatively, inducing a significantly larger increase than expected from the summation of the individual androgen and peptide treatments (paired t-test; $\tau_{\mathrm{p} 2} \mathrm{t}=-5.56$, $\mathrm{df}=5, \mathrm{p}<0.01 ;$ amplitude $\mathrm{t}=2.42, \mathrm{df}=5, \mathrm{p}=0.06$ ). Combined $\mathrm{T}$ and $\alpha$-MSH effects did not deviate significantly from the summation of individual hormone treatments (paired t-test; $\tau_{\mathrm{p} 2} \mathrm{t}=-0.80, \mathrm{df}=5, \mathrm{p}=0.46$; amplitude $\left.\mathrm{t}=1.84, \mathrm{df}=5, \mathrm{p}=0.13\right)$. 


\section{Discussion}

Of the two dominant teleost androgens, only 11-KT increased EOD amplitude and increased the response of amplitude to $\alpha-\mathrm{MSH}$ (Fig. 6, Table 2). It is important to note that both androgen implants elevated circulating $\mathrm{T}$ and 11-KT levels above normal physiological levels, compared to the baseline levels of Blank implanted males (Table 1) and the levels reported by Salazar and Stoddard (2009). However, despite the supraphysiological levels, T failed to elevate EOD amplitude or increase amplitude responsiveness to $\alpha-\mathrm{MSH}$ (Fig.6, Table 2), suggesting that the effects we observed are 11-KT specific. To our knowledge, this is the first study to show that EOD amplitude can be modulated by a non-aromatizable androgen, but not its precursor testosterone. In a previous study conducted on female $B$. gauderio, none of the DHT implant doses (0.03$1 \mathrm{mg} 10 \mathrm{~g}^{-1}$ of fish) significantly elevated EOD amplitude or enhanced the effects of melanocortins on amplitude (Allee et al., 2009). However, all androgen implants, DHT (Allee et al., 2009), T, and 11-KT enhanced baseline $\tau_{\mathrm{p} 2}($ Fig. 3A, C) and the responsiveness of $\tau_{\mathrm{p} 2}$ to injected melanocortins (Fig 6a).

In other gymnotiforms, androgens differentially affect the EOD signal. While 11KT masculinizes the EOD frequency and duration in all species tested to date (Dunlap et al., 1998; Dunlap and Zakon, 1998), the effects of T and DHT seem to be species-specific (Dunlap et al., 1998; Zakon et al., 1990). DHT lowers EOD frequency of Apteronotus albifrons, but has no effect on frequency of A. leptorhynchus. Conversely, $\mathrm{T}$ has no effect on EOD frequency of $A$. albifrons, while feminizing (lowering) the frequency of $A$. leptorhynchus and masculizinig (lowering) it in Sternopygus macrurus (Dunlap et al., 
1998; Meyer, 1983; Zakon, 1999). In B. gauderio and B. occidentalis T and DHT implants masculinize female EODs by increasing duration of the EOD's second phase (Hagedorn and Carr, 1985; Silva et al., 1999). While the differential sensitivity to T has been attributed to disparate aromatase activities in the brain (Zakon, 1999), the differential effect of DHT and 11-KT on EOD suggests that different androgens activate different pathways regulating waveform shape.

Androgen administration reproduced the enhancing effect of social interaction on the EOD $\tau_{\mathrm{p} 2}$. However, the EOD amplitude elevation induced by $11-\mathrm{KT}$ is not comparable to the large increase elicited by social stimulation (Fig. 3, Table 2), suggesting that another unidentified hormone is also involved in regulating EOD amplitude. Social stimulation did not affect EOD responsiveness to $\alpha-\mathrm{MSH}$ treatment (Fig. 7), possibly because endogenous melanocortins saturated melanocortin receptors during social interactions.

Differential effects of 11-KT and T on behavior have been reported mainly in species with alternative reproductive tactics (Grober and Bass, 2002; Hirschenhauser et al., 2004; Lee and Bass, 2005; Oliveira et al., 2005). In these species, 11-KT levels are highly correlated with aggressive and territorial behaviors of the "bourgeois" phenotypes, while $\mathrm{T}$ maintains the female and socially parasitic (sneaker and satellite) male phenotypes. For example, in the batrachoid fishes, $\mathrm{T}$ regulates only the vocalizations of females and type II sneaker males, while 11-KT regulates the vocalizations of type I, territorial, paternal males; vocal activity of type I males are insensitive to T (Bass, 2008). Interestingly, while some female gymnotiforms such as B. gauderio and members of the genus Apteronotus have higher plasma concentrations of $\mathrm{T}$ than males (Dunlap et al., 
1998; Salazar and Stoddard, 2009), these patterns have not been associated with any female-specific behaviors.

Among teleosts with fixed reproductive strategies the specific role of each androgen has been hard to elucidate. Androgen responses to aggressive interactions, territorial intrusions and females seem to reflect species-specific reproductive and parental strategies (Hirschenhauser et al., 2004). In general, 11-KT levels in all species are highly responsive to territorial intrusions, while $\mathrm{T}$ levels, do not vary significantly in response to social challenges in various species of cichlids (Hirschenhauser et al., 2004;

Parikh et al., 2006). In the three-spined stickleback, Gasterosteus aculeatus, 11-KT levels are greatest during the beginning stages of the courtship phase (Pall and Borg, 2002) and 11-KT is needed for the production of spiggin, a proteinacious glue for nest building (Olsson et al., 2005). Our findings demonstrate that EOD amplitude, which is also associated with competition intensity (Franchina et al., 2001; Salazar and Stoddard, 2009), is modulated preferentially by $11-\mathrm{KT}$ and is less sensitive to T manipulations, in B. gauderio, another species with fixed reproductive strategies.

\section{Behavioral significance of signal modulation}

Previous studies in our lab have found that EOD amplitude response to social challenge is specific to the sex of the challenger. Male challengers induce a rapid (10-20 min) amplitude increase, as well as a long-term amplitude increase, peaking within 24 hours. Female challengers, on the other hand, only elicit a long-term amplitude increase on the scale of days but no rapid increase on the scale of minutes comparable to that elicited by males (Franchina et al., 2001). As in our study (Fig. 4), Franchina et al.(2001) 
found that compared to EOD amplitude, duration was much more responsive to social challenge on both time scales and in response to either sex. In B. gauderio, increased male-male competition causes an increase in amplitude and $\tau_{\mathrm{p} 2}$ (Salazar and Stoddard, 2009). EOD amplitude and the variances of circulating 11-KT levels track competition intensity, increasing as the male density in a pool is increased. On the other hand, $\tau_{\mathrm{p} 2}$ and $\mathrm{T}$ levels seem to track the presence or absence of competition (Salazar and Stoddard, 2009). In all of the studies on $B$. gauderio, $\tau_{\mathrm{p} 2}$ is always more responsive than amplitude to any stimulus (Allee et al., 2009; Franchina et al., 2001; Markham and Stoddard, 2005; Salazar and Stoddard, 2009).

The differential time course in response to different types of social stimuli might reflect the reproductive behaviors of B. gauderio, which breed seasonally in temperate areas (Quintana et al., 2004; Silva et al., 2002) in an exploded lek polygyny breeding system (Miranda et al., 2008). The transition from non-breeding to breeding season is likely preceded by increasing androgen levels, which stimulate the development of secondary sexual characteristics (Adkins-Regan, 2005), and expression of androgen receptors in the pacemaker nucleus (Pouso et al., 2010). Increased androgen levels masculinize EOD waveform (Hagedorn and Carr, 1985; Pouso et al., 2010; Silva et al., 2002) and likely increase melanocortin sensitivity (see below). As males compete for and establish territories during the breeding season, rapid EOD enhancement can signal quality and competitive ability to nearby competitors and potential mates. These shortterm responses are driven by melanocortins (Markham et al., 2009a; Markham and Stoddard, 2005). 


\section{Proposed mechanism for androgen regulation of melanocortin-driven EOD}

\section{signaling}

Androgens might increase melanocortin sensitivity through different mechanisms. In the distantly related gymnotiform Sternopygus macrurus, the sexually dimorphic EOD waveform duration is regulated by the kinetics of $\mathrm{Na}^{+}$and $\mathrm{K}^{+}$currents in the electrocytes (Ferrari et al., 1995; Few and Zakon, 2001; 2007; Schaefer and Zakon, 1996). The kinetics of voltage-gated ion channels in S. macrurus electrocytes are regulated by steroid hormones, and accordingly, electrocytes express androgen receptors (Dunlap and Zakon, 1998; Few and Zakon, 2001; 2007; Liu et al., 2008). In addition, circadian rhythmicity and short-term EOD amplitude modulations of B. gauderio and S. macrurus are regulated by melanocortins through the activation of the cAMP/PKA pathway (Markham and Stoddard, 2005; McAnelly et al., 2003; Stoddard et al., 2006). Recent findings show that the melanocortin ACTH activates the cAMP/PKA pathway, promoting exocytosis of preformed voltage-gated $\mathrm{Na}^{+}$and inward rectifying $\mathrm{K}^{+}$channels from vesicles into the electrocyte membrane, thus increasing electrocyte sodium flux during the action potential, causing EOD amplitude to increase (Markham et al., 2009b).

Androgens might enhance melanocortin sensitivity of electrocytes by either affecting the expression of melanocortin receptors or the density and kinetics of voltagegated ion channels. Data from other vertebrates have shown that androgens can stimulate melanocortin receptor expression (Ducrest et al., 2008; Wikberg et al., 2000). The expression of the recently described, $\mathrm{Na}^{+}$channel $\left(\mathrm{Na}_{\mathrm{v}} 1.4 \mathrm{bL}\right)$ splice variant in the electric organ of $S$. macrurus is positively correlated with EOD frequency and is lowered by androgen treatment. An alternate splice variant, $\mathrm{Na}_{\mathrm{v}} 1.4 \mathrm{a}$ is constitutively expressed in the 
electric organ and muscle. Possibly, androgens selectively alter $\mathrm{Na}^{+}$channel splicing in favor of decreased $\mathrm{Na}_{\mathrm{v}} 1.4 \mathrm{bL}$ levels, thereby reducing the rate of $\mathrm{Na}^{+}$current inactivation and masculinizing the waveform (Liu et al., 2008). A similar mechanism might operate for the sexually dimorphic expression of the potassium channels Kv1.1a and Kv1.2a (Few and Zakon, 2007). Thus, androgens might increase EOD sensitivity to melanocortins either by increasing melanocortin receptor synthesis or by selectively changing the ratio of $\mathrm{Na}^{+}$channel splice variants synthesized. Melanocortins, in turn, could activate the cAMP/PKA pathway shuttling the newly formed channels into the electrocyte membrane to produce EOD waveform enhancement or could alter kinetics by directly phosphorylating existing membrane channels.

In our study only 11-KT enhanced EOD amplitude in response to $\alpha-\mathrm{MSH}$ injections, while both androgens increased EOD $\tau_{\mathrm{p} 2}$ response to MSH (Fig. 6, Table 2). 11-KT implants significantly elevated circulating 11-KT levels (Table 1) and increased nighttime amplitude (Fig. 2; $p=0.012$ ). Since the types of androgen receptors found in some teleosts (AR1 and AR2) have the highest affinities for T and DHT (Larsson et al., 2002; Sperry and Thomas, 1999), differential androgen receptor expression on the electrocyte surface cannot account for the 11-KT specific, multiplicative enhancement of amplitude and $\tau_{\mathrm{p} 2}$. Since AR2 affinity for $\mathrm{T}$ is still higher than for $11-\mathrm{KT}$, it is not likely that $\alpha-\mathrm{MSH}$ amplitude response is specific to a particular receptor. However, since androgen receptor affinities have not been examined in gymnotiforms, it is possible that unlike the AR1 and AR2 found in Atlantic croaker (Sperry and Thomas, 1999), androgen receptors in gymnotiforms have higher affinity for 11-KT than $\mathrm{T}$. The recent finding that one of the androgen receptors has been lost in the Otophysi lineage (Douard et al., 2008) 
suggests that the remaining receptor might mediate the actions of $\mathrm{T}$ and $11-\mathrm{KT}$ differently than in species with two functional receptors. Preliminary findings in our lab suggest that the electrocytes of B. gauderio express only one type of AR receptor (Villinger and Stoddard, unpublished observations). Thus, the AR receptor in B. gauderio might be preferentially activated by $11-\mathrm{KT}$, independent of binding affinity, as has been reported in three-spined stickleback (Olsson et al., 2005). Preferential sensitivity to 11KT could also explain the differential magnitude of the combined androgen-melanocortin treatments, with 11-KT upregulating expression of melanocortin receptors or ion channel densities in active membranes of the electrocyte more effectively than $\mathrm{T}$.

The finding that 11-KT but not $\mathrm{T}$ enhances EOD amplitude and the melanocortin action on amplitude suggest that EOD amplitude is regulated by a different mechanism or pathway than EOD duration, allowing different information to be communicated by the two signal parameters.

\section{Conclusions}

Both sexually dimorphic EOD parameters are regulated by short-term and longterm modulators. 11-KT modulates EOD amplitude in the long-term while melanocortins modulate it in the short-term. Likewise, $\mathrm{T}$ and $11-\mathrm{KT}$ modulate $\tau_{\mathrm{p} 2}$ in the long-term while melanocortins modulate it in the short-term. Changing social environment, competition for mates, and aggressive interactions all can stimulate a behavioral and motivational response within minutes, which would be reflected on the EOD via melanocortins. Continuous stimulation or seasonal changes would enhance the EOD via long-term action of androgens. We suspect that increased androgen levels during the breeding season 
stimulate ion channel synthesis in the electrocytes, in anticipation of increased social interactions. The synergistic and differential effects of steroid and peptide hormones on modulation of EOD parameters allows changes in the signal to track long-term and shortterm physiological responses. Because fish can increase $\mathrm{T}$ without increasing 11-KT, the

differential sensitivity of EOD amplitude and $2^{\text {nd }}$ phase duration to the two androgens (only 11-KT modulates EOD amplitude, while both androgens modulate signal duration) provides a potential mechanism for independent regulation of these two sexually dimorphic signal traits.

\section{Acknowledgements:}

Financial support and equipment were provided by NIH grants MBRS GM08205 (PKS) and MBRS graduate fellowship and Graduate Student Association Research Grant (AG) and NIH BRI (SG). Susan Allee assisted with initial experiments examining the role of androgen implants on B. gauderio waveform. We thank Fernando Noriega for use of the plate reader for plasma steroid analyses, and Joel Baez and Carol Curtis for help with fish care. The suggestions of two anonymous reviewers significantly improved the manuscript. 


\section{References}

Adkins-Regan, E., 2005. Hormones and animal social behavior. Princeton University Press, Princeton.

Allee, S.J., Markham, M.R., Stoddard, P.K., 2009. Androgens enhance plasticity of an electric communication signal in female knifefish, Brachyhypopomus pinnicaudatus. Horm. Behav. 56, 264-273.

Bass, A.H., 2008. Steroid-dependent plasticity of vocal motor systems: novel insights from teleost fish. Brain Res. Rev. 57, 299-308.

Bass, A.H., Hopkins, C.D., 1984. Shifts in frequency tuning of electroreceptors in androgen-treated mormyrid fish. J. Comp. Physiol., A 155, 713-724.

Bass, A.H., Volman, S.F., 1987. From behavior to membranes: testosterone-induced changes in action potential duration in electric organs. Proc.Natl. Acad. Sci. U.S.A. 84, 9295-9298.

Brain, P.F., Evans, A.E., 1977. Acute influences of some ACTH-related peptides on fighting and adrenocortical activity in male laboratory mice. Pharmacol. Biochem. Behav. 7, 425-433.

Carlson, B.A., Hopkins, C.D., Thomas, P., 2000. Androgen correlates of socially induced changes in the electric organ discharge waveform of a mormyrid fish. Horm. Behav. 38, $177-186$.

Douard, V., Brunet, F., Boussau, B., Ahrens-Fath, I., Vlaeminck-Guillem, V., Haendler, B., Laudet, V., Guiguen, Y., 2008. The fate of the duplicated androgen receptor in fishes: a late neofuncitonalization event? BMC Evol. Biol. 8, 336-355.

Ducrest, A.L., Keller, L., Roulin, A., 2008. Pleiotropy in the melanocortin system, coloration and behavioural syndromes. Trends Ecol. Evol. 23, 502-510.

Dunlap, K.D., 2002. Hormonal and body correlates of electrocommunication behavior during dyadic interactions in a weakly electric fish, Apteronotus leptorhynchus. Horm. Behav. 41, 187-194.

Dunlap, K.D., Thomas, P., Zakon, H.H., 1998. Diversity of sexual dimorphism in electrocommunication signals and its androgen regulation in a genus of electric fish, Apteronotus. J, Comp. Physiol., A183, 77-86.

Dunlap, K.D., Zakon, H.H., 1998. Behavioral actions of androgens and androgen receptor expression in the electrocommunication system of an electric fish, Eigenmannia virescens. Horm. Behav.3, 30-38. 
Ferrari, M.B., McAnelly, L.M., Zakon, H.H., 1995. Individual variation in and androgenmodulation of the sodium current in electric organ. J. Neurosci. 15, 4023-4032.

Few, W.P., Zakon, H.H., 2001. Androgens alter electric organ discharge pulse duration despite stability in electric organ discharge frequency. Horm. Behav. 40, 434-442.

Few, W.P., Zakon, H.H., 2007. Sex differences in and hormonal regulation of Kv1 potassium channel gene expression in the electric organ: molecular control of a social signal. Dev. Neurobiol. 67, 535-549.

Franchina, C.R., 1997. Ontogeny of the electric organ discharge and the electric organ in the weakly electric pulse fish Brachyhypopomus pinnicaudatus (Hypopomidae, Gymnotiformes). J. Comp. Physiol., A 181, 111-119.

Franchina, C.R., Salazar, V.L., Volmar, C.-H., Stoddard, P.K., 2001. Plasticity of the electric organ discharge waveform of male Brachyhypopomus pinnicaudatus. II. Social effects. J. Comp. Physiol., A 187, 45-52.

Franchina, C.R., Stoddard, P.K., 1998. Plasticity of the electric organ discharge waveform of the electric fish Brachyhypopomus pinnicaudatus I. Quantification of daynight changes. J. Comp. Physiol., A 183, 759-768.

Giora, J., Malabara, L.R., 2009. Brachyhypopomus gauderio, new species, a new example of underestimated species diversity of electric fishes in the southern South America (Gymnotiformes: Hypopomidae). Zootaxa 2093, 60-68.

Gonzalez, M.I., Vaziri, S., Wilson, C.A., 1996. Behavioral effects of alpha-MSH and $\mathrm{MCH}$ after central administration in the female rat. Peptides 17, 171-177.

Grober, M., Bass, A.H., 2002. Life history, neuroendocrinology, and behavior in fish, in: Pfaff, D., Arnold, A., Etgen, A., Fahrbach, S., Rubin, R., Frank, L. (Eds.), Hormones, Brain and Behavior. Academic Press, New York.

Hagedorn, M., Carr, C., 1985. Single electrocytes produce a sexually dimorphic signal in South American electric fish, Hypopomus occidentalis (Gymnotiformes, Hypopomidae).

J. Comp. Physiol., A 156, 511-523.

Hagedorn, M., Zelick, R., 1989. Relative dominance among males is expressed in the electric organ discharge characteristics of a weakly electric fish. An. Behav. 38, 520-525.

Heiligenberg, W., 1991. Neural Nets in Electric Fish. MIT Press, Cambridge, MA.

Hirschenhauser, K., Taborsky, M., Oliveira, T., Canario, A.V.M., Oliveira, R.F., 2004. A test of the 'challenge hypothesis' in cichlid fish: simulated partner and territory intruder experiments. An. Behav. 68, 741-750. 
Hopkins, C.D., 1995. Convergent designs for electrogenesis and electroreception. Curr. Opin Neurobiol. 5, 761-777.

Hopkins, C.D., 1999. Design features for electric communication. J. Exp. Biol. 202, 1217-1228.

Hopkins, C.D., Comfort, N.C., Bastian, J., Bass, A.H., 1990. Functional analysis of sexual dimorphism in an electric fish Hypopomus pinnicaudatus, order Gymnotiformes. Brain Behav. Evol. 35, 350-367.

Ketterson, E.D., Atwell, J.W., McGlothlin, J.W., 2009. Phenotypic integration and independence: hormones, performance, and response to environmental change. Integr. Comp. Biol. 49, 365-379.

Larsson, D., Sperry, T., Thomas, P., 2002. Regulation of androgen receptors in Atlantic croaker brains by testosterone and estradiol. Gen. Comp. Endocrinol. 128, 224-230.

Lee, J., Bass, A.H., 2005. Differential effects of 11-ketotestosterone on dimorphic traits in a teleost with alternative reproductive morphs. Horm. Behav. 47, 523-531.

Liu, H., Wu, M., Zakon, H.H., 2008. A novel Na+ channel splice form contributes to the regulation of an androgen-dependent social signal. J. Neurosci. 28, 9173-9182.

Markham, M.R., Allee, S., Goldina, A., Stoddard, P.K., 2009a. Melanocortins regulate the electric waveforms of gymnotiform electric fish. Horm. Behav. 55, 306-313.

Markham, M.R., McAnelly, L.M., Stoddard, P.K., Zakon, H.H., 2009b. Circadian and social cues regulate ion channel trafficking. PLOS Biol. 7, 1-14.

Markham, M.R., Stoddard, P.K., 2005. Adrenocorticotropic hormone enhances the masculinity of an electric communication signal by modulating the waveform and timing of action potentials within individual cells. J. Neurosci. 25, 8746-8754.

McAnelly, L.M., Silva, A., Zakon, H.H., 2003. Cyclic AMP modulates electrical signaling in a weakly electric fish. J. Comp. Physiol., A 189, 273-282.

McGlothlin, J.W., Jawor, J.M., Greives, T.J., Casto, J.M., Phillips, J.L., Ketterson, E.D., 2008. Hormones and honest signals: males with larger ornaments elevate testosterone more when challenged. J. Evol. Biol. 21, 39-48.

McGlothlin, J.W., Ketterson, E.D., 2008. Hormone-mediated suites as adaptations and evolutionary constraints. Philos. Trans. R. Soc. Lon B Biol. Scie. 363, 1611-1620. 
Metz, J.R., Peters, J.J.M., Flik, G., 2006. Molecular biology and physiology of the melanocortin system in fish: a review. Gen. Comp. Endocrinol.

Metzner, W., 1999. Neural circuitry for communication and jamming avoidance in gymnotiform electric fish. J. Exp. Biol 202, 1365-1375.

Meyer, J.H., 1983. Steroid influences upon the discharge frequencies of a weakly electric fish. J. Comp. Physiol. 153, 29-37.

Mills, A., Zakon, H.H., 1991. Chronic androgen treatment increases action potential duration in the electric organ of Sternopygus. J. Neurosci. 11, 2349-2361.

Miranda, M., Silva, A.C., Stoddard, P.K., 2008. Use of space as an indicator of social behavior and breeding systems in the gymnotiform electric fish Brachyhypopomus pinnicaudatus. Env. Biol. Fishes 82, 379-389.

Oliveira, R.F., 2005. Hormones, social context and animal communication, in: McGregor, P.K. (Ed.), Animal Communication Networks. Cambridge University Press, Cambridge, pp. 481-520.

Oliveira, R.F., Ros, A., Gonclaves, D., 2005. Intra-sexual variation in male reproduction in teleost fish: a comparative approach. Horm. Behav. 48, 430-439.

Olsson, P., Berg, A., Hofsten, J., Grahn, B., Hellqvist, A., Larsson, A., Karlsson, J., Modig, C., Borg, B., Thomas, P., 2005. Molecular cloning and characterization of a nuclear androgen receptor activated by 11-ketotestosterone. Reprod. Biol. Endocrinol. 3, 3-37.

Pall, M., Borg, B., 2002. Androgen and behavior in the male three-spined stickleback, Gasterosteus aculeatus I. Changes in 11-ketotestosterone levels during the nesting cycle. Horm. Behav. 41, 377-383.

Parikh, V., Clement, T., Fernald, R., 2006. Androgen level and male social status in the African cichlid, Astatotilapia burtoni. Behav. Brain Res. 166, 291-295.

Perry, A., Grober, M., 2003. A model for social control of sex change: interactions of behavior, neuropeptides, glucocorticoids, and sex steroids. Horm. Behav. 43, 31-38.

Pouso, P., Quintana, L., Bolatto, C., Silva, A., 2010. Brain androgen receptor expression correlates with seasonal changes in the behavior of a weakly electric fish, Brachyhypopomus gauderio. Horm. Behav. 58, 729-736.

Quintana, L., Silva, A., Berois, N., Macadar, O., 2004. Temperature induces gonadal maturation and affects electrophysiological sexual maturity indicators in Brachyhypopomus pinnicaudatus from a temperate climate. J. Exp. Biol. 207, 1843-1853. 
Remage-Healey, L., Bass, A.H., 2006. From social behavior to neural circuitry: steroid hormones rapidly modulate advertisement calling via a vocal pattern generator. Horm. Behav. 50, 432-441.

Salazar, V.L., Stoddard, P.K., 2009. Social competition affects electric signal plasticity and steroid levels in the gymnotiform fish Brachyhypopomus gauderio. Horm. Behav. 56, 399-409.

Schaefer, J.E., Zakon, H.H., 1996. Opposing actions of androgen and estrogen on in vitro firing frequency of neuronal oscillators in the electromotor system. J. Neurosci. 16, 28602868.

Silva, A., Quintana, L., Ardanaz, J.L., Macadar, O., 2002. Environmental and hormonal influences upon EOD waveform in gymnotiform pulse fish. J. Physiol. Paris 96, 473-484.

Silva, A., Quintana, L., Galeano, M., Errandonea P., Macadar, O., 1999. Water temperature sensitivity of EOD waveform in Brachyhypopomus pinnicaudatus. J. Comp. Physiol., A 185, 187-197.

Sperry, T., Thomas, P., 1999. Characterization of two nuclear androgen receptors in Atlantic croaker: comparison of their biochemical properties and binding specificities. Endocrinology 140, 1602-1611.

Stoddard, P.K., Markham, M.R., Salazar, V.L., 2003. Serotonin modulates the electric waveform of the gymnotiform electric fish, Brachyhypopomus pinnicaudatus. J. Exp. Biol. 206, 1353-1362.

Stoddard, P.K., Markham, M.R., Salazar, V.L., Allee, S., 2007. Circadian rhythms in electric waveform structure and rate in the electric fish Brachyhypopomus pinnicaudatus. Physiol Behav 90, 11-20.

Stoddard, P.K., Zakon, H.H., Markham, M.R., McAnelly, L., 2006. Regulation and modulation of electric waveforms in gymnotiform electric fish. J. Comp. Physiol., A 192, 613-624.

Szabo, T., 1974. Anatomy of the specialized lateral line organs of electroreception, in: Fessard, A. (Ed.), Handbook of Sensory Physiology. Springer-Verlag, Berlin, pp. 13-58.

Wikberg, J.E.S., Muceniece, R., Mandrika, I., Prusis, P., Lindblom, J., Post, C., Skottner, A., 2000. New aspects on the melanocortins and their receptors. Pharmacol Res. 42, 393420. 
Wilczynski, W., Chu, J., 2001. Acoustic communication, endocrine control, and the neurochemical systems of the brain, in: Ryan, M.J. (Ed.), Anuran communication. Smithsonian Institution Press, Washington, pp. 23-35.

Zakon, H.H., 1993. Weakly electric fish as model systems for studying long-term steroid action on neural circuits. Brain Behav. Evol. 42, 242-251.

Zakon, H.H., Dunlap, D. K., 1999. Sex steroids and communication signals in electric fish: a tale of two species. Brain Behav. Evol. 54, 61-69.

Zakon, H.H., Smith, G.T., 2002. Weakly electric fish: neurobiology, and neuroendocrinology. Horm. Brain Behav. 2, 349-374.

Zakon, H.H., Yan, H.-Y., Thomas, P., 1990. Human chorionic gonadotropin-induce shifts in the electrosensory system of the weakly electric fish, Sternopygus. J. Neurobiol. $21,826-833$.

Zupanc, G.K.H., Maler, L., 1997. Neuronal control of behavioral plasticity: the prepacemaker nucleus of weakly electric fish. J. Comp. Physiol., A 180, 99-111. 

Table 1. Androgen implants significantly elevated plasma T and 11-KT levels compared to blank implanted males ( $\mathrm{T}$ implant: $\mathrm{p}<0.001 ; 11-\mathrm{KT}$ implant: $\mathrm{p}=0.01$ ).

\begin{tabular}{|c|l|r|}
\hline \multirow{2}{*}{$\begin{array}{c}\text { Implant } \\
\text { Type }\end{array}$} & \multicolumn{2}{|c|}{ Plasma androgen levels (mean \pm SEM) } \\
\cline { 2 - 3 } & \multicolumn{1}{|c|}{$\mathbf{T}(\mathbf{n g} / \mathbf{m l})$} & $\mathbf{1 1 - K T}(\mathbf{n g} / \mathbf{m l})$ \\
\hline Blank & $1.23 \pm 0.09(\mathrm{n}=4)$ & $2.44 \pm 2.27(\mathrm{n}=4)$ \\
\hline $\mathrm{T}$ & $16.58 \pm 3.79(\mathrm{n}=5)$ & $1.66 \pm 0.98(\mathrm{n}=5)$ \\
\hline $11-\mathrm{KT}$ & $2.19 \pm 0.91(\mathrm{n}=4)$ & $11.0 \pm 2.63(\mathrm{n}=4)$ \\
\hline
\end{tabular}


Table 2. Androgen implants and social challenge significantly enhanced EOD $\tau_{\mathrm{p} 2}$ and the effects of $\alpha-\mathrm{MSH}$ on $\tau_{\mathrm{p} 2}$

\begin{tabular}{|c|c|c|}
\hline Treatment & $\begin{array}{c}\text { EOD } \\
\text { amplitude }\end{array}$ & $\begin{array}{c}\text { EOD } \\
\tau_{\mathrm{p} 2}\end{array}$ \\
\hline$\alpha-$-MSH & $\Uparrow$ & $\Uparrow$ \\
\hline $\mathbf{T}$ & - & $\Uparrow \Uparrow$ \\
\hline 11-KT & $\Uparrow$ & $\Uparrow \Uparrow \Uparrow$ \\
\hline Social challenge & $\Uparrow \Uparrow$ & $\Uparrow \Uparrow \Uparrow$ \\
\hline $\mathbf{T} \rightarrow \alpha$-MSH & $\approx \alpha$-MSH & $>\alpha$-MSH \\
\hline 11-KT $\rightarrow \alpha$-MSH & $>\alpha$-MSH & $>>$-MSH \\
\hline Social $\rightarrow \alpha$-MSH & $\approx \alpha$-MSH & $\approx \alpha$-MSH \\
\hline
\end{tabular}

However, only 11-KT elevated EOD amplitude and increased the effects of $\alpha$-MSH on amplitude. Upward arrows indicate elevation and the horizontal bar (-) indicates no significant change. Arrow number reflects the magnitude of the change. Effects of steroid implants and social challenge on $\alpha$-MSH response are compared directly to $\alpha$-MSH effects alone. 
A

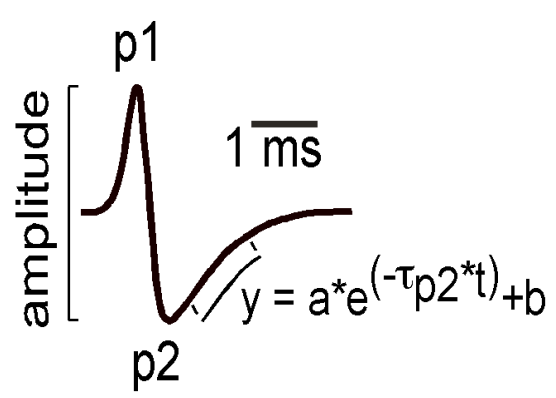

B

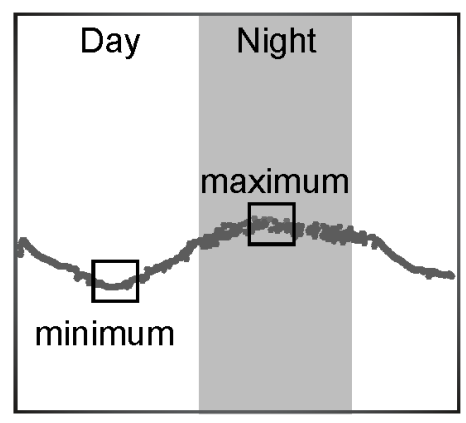

Figure 1. (A) The EOD waveform of B. gauderio varies in peak-to-peak amplitude and in duration of the second phase (parameterized as $\tau_{\mathrm{p} 2}$ ), (B) We recorded EODs around the clock for the duration of the experiment. We selected for analysis the amplitude and $\tau_{\mathrm{p} 2}$ when the EOD reached a daytime minimum and nighttime maximum. 


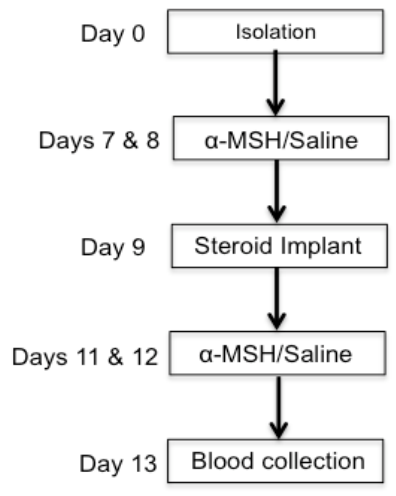

Figure 2. Design of experiment 2. See methods section for details. 

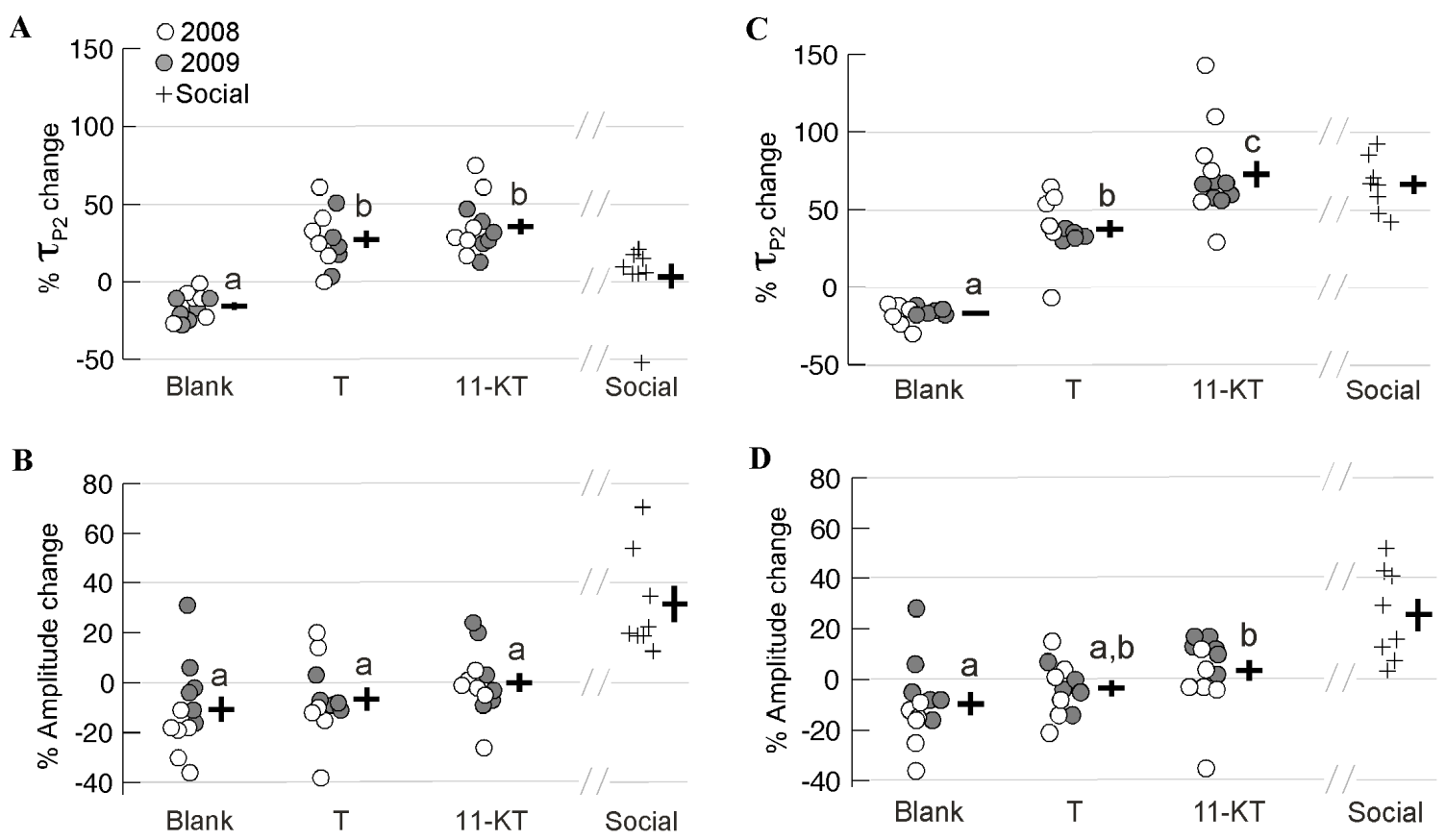

Figure 3. Effect of androgen implants on daytime (A, B) and nighttime (C, D) EOD. (A) 11-KT and $\mathrm{T}$ implants increased $\tau_{\mathrm{p} 2}$ during the day $(11-\mathrm{KT} \mathrm{p}<0.01 ; \mathrm{T} \mathrm{p}<0.01)$, but neither androgen implant increased daytime amplitude (B. 11-KT p=0.09; T p=0.51). (C) 11-KT caused higher elevation of $\tau_{\mathrm{p} 2}$ than $\mathrm{T} \operatorname{did}(\mathrm{p}<0.01$ for $11-\mathrm{KT} ; \mathrm{p}<0.01$ for $\mathrm{T})$, but only 11 KT elevated EOD amplitude (D. 11-KT p $=0.02 ; \mathrm{T} p=0.23$ ). Relative change in $\tau_{\mathrm{p} 2}$ and amplitude following social stimulation are shown separately because the data were collected the following year. Circles and crosses represent individual data points represented as relative change. Horizontal and vertical bars depict mean and SEM, respectively. Open and shaded circles represent the two years, 2008 and 2009, respectively, over which these experiments were conducted. For comparison, EOD response to social challenges is presented as plusses next to the implant data. Different 
letters represent significant differences between treatments $(p<0.05)$, based on LSD pairwise comparisons. 


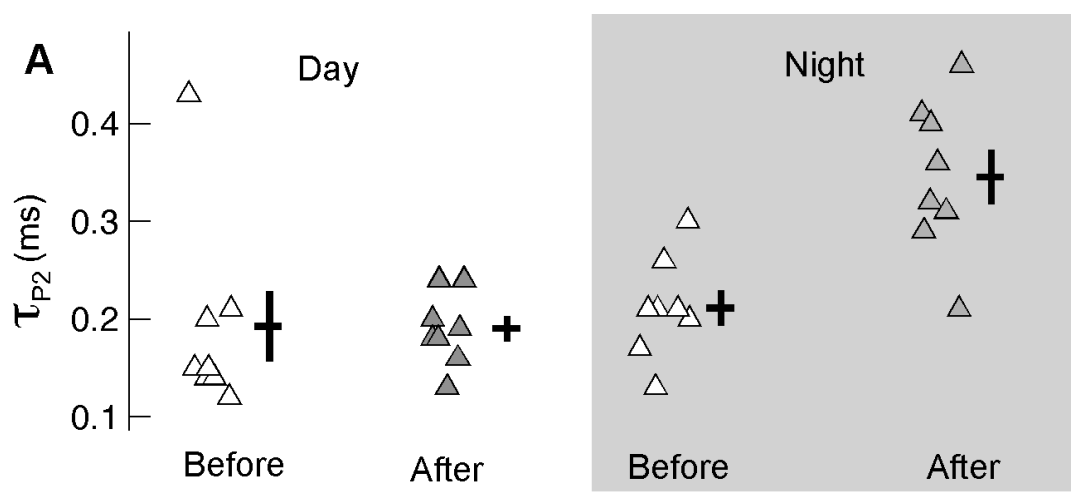

$\mathbf{B}$

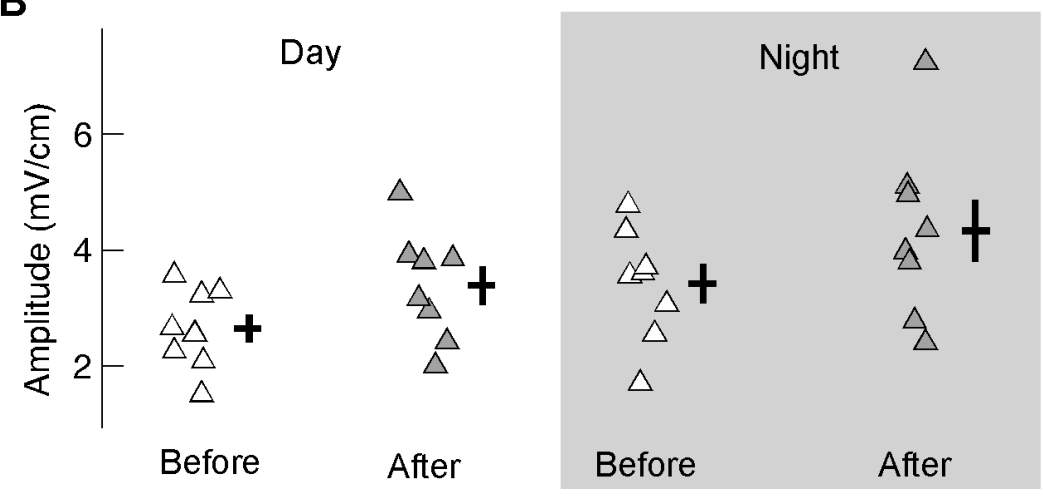

Figure 4. Effect of social challenge on the EOD waveform. Social challenge significantly increased daytime amplitude $(\mathbf{B}$. paired t-test, $\mathrm{t}=-3.47, \mathrm{p}=0.01)$, but not $\tau_{\mathrm{p} 2}(\mathbf{A}$. paired $\mathrm{t}$ test, $\mathrm{t}=0.09, \mathrm{p}=0.93)$. However, at night, $\tau_{\mathrm{p} 2}$ was significantly higher after the social challenge (A. paired t-test, $\mathrm{t}=-8.73, \mathrm{p}<0.01$ ) as was amplitude (B. paired t-test, $\mathrm{t}=-3.39$, $\mathrm{p}=0.01)$. "Before" refers to the amplitude and $\tau_{\mathrm{p} 2}$ measured before a social challenger was placed in the tank. "After" indicates the peak of the EOD waveform caused by the presence of the social stimulus. Triangles $=$ data points, horizontal bars $=$ means, and vertical bars $=$ SEM. 

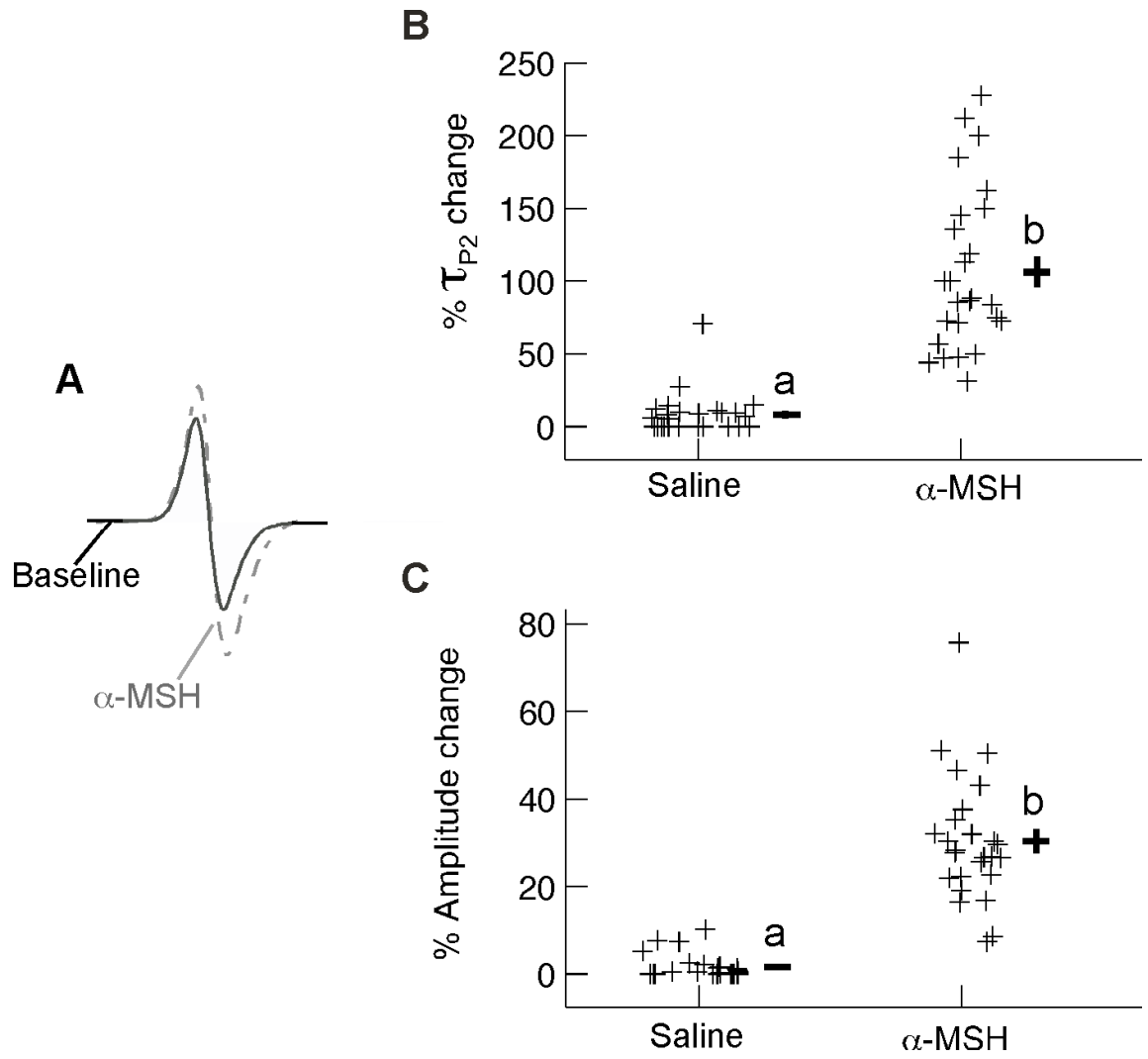

Figure 5. Effect of $\alpha-\mathrm{MSH}$ on EOD waveform. (A) $\alpha$-MSH injections increase the amplitude and $\tau_{\mathrm{p} 2}$ in the biphasic EOD of $B$. gauderio. Compared to saline, $\alpha-\mathrm{MSH}$ injections increase $\tau_{\mathrm{p} 2}($ B. paired t-test, $\mathrm{t}=3.23, \mathrm{df}=25, \mathrm{p}<0.01)$ and amplitude $(\mathbf{C}$. paired t-test, $\mathrm{t}=8.87, \mathrm{df}=25, \mathrm{p}<0.01)$. Different letters represent significant differences between treatments $(\mathrm{p}<0.05)$. Pluses, horizontal bars and vertical bars represent individual data points, mean, and SEM, respectively. 

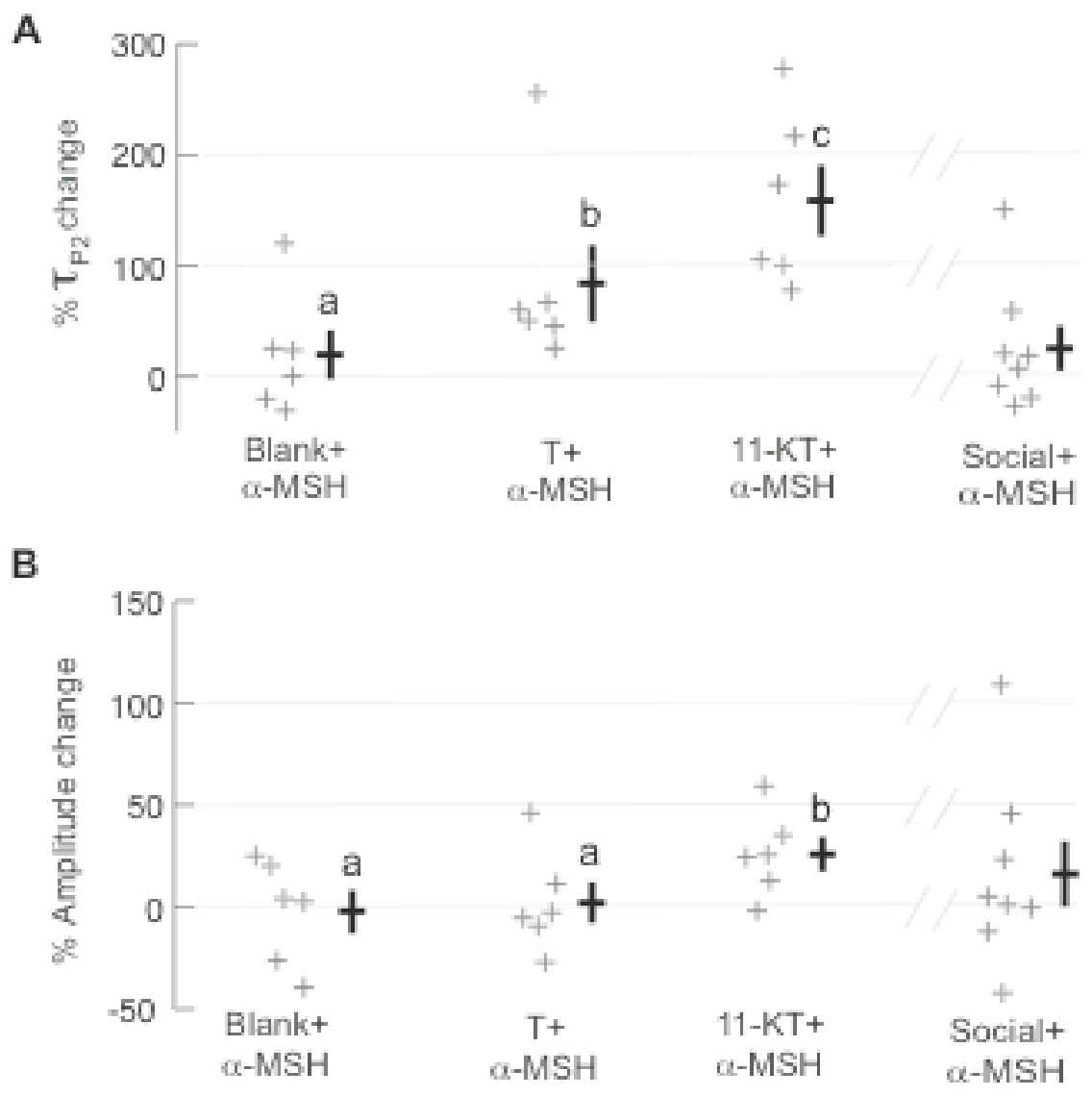

Figure 6. Androgen effect on EOD responsiveness to $\alpha$-MSH injections. (A) $11-\mathrm{KT}$ and $\mathrm{T}$ implants increased the $\tau_{\mathrm{p} 2}$ of the MSH response relative to blank implants $(\mathrm{p}<0.01$ for $11-\mathrm{KT}, \mathrm{p}=0.03$ for $\mathrm{T})$. Only $11-\mathrm{KT}$ increased amplitude responsiveness to $\alpha-\mathrm{MSH}$ injections (B. 11-KT p=0.02; $\mathrm{T} p=0.78)$. Social challenge had no effect the magnitude of $\alpha-\mathrm{MSH}$ response in $\tau_{\mathrm{P} 2}$ (paired t-test, $\mathrm{t}=-1.21, \mathrm{p}=0.86$ ) or amplitude (paired $\mathrm{t}$-test, $\mathrm{t}=$ $0.19, \mathrm{p}=0.27)$. Pluses, horizontal bars, and vertical bars represent individual data points, mean, and SEM, respectively. Different letters represent significant differences between treatments $(\mathrm{p}<0.05)$, based on LSD pairwise comparisons. 


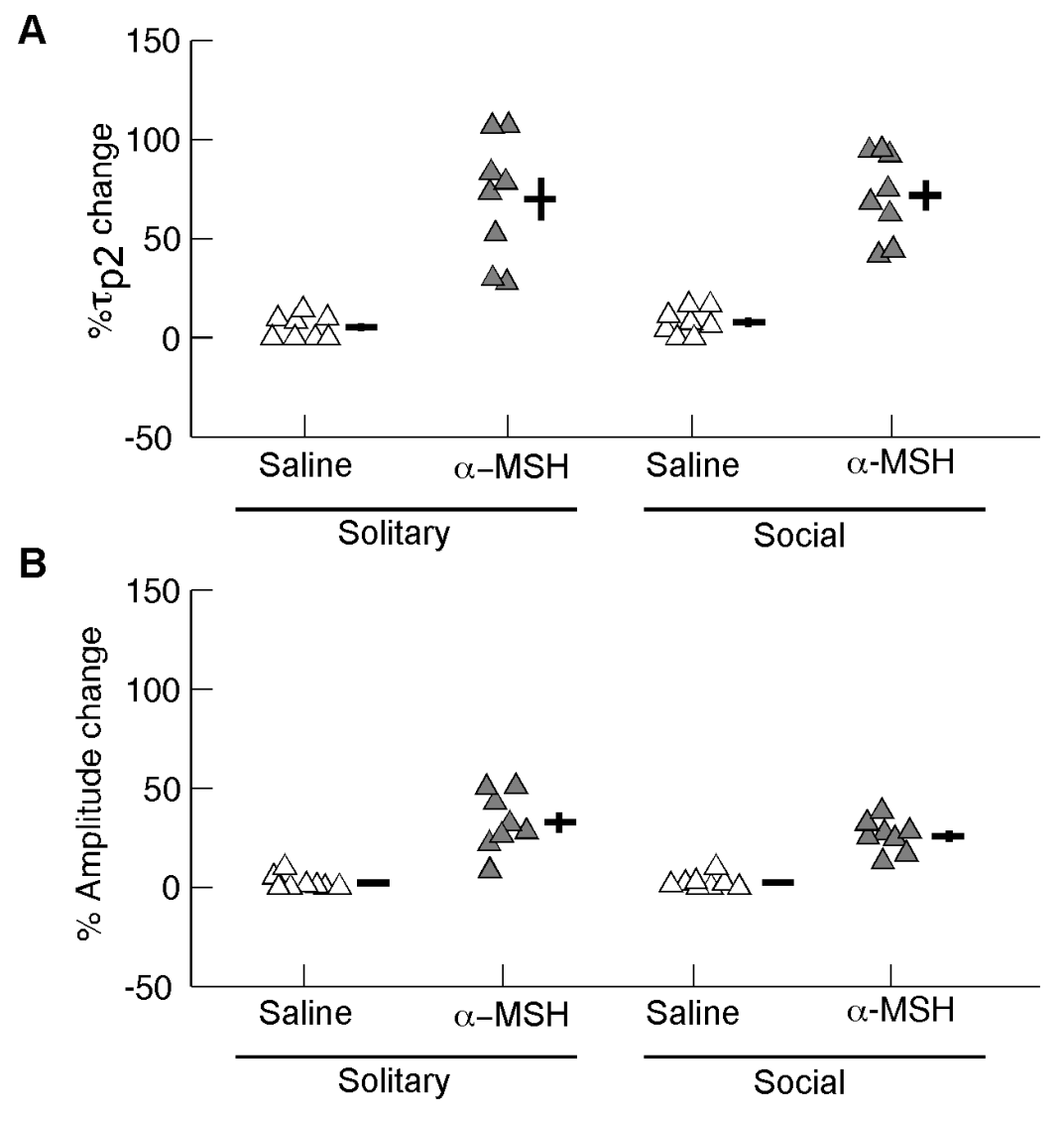

Figure 7. Effect of social challenge on melanocortin responsiveness. Social challenge had no effect the magnitude of $\alpha-\mathrm{MSH}$ response in $\tau_{\mathrm{p} 2}(\mathbf{A}$, paired t-test, $\mathrm{t}=-1.21, \mathrm{p}=0.85)$ or amplitude (B. paired t-test, $\mathrm{t}=-0.19, \mathrm{p}=0.26)$. Horizontal bars and vertical bars represent mean, and SEM, respectively. 


\section{CHAPTER IV}

HORMONALLY REGULATED SIGNAL PLASTICITY TRACKS SOCIALITY ACROSS GYMNOTIFORM FISH 


\begin{abstract}
While sociality can promote the evolution of complex communication signals, the need to remain recognizable by conspecifics might constrain signal plasticity. I propose that signal plasticity is related to sociality levels in the gymnotiform electric fishes. Taxa that maintain very loose social networks should produce plastic signals that reflect their immediate condition and reproductive state, while highly territorial and aggressive taxa should produce stable signals that preserve the encoding of individual identity. In gymnotiforms, electric signal plasticity is mediated by slow action of androgens and rapid action of melanocortins. I tested the hypothesis that differential sensitivity of electric signals to the known signal modulating hormones, androgens and melanocortins, maintain stable signature signals in species where individual recognition is important, while promoting dynamic signaling in species with loose social networks. I tested four species each from a different gymnotiform family; two territorial, highly aggressive species, Gymnotus carapo and Apteronotus leptorhynchus, one highly gregarious species, Eigenmannia $c f$. virescens, and one intermediate short-lived species with a fluid social system, Brachyhypopomus gauderio. Fish were implanted with (i) testosterone, (ii) 11ketotestosterone or (iii) blank silicone implants and twice injected with the melanocortin peptide hormone $\alpha-\mathrm{MSH}$, before the implant and at the peak of the implant effect. The waveforms of the two most territorial and aggressive species were insensitive to hormone treatments, maintaining static and stereotyped waveform shapes and amplitudes, while waveforms of the two less aggressive species were highly modulated by hormone treatment. Intermediate plasticity, was observed in G. carapo and E. virescens. These
\end{abstract}


data are consistent with my hypothesis that social strategies could facilitate or inhibit dynamic signaling through differential responsiveness to hormones.

Keywords: 11-ketotestosterone (11-KT); alpha-melanocyte stimulating hormone $(\alpha-$ MSH); androgen; communication signal; electric fish, electric organ discharge (EOD; gymnotiform; plasticity; Testosterone $(\mathrm{T})$, sociality.

\section{Introduction}

Animals living in social groups must balance the trade-off between maintaining stable communication signals that accurately portray their individual identity, versus the benefits of adjusting these signals to reflect changes in reproductive competitive states. Birds, amphibians, and some mammals typically resolve this conflict by producing separate signals or signal traits that are relegated to each function (Berg et al., 2011; Falls, 1982; Gerhardt, 1991; Mammen and Nowicki, 1981; May-Collado et al., 2007; Stoddard, 1996; Templeton et al., 2005), but the conflict may persist within a class of signals or in animals with limited signal repertoires. Through dynamic signal regulation an individual can increase signal extravagance when beneficial (e.g., males in the presence of breeding females or rival males), and decrease extravagance when costs are high (e.g., when predators or other hostile eavesdroppers are present) or benefits are low (e.g., intended receivers such as mates or rivals are absent). However, animals living in stable social groups must be able to maintain a signature signal that is stereotyped enough to be identified by conspecifics and is an accurate representation of the individual's status or identity at all times (Bond et al., 2003; Falls, 1982). 
Certain social systems may foster stereotypy of an entire signal or of selected signal traits to aid individual recognition. For example, delphinid species with increasing sociality levels produce signals with greater tonal frequency and complexity relative to solitary species (May-Collado et al., 2007). Emperor penguins live in large colonies, and carry their chicks on their feet. When one adult in the mated pair returns from foraging it must be able to find its mate and offspring. Adults and chicks use only the first three harmonics of the adult signal to recognize their parents' and mate's call (Jouventin et al., 1999). In the black-capped chickadee call the "chicka" part is stable to the individual, while the "dee" is dynamic, assuming the flock identity signal (Mammen and Nowicki, 1981). In the African electric fish Pollimyrus adspersus and Pollimyrus isidori, communication signals are highly stable, sexually dimorphic, and exhibit greater variability between than within individuals, making them ideal for individual recognition. Males of both of these species are highly territorial, they build and guard nests and produce stereotypical courting signals (Crawford, 1992; Paintner and Kramer, 2003). Interestingly, in $P$. isidori only the amplitude of the first phase of the signal varies significantly between the sexes, while differences in signal duration and amplitude of the first phase distinguish between individuals, suggesting that recognition does not require stereotypy of the entire signal (Crawford, 1992). Another African electric species, Brienomyrus brachyistius establishes hiding places and breeding territories; all characteristics of animals with signature signals and their electric signals are stereotypic enough to allow consistent tracking and differentiation between females/juveniles and males (Friedman and Hopkins, 1996), 
In this study I ask, how is the trade-off between dynamic and stable signaling mediated by the endocrine mechanisms that control signal production and modulation in the weakly electric gymnotiform fish with different sociality levels. Members of the South American order Gymnotiformes comprise five families of weakly electric species with over 250 species (Albert and Crampton, 2005). They occupy diverse fresh water habitats varying in depth, temperature, conductivity, dissolved oxygen, flood period, and vegetation (Albert and Crampton, 2005). Gymnotiforms produce weak electric organ discharges (EODs) for electrolocation and communication. EODs have characteristic time $\mathrm{x}$ voltage waveforms that are often distinctive to species, sex, maturity, and social status. Electric signaling plays a key role in aggression, territoriality, and mate assessment (Hagedorn and Zelick, 1989; Hopkins, 1988). EODs of some species exhibit circadian rhythms during the breeding season (Dunlap et al., 2011; Pouso et al., 2010; Silva et al., 2002), increasing sexually selected signal parameters as night approaches, to enhance the signal at the onset of activity (Franchina and Stoddard, 1998; Goldina et al., 2006; Moller, 1995; Stoddard et al., 2007). EODs also change in a species-specific manner in the context of competition, aggression and mating (Black-Cleworth, 1970; Dunlap and Larkins-Ford, 2003b; Franchina et al., 2001; Hagedorn and Heiligenberg, 1985; Salazar and Stoddard, 2009).

The neural circuitry and endocrine pathways that regulate EOD production and modulation have been well described, making electric fish great models for understanding the interplay between proximate and ultimate factors driving the evolution of diverse communication strategies. The EOD is produced by the summation of action potentials generated by electrocytes, electrically excitable cells of the electric organ 
(Szabo, 1974) and can vary in frequency and waveform. Frequency is determined by the firing rate of the oscillatory neurons in the medullary pacemaker nucleus, which innervate the electromotoneurons in the spinal cord. Electromotoneurons synapse on electrocytes, giant cells derived from muscle cells. In one family, Apteronotidae, modified electromotoneurons serve as electrocytes. Phases of EOD waveforms can vary in number, polarity, amplitude, and duration. Waveform is modulated by the ion channel properties of the electrocytes (Zakon et al., 1999), the innervation patterns and the presence of excitable faces of the individual electrocytes, as well as presence and location of accessory electric organs (Caputi et al., 2005; Kirschbaum and Schwassmann, 2008).

The EOD is regulated centrally and peripherally by steroid hormones. Androgens masculinize the waveform by increasing the firing rate of the pacemaker nucleus and broadening action potentials of individual electrocytes in the periphery (Few and Zakon, 2001). Elevated levels of 11-ketotestosterone (11-KT) in Apteronotids are positively correlated with increased rat of chirps, modulations used in the contexts of aggression and courtship. Androgen implants stimulate chirp production in Apteronotus leptorhynchus (Dunlap, 2002a, b; Dunlap and Larkins-Ford, 2003a) and increase amplitude and second phase duration of Brachyhypopomus gauderio (Allee et al., 2009; Goldina et al., 2011; Silva et al., 2002). While androgens affect EOD waveform on a timescale of days to months, melanocortin peptide hormones, such as adrenocorticotropic hormone (ACTH) and $\alpha$-melanocyte stimulating hormones ( $\alpha-\mathrm{MSH})$, induce rapid changes in the EOD within minutes of injection or direct application to electrocytes (Stoddard et al., 2006). Melanocortin peptides are involved in learning, grooming, aggression, sexual behaviors, and social signaling (Brain and Evans, 1977; Gonzalez et 
al., 1996; Wikberg et al., 2000). In gymnotiform electric fish, melanocortin application induces EOD modulations that resemble signal changes observed during social interactions (Markham and Stoddard, 2005; Stoddard et al., 2006). Furthermore, in $B$. gauderio, androgens and melanocortins interact in the regulation of EOD pulse amplitude and duration, making the EOD a highly dynamic communication signal (Goldina et al., 2011).

I offer the hypothesis that insensitivity of signal-generation structures to androgens and melanocortins enables highly aggressive and or territorial species to maintain a stable signature signal, while sensitivity to these hormones enables gregarious species with loose social networks to produce dynamic communication signals that adjust to changing social environments. To evaluate this hypothesis, I chose four gymnotiform species from different families, selecting species that exhibit different sociality levels (Table 1, Fig. 1). Gymnotus carapo (family Gymnotidae) is sexually monomorphic in EOD waveform and morphology (Albert and Crampton, 2005), highly aggressive and territorial (BlackCleworth, 1970; Westby, 1988). Gymnotus species are typically solitary. Their EODs are believed to serve as individual-specific signature signals in the context of territorial aggression (McGregor and Westby, 1992). In addition, G. carapo is one of only three gymnotiform genera with paternal behavior and the only genus reported where males mouthbrood the eggs and guard juveniles (Crampton and Hopkins, 2005; Kirschbaum and Schugardt, 2002). Like G. carapo, Apteronotus leptorhynchus (family Apternonotidae) is highly aggressive and territorial. In captivity, fish fight until death to maintain sole control of a shelter (Hagedorn and Heiligenberg, 1985; Hupe and Lewis, 2008). Apteronotus leptorhynchus establishes dominance hierarchies based on EOD 
frequency and size, but does not exhibit parental behavior (Hagedorn and Heiligenberg, 1985; Kirschbaum and Schugardt, 2002). Eigenmannia cf. virescens (family Sternopygidae) is a gregarious species (Hagedorn and Heiligenberg, 1985). Fish aggregate into shoals during the light hours and disperse at nighttime. If threatened by a predator, individuals aggregate into a more compact group (Oestreich and Zakon, 2005). Eigenmannia cf. virescens also lack parental behavior (Kirschbaum and Schugardt, 2002). Finally, Brachyhypopomus gauderio (family Hypopomidae) is a short-lived polygynous species that aggregates into mixed-sex social networks (Dunlap et al., 2011; Miranda et al., 2008). Brachyhypopomus. gauderio generates dynamic waveforms which increase at night, in response to social interaction, and in response to $\alpha$-MSH injections (Franchina et al., 2001; Franchina and Stoddard, 1998; Stoddard et al., 2007).

In this study I examine the relationship between hormone responsiveness and sociality structures of the four gymnotiform species described above. Specifically, I compare EOD waveform plasticity and responsivity to the androgens testosterone and 11ketotestosterone ( $\mathrm{T}$ and 11-KT) and the peptide hormone $\alpha-\mathrm{MSH}$. I predict that gregarious species with loose social networks such as B. gauderio and E. cf. virescens, generate temporally plastic signals through enhanced sensitivity to androgens and melanocortins. In aggressive and territorial species such as G. carapo and $A$. leptorhynchus, where the costs of dynamic signaling outweigh the benefits (i.e., inability to be identified by neighboring conspecifics can incur attacks and injury (McGregor, 1993; McGregor and Westby, 1992), a temporally static signal will be maintained through insensitivity of the electric organ to short-term hormonal fluctuations. 


\section{Methods}

\section{Subjects}

I used individuals from four Gymnotiform species, Gymnotus carapo, Apteronotus leptorhynchus, Eigenmannia cf. virescens, and Brachyhypopomus gauderio. Gymnotus carapo $(\mathrm{N}=14$, total length $25.60 \pm 2.60 \mathrm{~cm}$, weight $57.28 \pm 12.71 \mathrm{~g})$, Apteronotus leptorhynchus $(\mathrm{N}=17$, total length $=18.03 \pm 7.35 \mathrm{~cm}$, weight $17.94 \pm 7.33 \mathrm{~g})$, and Eigenmannia cf. virescens $(\mathrm{N}=27$, total length $17.65 \pm 5.85 \mathrm{~cm}$, weight $11.26 \pm 13.08 \mathrm{~g})$ were purchased from Ruineman's Aquariums (Miami, FL) kept in an indoor facility in individual or group tanks. The tanks were kept in a light- and temperature-controlled room on a $12 \mathrm{~L}: 12 \mathrm{D}$ light cycle, with water temperatures $27-28^{\circ} \mathrm{C}$ and conductivity 120 $150 \mu \mathrm{S} \mathrm{cm}^{-1}$. Captive bred Brachyhypopomus gauderio $(\mathrm{N}=35$, total length $=17.9 \pm 1.9$ $\mathrm{cm}$, weight $=8.7 \pm 2.9 \mathrm{~g}$ ) were maintained 450 liter pools in our outdoor breeding colony at Florida International University. Fish were kept in mixed-sex groups of 5-10 individuals. The pools were covered with water hyacinths, Eichhornia crassipes. Water conductivity was maintained at $70-100 u \mathrm{~S} \mathrm{~cm}^{-1}$. Data presented for $B$. gauderio were presented in more detail by Goldina et al. (2011); I present these data here in condensed form for comparison with the other three species.

All fish were fed oligochaete "blackworms" ad libitum every two days. For data collection fish were brought indoors and placed individually in 284 liter aquaria. Experiments complied with the National Institutes of Health Guide for the Care and Use of Laboratory Animals (DHEW Publication 80-23, revised 1985) and were approved by the FIU IACUC (protocol approval no. 08-023). 


\section{Data collection}

EODs were recorded in an automated, calibrated recording system previously described in detail (Stoddard et al., 2003). Briefly, fish were placed into aquaria, 120 x 44 x $44 \mathrm{~cm}$, in a temperature- and light-controlled room (12L:12D). Water conductivity was maintained at $100-120 u \mathrm{~S} \mathrm{~cm}^{-1}$. Each tank was divided into thirds by plastic mesh screening, with plastic funnels directing fish through an unglazed ceramic tube that joined the outer two compartments. EODs were amplified and digitized from nichrome wire electrodes affixed to opposite ends of the tank. To obtain repeatable measurements, EODs were recorded only when the fish was geometrically centered in the tank. Position was determined by a circuit that monitored the intensity of electric signals recorded from electrodes on the surface of the resting tube. The system automatically recorded EODs when the fish passed through the ceramic tube, the geometric center of the tank. Nine EODs were recorded every minute around the clock. The recorded signals were amplified 500X and low-pass filtered at $10 \mathrm{kHz}$.

\section{Experimental design}

A week of social isolation in B. gauderio lowers circulating androgens (Salazar and Stoddard, 2009) which causes the male's EOD to diminish considerably in its sexually dimorphic properties (Franchina et al., 2001). In this experiment, individuals of each species (sample sizes explained below) were placed into individual EOD recording tanks for an initial isolation period of six days during which their EODs were recorded and monitored. On days 7 and 8 of social isolation, before steroid treatment, each fish was

injected with either $25 \mu \mathrm{M} \mathrm{g}^{-1}$ body weight $\alpha-\mathrm{MSH}$ or saline control, in counterbalanced 
random order. This dose of $\alpha-\mathrm{MSH}$ was chosen based on previous studies showing that $25 \mu \mathrm{M} \mathrm{g}^{-1}$ fully enhances the EOD (Markham et al., 2009a; Markham and Stoddard, 2005). On the ninth day of recording, individuals were removed from their recording tanks, implanted with silicone implants (Blank, T, or 11-KT), and quickly returned to their tanks for 7 more days of recording.

The effect of androgen implants on EOD amplitude was monitored daily. When the EOD amplitude reached a maximum, determined by the lack of increase for 24 hours (usually 2-4 days after the implant), fish were re-injected with $25 \mu \mathrm{M} \alpha-\mathrm{MSH}$ and saline, as explained above. Because the EOD amplitudes of $A$. leptorhynchus did not respond to either steroid implant (pilot experiments for this study), I injected these individuals three days after implanting to maintain an experimental design comparable to the other species.

I used at least six individuals for each implant group. Because Gymnotus carapo are extremely robust, but limited in availability, I used the same six individuals for all three implant groups (see below) in a repeated-measures design. Implant order was randomized for each individual and individuals were given at least two weeks to recover between implants. Because the other three species are more fragile but relatively easy to obtain, I used 18 separate individuals, six for each implant group.

\section{Androgen implants}

11-Ketotestosterone (Sigma, K8250) or Testosterone (Sigma, T6147) was mixed with silicone (Dow Corning 3140 MIL-A-461 45 RTV coating) in a 1:4 ratio. The mixture was allowed to cure for about a week and the concentration of 11-KT or T implant was recalculated to adjust for silicone mass lost through evaporation. The final ratio of 11- 
KT: silicone was 1:3.8 and 1:4 for T: silicone. Implants were custom cut for each test fish based on its weight, for a final concentration of $0.05 \mathrm{mg}$ of $11-\mathrm{KT}$ or T per 10 grams of fish. Validation that these implants elevate circulating androgen levels was conducted in B. gauderio (Allee et al., 2009; Salazar and Stoddard, 2009; Goldina et al., 2011).

To insert the implants, I anesthetized the fish by immersion in a $0.075 \%$ solution of 2-phenoxyethanol (Sigma, P-1126FD) and, using an 18-gauge hypodermic needle, made a small hole in the fatty area of the trunk, dorsal to the anal fin and lateral to the pterygiophore muscle and electric organ, into which we placed an implant. The incision was closed with surgical glue and the fish was returned to the recording tank. EOD amplitude and duration were monitored for changes over the subsequent days.

\section{MSH injections}

$\alpha$-Melanocyte stimulating hormone ( $\alpha-\mathrm{MSH})$ (Sigma, M4135) was dissolved in physiological saline: $\mathrm{NaCl} 114 \mathrm{mmol} \mathrm{l}^{-1}, \mathrm{KCl} 2 \mathrm{mmol} \mathrm{1}^{-1}, \mathrm{CaCl}_{2} \cdot 2 \mathrm{H}_{2} \mathrm{O} 4 \mathrm{mmol} \mathrm{1}^{-1}$, $\mathrm{MgCl}_{2} \cdot 6 \mathrm{H}_{2} \mathrm{O} 2 \mathrm{mmol}^{-1}$, HEPES $2 \mathrm{mmol}^{-1}$, adjusted to $\mathrm{pH} 7.2$ with $\mathrm{NaOH}$ for a final concentration of $25 \mu \mathrm{M}$. Aliquots were frozen until and diluted to $2.5 \mu \mathrm{M}$ on the day of injection. Physiological saline was used as a control for handling and injection.

Experimental and control solutions were injected at $1 \mu \mathrm{g}^{-1}$ of fish intramuscularly using a Hamilton syringe fitted with a disposable 31.5 gauge needle for all species except $G$. carapo for which we used a 21 gauge needle to pierce its much thicker skin. All injections were done between 1100 and 1400 . 


\section{Data treatment and analyses}

To quantify the effects of androgens and $\alpha-\mathrm{MSH}$ on the waveform, I measured total, peak-to-peak amplitude and duration of each species. In addition, since different phases

of the waveform are differentially sensitive to androgen treatments (Dunlap and Zakon, 1998; Silva et al., 2002), for species with multiphasic waveforms, I measured the duration and amplitude of each phase (i.e., P1, P2, and P3 for G. carapo, and P1 and P2 for B. gauderio and A. leptorhynchus (Fig.1)) .

In all species, I examined treatment effects by measuring relative change of each parameter (amplitude and duration) before and after each hormone treatment. I assessed the effects of androgen implants on waveform response to $\alpha$-MSH injections by comparing EOD responses to $\alpha-\mathrm{MSH}$ before and after implant treatments. Since each individual G. carapo underwent all three implant treatments, waveform responses to $\alpha$ MSH injections during different implant treatments were compared within each individual. In the other three species, treatment effects were compared among individuals (see Statistical analyses below).

\section{Statistical analyses}

The effect of androgen implants on baseline waveforms and $\alpha$-MSH responsiveness of $B$. gauderio, A. leptorhynchus, and E. cf. virescens was analyzed with a one-way MANCOVA (GLM multivariate procedure in SPSS 14.0, Model III). We used response variables (i) baseline, (ii) $\alpha-\mathrm{MSH}$ response, and (iii) saline response, with two levels 
each, before and after implant, as within-subject factors. Implant type (Blank, T, and 11KT) was the between-subject factor.

Since the same G. carapo individuals were used for all three implant treatments, I used a one-way repeated measures MANCOVA (GLM repeated measures procedures, v.14.0 Model III) with (1) EOD amplitude and (2) EOD duration as within-subject factors with three levels each (i) Blank, (ii) $\mathrm{T}$, and (iii) 11-KT to examine the effects of steroid implants on the four phases of their waveforms. Thus androgen effects on the EOD were compared within individuals relative to the effects of control (blank) implants. The effect of steroid implants on EOD response to $\alpha-\mathrm{MSH}$ injections was examined with a two-way repeated measures MANCOVA using time [two levels: (i) before implant and (ii) after implant], EOD amplitude, and EOD duration as within-subject factors. During the course of the experiments, some individuals got sick and were removed from the study and analyses. Thus, total sample size of G. carapo was reduced to 11 for assessment of androgen effects and 10 for measuring androgen effects on $\alpha-\mathrm{MSH}$ responsiveness on the waveform.

Paired t-tests compared the effects of saline and $\alpha-\mathrm{MSH}$ injections on EOD amplitude and EOD duration. Body weight and length were used as covariates in all analyses to account for possible influence of size on response variables. Where MANCOVA differences were significant $(\mathrm{p}<0.05)$, I used the protected LSD post hoc analysis to determine significant pairwise differences. Data are reported as mean \pm SEM. All analyses were performed using MATLAB and SPSS (version 14.0), $\alpha=0.05$ two tailed. 


\section{Results}

\section{Androgen effect on EOD waveform}

\section{Gymnotus carapo}

Overall, androgens enhanced multiple phases of G. carapo amplitude and duration (GLM multivariate tests: amplitude $F_{7,2}=1767.39, p<0.01$; duration $F_{8,3}=15.327, p=0.02$ ). Neither androgen changed the total peak-to-peak EOD amplitude, (univariate withinsubjects test: $\mathrm{p}=0.34$; Table 2, Fig. 2A), but 11-KT elevated P1 amplitude (LSD posthoc: $11-\mathrm{KT} \mathrm{p}<0.01 ; \mathrm{T} \mathrm{p}=0.26$, Table 2). Likewise, the interaction between EOD amplitude and body weight was related to amplitude of P1 (GLM univariate tests: $\left.\mathrm{F}_{2,16}=4.203, \mathrm{p}=0.03\right)$, but not other phases. Neither androgen changed amplitudes of P2 or P3 phase of the G. carapo EOD (Table 2).

Only 11-KT increased P3 (LSD post-hoc: P3 11-KT p $<0.01, \mathrm{~T} p=0.13$; total 11KT $\mathrm{p}<0.01, \mathrm{~T} p=0.21$; Fig. 2A). Testosterone implants had no effect on either phase duration (post-hoc LSD: P1 p = 0.70; P2 p=0.70; P3 p =0.13; total $p=0.21$; Table 2).

Neither body weight, nor body length was significantly related to EOD change in amplitude or duration in response to androgen treatments (GLM multivariate tests: amplitude weight $\mathrm{F}_{4,5}=1.869, \mathrm{p}=0.25$; length $\mathrm{F}_{4,5}=0.148, \mathrm{p}=0.96$; duration weight $\mathrm{F}_{4,5}=0.804, \mathrm{p}=0.57$; length $\left.\mathrm{F}_{4,5}=1.232, \mathrm{p}=0.40\right)$.

\section{Brachyhypopomus gauderio}

Only 11-KT elevated EOD amplitude relative to controls (post-hoc LSD: $\mathrm{T} p=0.23 ; 11$ KT p=0.02; Fig. 2C). However, both androgens increased duration of P1 \& P2 (LSD post-hoc: P1 T p=0.03, KT p=0.01; P2 T p $<0.01,11-\mathrm{KT} \mathrm{p}<0.01$; data not shown) and 
total duration (LSD post-hoc: $\mathrm{T} p<0.01 ; 11-\mathrm{KT} \mathrm{p}<0.01$; Fig. 2D). Neither body length nor body weight had any relation to either EOD duration (GLM multivariate tests; weight $\mathrm{F}_{6,25}=0.75, \mathrm{p}=0.62$, length $\mathrm{F}_{6,25}=0.39, \mathrm{p}=0.88$ ) or to $\mathrm{EOD}$ amplitude (GLM multivariate tests; weight $\mathrm{F}_{2,29}=0.76, \mathrm{p}=0.48$, length $\mathrm{F}_{2,29}=1.25 \mathrm{p}=0.30$ ).

\section{Eigenmannia $\mathrm{cf}$ virescens}

11-KT implants elevated baseline amplitude of $E$. cf. virescens (LSD post-hoc: 11-KT $\mathrm{p}<0.01, \mathrm{~T} p=0.24$; Fig. $2 \mathrm{E}$ ). Body weight related positively with EOD amplitude (GLM multivariate tests: weight $\mathrm{F}_{1,23}=121.01, \mathrm{p}<0.01$ ), but not EOD duration (GLM multivariate tests: weight $\left.\mathrm{F}_{1,23}=0.601, \mathrm{p}=0.45\right)$.

Apteronotus leptorhynchus

Androgens had no effect on EOD amplitude or total duration in A. leptorhynchus (GLM univariate tests: amplitude $\mathrm{F}_{1,12}=0.307, \mathrm{p}=0.74$; duration $\mathrm{F}_{2,12}=0.177, \mathrm{p}=0.84$ : Fig $2 \mathrm{G}$, H). However, while the duration of either EOD phase did not change significantly in response to androgen implants (GLM univariate tests: $\mathrm{P} 1 \mathrm{~F}_{2,12}=3.59, \mathrm{p}=0.06 ; \mathrm{p} 2 \mathrm{~F}_{2}$, ${ }_{12}=0.27, \mathrm{p}=0.77$ ), 11-KT increased duration of P1 (post-hoc LSD: $11-\mathrm{KT} \mathrm{p}=0.04, \mathrm{~T}$ $\mathrm{p}=0.93$ ). Neither body length, nor weight, significantly predicted baseline amplitude (univariate tests: weight $\mathrm{F}_{1,12}=0.47, \mathrm{p}=0.51$; length $\mathrm{F}_{1,12}=0.29, \mathrm{p}=0.60$ ) or duration (univariate tests: weight $\mathrm{F}_{1,12}=0.06, \mathrm{p}=0.85$; length $\mathrm{F}_{1,12}=0.69, \mathrm{p}=0.42$ ). 


\section{Androgen effects on $\alpha$-MSH challenge}

\section{Gymnotus carapo}

$\alpha-\mathrm{MSH}$ injections significantly enhanced P2 and total peak-to-peak amplitude and duration (GLM multivariate tests: amplitude $\mathrm{F}_{20,200}=2.26, \mathrm{p}<0.01$; duration $\mathrm{F}_{20,180}=1.63$, $\mathrm{p}=0.05$, Table 2). However, androgens did not affect response of EOD duration to $\alpha$ MSH (GLM multivariate tests: duration $\mathrm{F}_{8,32}=1.04, \mathrm{p}=0.43$, Fig. 3B). Androgen implants enhanced the effect of $\alpha-\mathrm{MSH}$ injection on amplitudes of P2 and P3 (univariate tests: $\mathrm{P} 2 \mathrm{p}=0.06$; $\mathrm{P} 3=0.04$ ), but not total amplitude (univariate tests: $\mathrm{F}_{2,18}=1.00, \mathrm{p}=0.39$; Fig 3A). Neither body length, nor weight, significantly predicted baseline amplitude (GLM multivariate tests: weight $\mathrm{F}_{4,4}=1.28, \mathrm{p}=0.41$; length $\mathrm{F}_{4,4}=0.08, \mathrm{p}=0.99$ ) or duration (GLM multivariate tests: weight $\mathrm{F}_{4,4}=1.82, \mathrm{p}=0.29$; length $\mathrm{F}_{4,4}=5.04, \mathrm{p}=0.07$ ).

\section{Brachyhypopomus gauderio}

As reported previously (Stoddard et al., 2006), $\alpha-\mathrm{MSH}$ enhanced both total duration $(\mathrm{t}=-$ 15.33, $\mathrm{df}=17, \mathrm{p}<0.01)$ and amplitude $(\mathrm{t}=7.47, \mathrm{df}=17, \mathrm{p}<0.01)$. Both $\mathrm{T}$ and 11-KT enhanced the response of EOD duration to $\alpha$-MSH (Fig. 3D), but only $11-\mathrm{KT}$ enhanced the response of EOD amplitude to $\alpha$-MSH (Fig. 3C). Neither body length nor weight predicted the magnitude of $\alpha-\mathrm{MSH}$ injection response to implant treatments (GLM multivariate tests: weight $\mathrm{F}_{2,12}=0.41, \mathrm{p}=0.67$; length $\mathrm{F}_{2,12}=0.16, \mathrm{p}=0.86$ ). While both androgen implants increased duration response to $\alpha$-MSH (Fig. 3D; post-hoc LSD; $11-$ $\mathrm{KT} \mathrm{p}<0.01$; and $\mathrm{T} \mathrm{p}=0.03$ ), only $11-\mathrm{KT}$ increased the responsive of amplitude to $\alpha$-MSH (Fig. 3C; post-hoc LSD: 11-KT p=0.02; T p=0.78). Also, only 11-KT significantly 
enhanced P2 duration (post-hoc LSD: 11-KT $\mathrm{p}<0.01 ; \mathrm{T} p=0.10$ ), while neither implant enhanced P1 duration (post-hoc LSD: $11-\mathrm{KT} p=0.66$; $\mathrm{T} p=0.94$; data not shown.)

\section{Eigenmannia cf. virescens}

Compared to saline injections, $\alpha-\mathrm{MSH}$ enhanced amplitude $(\mathrm{t}=10.02, \mathrm{df}=26, \mathrm{p}<0.01)$, but not duration $(\mathrm{t}=0.02, \mathrm{df}=256, \mathrm{p}=0.98)$ in E. virescens. Implant type had a significant effect on EOD duration, but not amplitude response to $\alpha$-MSH (GLM univariate tests: amplitude $\mathrm{F}_{2,23}=1.17, \mathrm{p}=0.33$; duration $\mathrm{F}_{2,23}=6.62, \mathrm{p}<0.01$; Fig. $\left.3 \mathrm{E}, \mathrm{F}\right)$. Relative to blank implants, duration was higher in 11-KT implanted fish (post-hoc LSD: 11-KT $\mathrm{p}<0.01$, $\mathrm{T}=0.70$ ). There was a significant interaction effect between response to $\alpha$-MSH injection and implant type on amplitude, but not duration (GLM multivariate tests; amplitude $\mathrm{F}_{2,23}=6.19, \mathrm{p}<0.01$, duration $\left.\mathrm{F}_{2,23}=2.23, \mathrm{p}=0.13\right)$. Relative to blank implants, 11-KT increased amplitude responsiveness to $\alpha-\mathrm{MSH}$ injections (post-hoc LSD: amplitude $p=0.03$, Fig 3E). $T$ had no effect on melanocortin response of either amplitude or duration (post-hoc LSD: amplitude $\mathrm{p}=0.23$; duration $\mathrm{p}=0.7$; Fig. $3 \mathrm{E}, \mathrm{F}$ ). Weight did not predict the magnitude of $\alpha-\mathrm{MSH}$ injection amplitude or duration response to implant treatments (GLM multivariate tests: amplitude $\mathrm{F}_{1,23}=1.26, \mathrm{p}=0.27$, duration $\mathrm{F}_{2,23}=0.35, \mathrm{p}=0.6$ ).

\section{Apteronotus leptorhynchus}

Relative to saline, $\alpha-\mathrm{MSH}$ injections had no effect on A. leptorhynchus amplitude or total duration (paired t-test: amplitude $\mathrm{t}=0.30, \mathrm{df}=16, \mathrm{p}=0.3$; duration $\mathrm{t}=1.41, \mathrm{df}=16, \mathrm{p}=0.18$ ). Overall, neither implant had a significant affect on $\alpha$-MSH responsiveness of amplitude 
or total duration (GLM multivariate tests: amplitude $\mathrm{F}_{2,13}=0.38, \mathrm{p}=0.5$, Fig $3 \mathrm{G}$; total duration $\mathrm{F}_{2,12}=1.66, \mathrm{p}=0.2$, Fig. $3 \mathrm{H}$ ).

\section{Discussion}

My findings demonstrate that the extent of hormonally-mediated communication signal plasticity in the Gymnotiformes order reflects the species-specific social systems. The most territorial and socially aggressive taxa, A. leptorhynchus and G. carapo, have the most stable signals with the least capacity for hormonally-mediated signal plasticity, while the highly gregarious $E$. cf. virescens exhibit hormonally-mediated plasticity in EOD amplitude, yet retain stability of EOD duration. The short-lived exploded lek species, B. gauderio, has the least stable signal and the most hormonally-mediated plasticity of both EOD amplitude and duration (Fig. 4).

Apteronotus leptorhynchus does not modulate its EOD waveform either in a circadian manner or during social interactions (Goldina et al., 2006), nor does it respond to short-term androgen implants or melanocortin injections (Fig. 4). I was surprised that neither T nor 11-KT induced a change in A. leptorhynchus amplitude or duration, since multiple studies have shown that EOD frequency, pulse duration and chirp production are modulated by 11-KT and T over longer time scales (Dunlap et al., 1998; Schaefer and Zakon, 1996). The quick-acting silicone implants I used release most of their steroid within the first five days, which produces dramatic enhancements of the waveforms of $B$.

gauderio evident on the $2^{\text {nd }}$ and $3^{\text {rd }}$ days post-treatment (Allee et al., 2009; Goldina et al., 2011). In previous studies of androgen effects on signals of gymnotiforms with wavetype EODs, signal changes appeared after two weeks of treatment. Because frequency 
change in electric fish with narrow-band wave-type EODs requires a coordinated modulation of the central and peripheral nervous systems (McAnelly and Zakon, 2000; Zakon and Smith, 2009), a longer exposure to androgens might be necessary to activate signal changes in wave-fish. Apteronotids, which appear basal to the other gymnotiforms (Arnegard et al., 2010) might never have gained the ability to rapidly alter their waveforms. Alternately, apteronotids might have lost the ability to respond rapidly to modulate EOD waveform - apteronotids have a derived electric organ comprised of motoneurons, in contrast to the rest of the clade, with myogenically derived electrocytes (Bennett, 1971).

I observed intermediate signal plasticity in G. carapo and E. cf. virescens. In both species 11-KT and $\alpha-\mathrm{MSH}$ increased signal amplitude. In G. carapo 11-KT and $\alpha-\mathrm{MSH}$ also enhanced waveform duration (Fig. 4). However, I did not observe waveform enhancement by $\mathrm{T}$ in either species as previously described (Dunlap and Zakon, 1998; Silva et al., 2002). As in A. leptorhynchus, the disparity between my findings and previous studies might be attributable to different time courses of steroid action. Interestingly, 11-KT increased the waveforms of both species (Table 2, Fig. 4), suggesting that (1) 11-KT is more effective in modulating signal plasticity, and (2) 11-KT and $\mathrm{T}$ have different functions in EOD modulation.

Both, A. leptorhynchus and G. carapo are long-lived, highly aggressive and territorial species. By keeping their signal waveforms insensitive to short-term hormonal fluctuations, these species can maintain stereotyped signals to aid in individual recognition. Similarly, by maintaining hormonal sensitivity in other aspects of signal production, (discharge frequency in A. leptorhynchus, differential phase duration or 
amplitude in the G. carapo), individuals can respond to rapid changes in their social environment without compromising identification by neighbors and mates. $A$. leptorhynchus waveform contains species-specific information and might be used for conspecific and mate recognition, while EOD frequency induces approach and chirp production (Fugere and Krahe, 2010). Thus, while EOD frequency is androgendependent, reflects individual sex, reproductive stage and social status, and is used in varying social contexts (i.e. JAR, chirps, rises) (Dunlap and Larkins-Ford, 2003a, b; Tallarovic and Zakon, 2005; Zakon et al., 2002; Zakon and Smith, 2002), EOD amplitude is a static parameter that might aid in individual and species recognition in habitats containing multiple sympatric species with overlapping frequencies (Crampton and Albert, 2006; Fugere and Krahe, 2010; Turner et al., 2007). While very little is known about the functional significance of waveform modulations in G. carapo, few studies have shown that G. carapo modulate EOD rate during aggressive interactions (BlackCleworth, 1970; McGregor and Westby, 1992). Unfortunately, no studies have examined whether differential phase modulation communicates social status, sex, or identity in Gymnotus spp. Unlike adults with multiphasic waveforms, larval and juvenile Gymnotus only produce the P1 phase (Crampton and Hopkins, 2005). Since P1 amplitude is the only phase sensitive to 11-KT (Table 2), relative amplitude of P1 might permit identification of developmental stage conspecifics. In response to melanocortins, P2 amplitude was the most plastic parameter of the whole waveform, while the other three phases remained static (Table 2). In Gymnotus, EOD duration might be key to discrimination of individuals or possibly species where multiple species occur in syntopy (Crampton et al., 2011). 
Greater EOD amplitudes have been suggested to be a sign of dominance in Eigenmannia (Zakon and Smith, 2009), and to serve as an attractive trait for female $B$. gauderio which prefer large males with greater amplitude and duration EODs (Curtis and Stoddard, 2003). By increasing signal amplitude, individuals boost the power of their signals, thus increasing active signal space (detectability range), as well as potentially enhancing perception of their size/dominance by potential mates and competitors (Stoddard and Salazar, 2011). Androgens and melanocortins increase signal power in $B$. gauderio (Allee et al., 2009, Goldina et al., 2006), which might be beneficial in cases of social instability, during the beginning of the breeding season when territories and dominance hierarchies are being established and males are looking for prospective mates. Interestingly, while B. gauderio are highly responsive to androgen and melanocortins in every aspect of the waveform, the duration of $\mathrm{P} 1$ is less responsive to melanocortins and the combined effect of melanocortins and androgens. Thus, the stereotypy of P1 is likely used for species-recognition, while $\mathrm{P} 2$ plasticity is used for male-male competition and mate attraction (Curtis and Stoddard, 2003; Franchina et al., 2001; Stoddard, 2010). In E. cf. virescens, EOD duration is a completely static signal, while amplitude is responsive to androgens and melanocortins (but with no interaction, Fig. 4). Eigenmannia is the most gregarious of all gymnotiform genera; individuals form stable networks and adjust their EOD frequencies to reflect intra-sexual social hierarchies while preventing jamming (Hagedorn and Heiligenberg, 1985; Oestreich and Zakon, 2005). Thus, Eigenmannia modify their frequency and signal amplitude, leaving only duration of their signal static. Interestingly, Sternopygus macrurus, a less gregarious Sternopygid than Eigenmannia, 
does change EOD pulse duration in response to melanocortins (Markham et al., 2009b; Zakon et al., 1990).

\section{Phenotypic independence and integration as a potential mechanism for generating EOD stereotypy and plasticity.}

Hormones integrate peripheral and central nervous system structures with environmental and social changes to produce and regulate dynamic communication signals. The extent to which hormones can mediate behavioral traits can enhance or constrain evolution of communication signals and consequently social systems. This mediation can range from phenotypic integration in which there is a direct relationship of a hormone on the expression of a phenotypic trait to phenotypic independence, where the phenotypic trait is decoupled from the influence of hormone (Ketterson et al., 2009). Thus, under phenotypic integration, I expect to see a correlation between hormone treatments and EOD modulations, while under phenotypic independence the EOD might be insensitive to hormonal fluctuations (Ketterson et al., 2009).

Evolution of dynamic signals requires development of structures to generate these signals in the signalers, as well as sensory and cognitive structures needed by receivers to discriminate among these signals. In the African mormyriforms, ability to generate complex, multiphasic EODs evolved in combination with a suite of traits: electrocytes with flexible innervation patterns, a broad spatial distribution of electroreceptors on the skin, and a differentiation of the brain region needed to discriminate among complex signals in the receivers (Carlson et al., 2011; Sullivan et al., 2000). The signals of one such species, Brienomyrus brachyistius, are known to reflect social structure, wherein 
dominant males produce the longest EOD durations and highest 11-KT levels (Carlson et al., 2000). Androgen hormone treatment has been shown to cause structural changes in the electrocytes (Bass and Volman, 1987; Freedman et al., 1989; Hagedorn and Carr, 1985) and social interaction and cortisol treatment have stimulated cell proliferation within electric communication centers of the brains of A. leptorhynchus and B. gauderio (Dunlap et al., 2006; Dunlap et al., 2011).

My data suggest the presence of both patterns between and within gymnotiform species (Fig. 4). In A. leptorhynchus, a highly territorial and aggressive species, complete phenotypic independence of short-term signaling plasticity is evident in the lack of waveform response to any hormone treatment (Fig. 4). An interesting finding in my study is the partial effect of T on the EOD waveform of $B$. gauderio and complete $\mathrm{T}$ insensitivity in the other species (Fig. 4). Since 11-KT is the dominant androgen in teleosts, it is commonly found that $\mathrm{T}$ levels are relatively similar (if not higher in females) in both sexes (Borg, 1994). Behavioral insensitivity to testosterone has been suggested as an adaptation in species with male parental care to prevent high T levels from compromising parental behavior (Lynn, 2008; Lynn et al., 2005). However of the species tested in this study, only G. carapo exhibits parental behavior (Crampton and Hopkins, 2005). Yet, all four species are, to some extent, insensitive to T (in B. gauderio second phase duration, but not amplitude, is enhanced by T). A short-lived species such as $B$. gauderio might invest more energy in signal production and elaboration through enhanced hormone sensitivity than a long-lived species such as G. carapo. Sensitivity to melanocortins, androgens, and the combined melanocortin-androgen treatments result in 
the greatest waveform enhancement and thus phenotypic integration in B. gauderio (Gavassa et al., 2011).

The relationship between hormone and signal modulation is multivariate, and independence or integration can occur in all or just one level of the signal response, (Ketterson et al., 2009), differentially affecting multiple signal parameters. For example, EOD rate originates in the medullary pacemaker nucleus and is regulated by androgens in both A. leptorhynchus and E. virescens (Dunlap et al., 1998; Dunlap and Zakon, 1998; Schaefer and Zakon, 1996; Zakon, 1999). Intermediate phenotypic integration between hormones and EOD waveform seems plausible in E. virescens and G. carapo, where $G$. carapo is sensitive to $11-\mathrm{KT}$ and $\alpha-\mathrm{MSH}$ treatments separately, but androgens only partially enhance EOD response to melanocortin treatments (Table 2 and Fig. 4). The EOD amplitude of E. virescens, on the other hand, responds to 11-KT, $\alpha-\mathrm{MSH}$, and 11KT further enhances amplitude response to melanocortins, but duration is insensitive to either hormone treatment (Figure 4). Through partial phenotypic integration individuals might be able to maintain certain aspects of their signal static and easily recognizable by conspecifics (i.e. duration in E. cf virescens, P1 of B. gauderio, P1 and P3 of G. carapo), while responding to changes in social environments using the dynamic traits (Figure 4).

\section{Conclusion}

I examined the role of short-term hormone regulation in generating communication signals, and found that response of the signal to steroid and peptide hormones reflects species-specific sociality levels. By evolving tissues that are differentially sensitive to endocrine signals, animals can adapt to the social challenges of their respective 
environments. Because of their nocturnal habits, relatively little is known about the natural history of gymnotiform electric fish. In addition to expanding the knowledge of electric fish social systems and reproductive behavior, further studies examining the possible differential expression of hormone receptors and enzymes regulating hormone action at relevant target sites are needed to understand the ultimate and proximate mechanisms leading to dynamic signaling. Equally important would be studies examining the meaning of signal enhancements to the animals themselves. Does enhancing signal amplitude or duration mean the same thing to a territorial, solitary animal as it does to a more gregarious animal?

\section{Acknowledgements}

Financial support and equipment were provided by NSF grant IOS-0956603 (PKS), NIH grants MBRS GM08205 (PKS) and MBRS graduate fellowship and Graduate Student Association Research Grant (AG). Susan Allee assisted with initial experiments and Sat Gavassa helped collect the data examining the role of androgen implants on B. gauderio waveform. I thank Carol Curtis, James Roach and Joel Baez for help with fish care and Paulette Johnson for help with statistical analyses. 


\section{References}

Albert, J.S., Crampton, W.G.R., 2005. Diversity and phylogeny of neotropical electric fishes (Gymnotiformes), in: Hopkins, C.D., Bullock, T.H., Fay, R.R., Popper, A.N. (Eds.), Electroreception, 1 ed. Springer, pp. 360-409.

Allee, S.J., Markham, M.R., Stoddard, P.K., 2009. Androgens enhance plasticity of an electric communication signal in female knifefish, Brachyhypopomus pinnicaudatus. Hormones and Behavior 56, 264-273.

Arnegard, M.E., Zwicki, D.J., Lu, Y., Zakon, H.H., 2010. Old gene duplication facilitates origin and diversification of an innovative communication system twice. PNAS 107, 22172-22177.

Bass, A.H., Volman, S.F., 1987. From behavior to membranes: testosterone-induced changes in action potential duration in electric organs. Proc.Natl. Acad. Sci. U.S.A. 84, 9295-9298.

Bennett, M.V.L., 1971. Electric organs, in: Hoar, W.S., Randall, D.J. (Eds.), Fish Physiology. Academic Press, London, pp. 347-491.

Berg, K., Delgado, S., Okawa, R., Beissinger, S.R., 2011. Contact calls are used for individual mate recognition in free-ranging green-rumped parrotlets, Forpus passerinus. Animal Behaviour 81, 241-248.

Black-Cleworth, P., 1970. The role of electrical discharges in the non-reproductive social behavior of Gymnotus carapo (Gymnotidae, Pisces). Animal Behavior Monographs 3, 177.

Bond, A.B., Kamil, A.C., Balda, R.P., 2003. Social complexity and transitive inference in corvids. Animal Behaviour 65, 479-487.

Borg, B., 1994. Androgens in teleost fishes. Comparative Biochemistry and Physiology 109C, 219-245.

Brain, P.F., Evans, A.E., 1977. Acute influences of some ACTH-related peptides on fighting and adrenocortical activity in male laboratory mice. Pharmacology Biochemistry \& Behavior 7, 425-433.

Caputi, A.A., Carlson, B.A., Macadar, O., 2005. Electric organs and their control, in: Bullock, T.H., Hopkins, C.D., Popper, A.N., Fay, R.R. (Eds.), Electroreception. Springer, New York, pp. 411-451. 
Carlson, B.A., Hasan, S.M., Hollmann, M., Miller, D.B., Harmon, L.J., Arnegard, M.E., 2011. Brain evolution triggers increased diversification of electric fishes. Science 332, 583-586.

Carlson, B.A., Hopkins, C.D., Thomas, P., 2000. Androgen correlates of socially induced changes in the electric organ discharge waveform of a mormyrid fish. Hormones and Behavior 38, 177-186.

Crampton, W.G.R., 2011. An ecological perspective on diversity and distributions, in: Albert, J.S., Reis, R.E. (Eds.), Historical biogeography of neotropical freshwater fishes. University of California Press, Berkeley, pp. 165-189.

Crampton, W.G.R., Albert, J.S., 2006. Evolution of electric signal diversity in gymnotiform fishes, in: Ladich, F., Collin, S.P., Moller, P., Kapoor, B.G. (Eds.), Communication in Fishes. Science Publishers, Enfield, NH, pp. 647-731.

Crampton, W.G.R., Hopkins, C.D., 2005. Nesting and paternal care in the weakly electric fish Gymnotus (Gymnotiformes: Gymnotidae) with descriptions of larval and adult electric organ discharges of two species. Copeia 1, 48-60.

Crampton, W.G.R., Lovejoy, N.R., Waddell, J.C., 2011. Reproductive character displacement and signal ontogeny in a sympatric assemblage of electric fish. Evolution $65,1650-1666$.

Crawford, J.D., 1992. Individual and sex specificity in the electric organ discharges of breeding mormyrid fish (Pollimyrus isidori). Journal of Experimental Biology 164, 79102.

Curtis, C.C., Stoddard, P.K., 2003. Mate preference in female electric fish, Brachyhypomus pinnicaudatus. Animal Behaviour 66, 329-336.

Dunlap, K.D., 2002a. Hormonal and body correlates of electrocommunication behavior during dyadic interactions in a weakly electric fish, Apteronotus leptorhynchus. Hormones and Behavior 41, 187-194.

Dunlap, K.D., Castellano, J.F., Prendaj, E., 2006. Social interaction and cortisol treatment increase cell addition and radial glial fiber density in the diencephalic peroventricular zone of adult electric fish, Apteronotus leptorhynchus. Hormones and Behavior 50, 1017.

Dunlap, K.D., Larkins-Ford, J., 2003a. Diversity in the structure of electrocommunication signals with a genus of electric fish, Apteronotus. Journal of Comparative Physiology A $189,153-161$. 
Dunlap, K.D., Larkins-Ford, J., 2003b. Production of aggressive electrocommunication signals to progressively realistic social stimuli in male Apteronotus leptorhynchus. Ethology 109, 243-258.

Dunlap, K.D., Pelczar, Patricia L., Knapp, Rosemarry, 2002b. Social interactions and cortisol treatment increase the production of aggressive electrocommunication signals in male electric fish, Apteronotus leptorynchus. Hormones and Behavior 42, 97-108.

Dunlap, K.D., Silva, A., Chung, M., 2011. Environmental complexity, seasonality and brain cell proliferation in a weakly electric fish, Brachyhypopomus gauderio. Journal of Experimental Biology 214, 794-805.

Dunlap, K.D., Thomas, P., Zakon, H.H., 1998. Diversity of sexual dimorphism in electrocommunication signals and its androgen regulation in a genus of electric fish, Apteronotus. Journal of Comparative Physiology A 183, 77-86.

Dunlap, K.D., Zakon, H.H., 1998. Behavioral actions of androgens and androgen receptor expression in the electrocommunication system of an electric fish, Eigenmannia virescens. Hormones and Behavior 3, 30-38.

Falls, B.J., 1982. Individual recognition by sounds in birds, in: Kroodsma, D.E., Miller, E.H., Ouellet, H. (Eds.), Acoustic Communication in Birds: Song Learning and its Consequences. Academic Press, New York, pp. 237-278.

Few, W.P., Zakon, H.H., 2001. Androgens alter electric organ discharge pulse duration despite stability in electric organ discharge frequency. Hormones and Behavior 40, 434442.

Franchina, C.R., Salazar, V.L., Volmar, C.-H., Stoddard, P.K., 2001. Plasticity of the electric organ discharge waveform of male Brachyhypopomus pinnicaudatus. II. Social effects. Journal of Comparative Physiology A 187, 45-52.

Franchina, C.R., Stoddard, P.K., 1998. Plasticity of the electric organ discharge waveform of the electric fish Brachyhypopomus pinnicaudatus I. Quantification of daynight changes. Journal of Comparative Physiology A 183, 759-768.

Freedman, E.G., Olyarchuk, J., Marchaterre, M.A., Bass, A.H., 1989. A temporal analysis of testosterone-induced changes in electric organs and electric organ discharges of mormyrid fishes. Journal of Neurobiology 20, 619-634.

Friedman, M.A., Hopkins, C.D., 1996. Tracking individual mormyrid electric fish in the field using electric organ discharge waveforms. Animal Behavior 51, 391-407. 
Fugere, V., Krahe, R., 2010. Electric signals and species recognition in the wave-type gymnotiform fish Apteronotus leptorhynchus. Journal of Experimental Biology 213, 225236.

Gavassa, S., Silva, A., Stoddard, P.K., 2011. Tight hormonal phenotypic integration ensures honesty of the electric signal of male and female Brachyhypopomus gauderio. Hormones and Behavior, 420-426.

Gerhardt, H.C., 1991. Female mate choice in treefrogs: static and dynamic acoustic criteria. Animal Behaviour 42, 615-635.

Goldina, A., Gavassa, S., Stoddard, P.K., 2011. Testosterone and 11-Ketotestosterone have different regulatory effects on electric communication signals of male Brachyhypopomus gauderio. Hormones and Behavior 60, 139-147.

Gonzalez, M.I., Vaziri, S., Wilson, C.A., 1996. Behavioral effects of alpha-MSH and $\mathrm{MCH}$ after central administration in the female rat. Peptides 17, 171-177.

Hagedorn, M., Carr, C., 1985. Single electrocytes produce a sexually dimorphic signal in South American electric fish, Hypopomus occidentalis (Gymnotiformes, Hypopomidae). Journal of Comparative Physiology A 156, 511-523.

Hagedorn, M., Heiligenberg, W., 1985. Court and spark:electric signals in the courtship and mating of gymnotid fish. Animal Behaviour 33, 254-265.

Hagedorn, M., Zelick, R., 1989. Relative dominance among males is expressed in the electric organ discharge characteristics of a weakly electric fish. Animal Behaviour 38, $520-525$.

Hopkins, C.D., 1988. Neuroethology of electric communication. Annual Reviews in Neuroscience 11, 497-535.

Hupe, G., Lewis, J., 2008. Electrocommunication signals in free swimming brown ghost knifefish, Apteronotus leptorhynchus. The Journal of Experimental Biology 211, 16571667.

Jouventin, P., Aubin, T., Lengagne, T., 1999. Finding a parent in a king penguin colony: the acoustic system of individual recognition. Animal Behaviour 57, 1175-1183.

Ketterson, E.D., Atwell, J.W., McGlothlin, J.W., 2009. Phenotypic integration and independence: hormones, performance, and response to environmental change. Integrative and Comparative Biology 49, 365-379.

Kirschbaum, F., Schugardt, C., 2002. Reproductive strategies and developmental aspects in mormyrid and gymnotiform fishes. Journal of Physiology-Paris 96. 
Kirschbaum, F., Schwassmann, H.O., 2008. Ontogeny and evolution of electric organs in gymnotiform fish. Journal of Physiology-Paris 102, 347-356.

Lynn, S.E., 2008. Behavioral insensitivity to testosterone: Why and how does testosterone alter paternal and aggressive behavior in some avian species but not others? General and Comparative Endocrinology 157, 233-240.

Lynn, S.E., Walker, B.G., Wingfield, J.C., 2005. A phylogenitically controlled test of hypotheses for behavioral insensitivity to testosterone in birds. Hormones and Behavior 47, 170-177.

Mammen, D.L., Nowicki, S., 1981. Individual differences and within-flock convergence in chickadee calls. Behavioral Ecology and Sociobiology 9, 179-186.

Markham, M.R., Allee, S., Goldina, A., Stoddard, P.K., 2009a. Melanocortins regulate the electric waveforms of gymnotiform electric fish. Hormones and Behavior 55, 306313.

Markham, M.R., McAnelly, L.M., Stoddard, P.K., Zakon, H.H., 2009b. Circadian and social cues regulate ion channel trafficking. PLOS Biology 7, 1-14.

Markham, M.R., Stoddard, P.K., 2005. Adrenocorticotropic hormone enhances the masculinity of an electric communication signal by modulating the waveform and timing of action potentials within individual cells. Journal of Neuroscience 25, 8746-8754.

May-Collado, L.J., Agnarsson, I., Wartzok, D., 2007. Phylogenetic review of tonal sound production in whales in relation to sociality. BMC Evolutionary Biology 7, 1-20.

McAnelly, L.M., Zakon, H.H., 2000. Coregulation of voltage-dependent kinetics of $\mathrm{Na}^{+}$ and $\mathrm{K}^{+}$currents in electric organ. The journal of Neuroscience 20, 3408-3414.

McGregor, P.K., 1993. Signalling in territorial systems: a context for individual identification, ranging and eavesdropping. Philosophical Transactions of the Royal Society of London, Series B 340, 237-244.

McGregor, P.K., Westby, G.W.M., 1992. Discrimination of individually characteristic electric organ discharges by a weakly electric fish. Animal Behaviour 43, 977-986.

Miranda, M., Silva, A.C., Stoddard, P.K., 2008. Use of space as an indicator of social behavior and breeding systems in the gymnotiform electric fish Brachyhypopomus pinnicaudatus. Environmental Biology of Fishes 82, 379-389.

Moller, P., 1995. Locomotor and electric organ discharge rhythms, Electric fishes: history and behavior. Chapman \& Hall, London, pp. 345-360. 
Oestreich, J., Zakon, H.H., 2005. Species-specific differences in sensorimotor adaptation are correlated with differences in social structure. Journal of Comparative Physiology A $191,845-856$.

Paintner, S., Kramer, B., 2003. Electrosensory basis for individual recognition in a weakly electric mormyrid fish, Pollimyrus adspersus (Gunther, 1866). Behavioral Ecology and Sociobiology 55, 197-208.

Pereira, A., Rodriguez-Cattaneo, A., Castello, M., Caputi, A.A., 2007. Post-natal development of the electromotor system in a pulse gymnotiform electric fish. Journal of Experimental Biology 210, 800-814.

Pouso, P., Quintana, L., Bolatto, C., Silva, A., 2010. Brain androgen receptor expression correlates with seasonal changes in the behavior of a weakly electric fish, Brachyhypopomus gauderio. Hormones and Behavior 58, 729-736.

Salazar, V.L., Stoddard, P.K., 2009. Social competition affects electric signal plasticity and steroid levels in the gymnotiform fish Brachyhypopomus gauderio. Hormones and Behavior 56, 399-409.

Schaefer, J.E., Zakon, H.H., 1996. Opposing actions of androgen and estrogen on in vitro firing frequency of neuronal oscillators in the electromotor system. Journal of Neuroscience 16, 2860-2868.

Silva, A., Quintana, L., Ardanaz, J.L., Macadar, O., 2002. Environmental and hormonal influences upon EOD waveform in gymnotiform pulse fish. Journal of Physiology-Paris 96, 473-484.

Stoddard, P.K., 1996. Vocal recognition of neighbors by territorial passerines, in: Kroodsma, D.E., Miller, E.H. (Eds.), Ecology and evolution of acoustic communication in birds. Comstock Publishing Associates, Ithaca, pp. 356-374.

Stoddard, P.K., 2010. Electric signals, in: Breed, M., Moore, J. (Eds.), Encyclopedia of animal behavior. Elsevier.

Stoddard, P.K., Markham, M.R., Salazar, V.L., 2003. Serotonin modulates the electric waveform of the gymnotiform electric fish, Brachyhypopomus pinnicaudatus. Journal of Experimental Biology 206, 1353-1362.

Stoddard, P.K., Markham, M.R., Salazar, V.L., Allee, S., 2007. Circadian rhythms in electric waveform structure and rate in the electric fish Brachyhypopomus pinnicaudatus. Physiology \& Behavior 90, 11-20.

Stoddard, P.K., Salazar, V.L., 2011. Energetic cost of communication. Journal of Experimental Biology 214, 200-205. 
Stoddard, P.K., Zakon, H.H., Markham, M.R., McAnelly, L., 2006. Regulation and modulation of electric waveforms in gymnotiform electric fish. Journal of Comparative Physiology A 192, 613-624.

Sullivan, J.P., Lavoue, S., Hopkins, C.D., 2000. Molecular systematics of the African electric fishes (Mormyridea: Teleostei) and a model for the evolution of their electric organs. Journal of Experimental Biology 203, 665-683.

Szabo, T., 1974. Anatomy of the specialized lateral line organs of electroreception, in: Fessard, A. (Ed.), Handbook of Sensory Physiology. Springer-Verlag, Berlin, pp. 13-58.

Tallarovic, S.K., Zakon, H.H., 2005. Electric organ discharge frequency jamming during social interactions in brown ghost knifefish, Apteronotus leptorhynchus. Animal Behaviour 70, 1355-1365.

Templeton, C.N., Greene, E., Davis, K., 2005. Allometry of alarm calls: black-capped chickadees encode information about predator size. Science 308, 1934-1937.

Turner, C.R., Derylo, M., de Santana, C.D., Alves-Gomes, J.A., Smith, G.T., 2007. Phylogenetic comparative analysis of electric communication signals in ghost knifefishes (Gymnotiformes: Apteronotidae). Journal of Experimental Biology 210, 4104-4122.

Westby, G.W.M., 1988. The ecology, discharge diversity and predatory behaviour of gymnotiform electric fish in the coastal streams of French Guiana. Behavioral Ecology and Sociobiology 22, 341-354.

Wikberg, J.E.S., Muceniece, R., Mandrika, I., Prusis, P., Lindblom, J., Post, C., Skottner, A., 2000. New aspects on the melanocortins and their receptors. Pharmacological Research 42, 393-420.

Zakon, H.H., Dunlap, D. K., 1999. Sex steroids and communication signals in electric fish: a tale of two species. Brain, Behavior and Evolution 54, 61-69.

Zakon, H.H., McAnelly, L.M., Smith, G.T., Dunlap, K.D., Lopreato Gregory F, Oestreich, J., Few, W.P., 1999. Plasticity of the electric organ discharge: implications for the regulation of ionic currents. The Journal of Experimental Biology 202, 1409-1416.

Zakon, H.H., Oestreich, J., Tallarovic, S.K., Triefenbach, F., 2002. EOD modulations of brown ghost electric fish: JARs, chirps, rises and dips. Journal of Physiology-Paris 96, 451-458.

Zakon, H.H., Smith, G.T., 2002. Weakly electric fish: neurobiology, and neuroendocrinology. Hormones, Brain and Behavior 2, 349-374. 
Zakon, H.H., Smith, G.T., 2009. Weakly electric fish: behavior, neurobiology, and neuroendocrinology, in: Pfaff, D., Arnold, A., Etgen, A., Fahrbach, S., Rubin, R. (Eds.), Hormones, brain and behavior, 2 ed. Academic press, Amsterdam, pp. 611-638.

Zakon, H.H., Yan, H.-Y., Thomas, P., 1990. Human chorionic gonadotropin-induced shifts in the electrosensory system of the weakly electric fish, Sternopygus. Journal of Neurobiology 21, 826-833. 
Table 1. Summary of gymnotiform sociality forms.

\begin{tabular}{|c|c|c|c|c|}
\hline & \multicolumn{4}{|c|}{ Behavior } \\
\hline Species & $\begin{array}{c}\text { Sociality } \\
\text { (group aggregation) }\end{array}$ & $\begin{array}{c}\text { Aggression } \\
\text { levels }\end{array}$ & $\begin{array}{l}\text { Parental } \\
\text { behavior }\end{array}$ & $\begin{array}{l}\text { Mating } \\
\text { strategy }\end{array}$ \\
\hline Gymnotus carapo & Solitary ${ }^{1,2}$ & High $^{1}$ & Paternal ${ }^{3,4}$ & Polygynous ${ }^{3,4}$ \\
\hline $\begin{array}{c}\text { Brachyhypopomus } \\
\text { gauderio }\end{array}$ & $\begin{array}{c}\text { Loose } \\
\text { aggregations }\end{array}$ & $\begin{array}{c}\text { Medium-low } \\
9\end{array}$ & Absent ${ }^{11}$ & $\begin{array}{l}\text { Exploded lek } \\
\text { polygyny }^{5}\end{array}$ \\
\hline $\begin{array}{c}\text { Eigenmannia } \mathrm{cf} . \\
\text { virescens }\end{array}$ & Shoaling ${ }^{7,8}$ & $\begin{array}{l}\text { Medium-low } \\
11\end{array}$ & Absent ${ }^{4}$ & Polygynous ${ }^{7}$ \\
\hline $\begin{array}{l}\text { Apteronotus } \\
\text { leptorhynchus }\end{array}$ & $\begin{array}{c}\text { Solitary / loose } \\
\text { aggregations }\end{array}$ & High $^{11}$ & Absent ${ }^{4,5}$ & Polygynous $^{7}$ \\
\hline
\end{tabular}

The patterns described in this table are discerned from studies that examined different aspect of gymnotiform social behavior. I based our assessments of sociality on lab observations and a few field studies showing spacing between individuals and willingness to share a shelter. For aggression levels, "high" implies that agonistic interactions often result in physical injury or death, while "medium-low" might result in loss of resources, but not bodily harm. The remaining parameters, parental behavior and mating strategies were based on published studies.

1. Black-Cleworth, 1970; 2. Westby, 1988; 3. Crampton and Hopkins, 2005;

4. Kirschbaum and Schugardt, 2002; 5. Miranda et al., 2008. 5. Dunlap et al., 2011; 7. Hagedorn and Heligenberg,1985; 8. Oestreich and Zakon, 2005; 9.

Salazar, 2009; 10. W.G.R. Crampton pers. com.; 11. Unpublished observations 
Table 2. Response of Gymnotus carapo to androgen and peptide hormone treatments.

\begin{tabular}{|c|c|c|c|c|}
\hline Amplitude & P1 & $\mathbf{P 2}$ & P3 & Total \\
\hline Blank & $0.003 \pm 0.03$ & $0.013 \pm 0.024$ & $0.039 \pm 0.022$ & $0.007 \pm 0.019$ \\
\hline $\mathbf{T}$ & $-0.042 \pm 0.033$ & $0.025 \pm 0.046$ & $-0.001 \pm 0.040$ & $0.011 \pm 0.042$ \\
\hline 11-KT & $-0.280 \pm 0.061 *$ & $-0.025 \pm 0.064$ & $-0.016 \pm 0.077$ & $-0.072 \pm 0.062$ \\
\hline$\alpha-$ MSH & $-0.124 \pm 0.153$ & $0.068 \pm 0.010 *$ & $0.033 \pm 0.055$ & $0.060 \pm 0.010 *$ \\
\hline$\alpha$-MSH (Blank) & $0.049 \pm 0.017$ & $0.068 \pm 0.010$ & $0.043 \pm 0.012$ & $0.065 \pm 0.011$ \\
\hline$\alpha-M S H(T)$ & $-0.071 \pm 0.113$ & $0.058 \pm 0.005 *$ & $0.047 \pm 0.007$ & $0.054 \pm 0.004$ \\
\hline$\alpha-\operatorname{MSH}(11-\mathrm{KT})$ & $0.043 \pm 0.018$ & $0.047 \pm 0.007 *$ & $-0.182 \pm 0.134$ & $0.041 \pm 0.009$ \\
\hline Duration & P1 & P2 & P3 & Total \\
\hline Blank & $-0.210 \pm 0.009$ & $-0.010 \pm 0.020$ & $0.012 \pm 0.023$ & $-0.007 \pm 0.015$ \\
\hline $\mathbf{T}$ & $-0.015 \pm 0.011$ & $-0.003 \pm 0.011$ & $0.063 \pm 0.014$ & $0.016 \pm 0.006$ \\
\hline 11-KT & $0.009 \pm 0.023$ & $0.034 \pm 0.040$ & $0.595 \pm 0.135^{*}$ & $0.224 \pm 0.065^{*}$ \\
\hline$\alpha$-MSH & $0.016 \pm 0.006$ & $0.013 \pm 0.005 *$ & $0.040 \pm 0.007 *$ & $0.023 \pm 0.004 *$ \\
\hline$\alpha$-MSH (Blank) & $0.013 \pm 0.007$ & $0.015 \pm 0.003$ & $0.018 \pm 0.010$ & $0.014 \pm 0.005$ \\
\hline$\alpha-M S H(T)$ & $0.014 \pm 0.004$ & $0.016 \pm 0.006$ & $0.031 \pm 0.006$ & $0.021 \pm 0.003$ \\
\hline$\alpha-M S H$ (11-KT) & $0.016 \pm 0.006$ & $0.011 \pm 0.006$ & $0.030 \pm 0.005$ & $0.019 \pm 0.004$ \\
\hline
\end{tabular}

Values represent mean change following treatment \pm SEM. Asterisks * represent significant changes $(p<0.05)$ of the EOD phase in response to hormone treatment.

Response to androgen implants were compared to blank implant using post-hoc LSD. $\alpha$ MSH response was compared to saline treatment using paired t-tests. 
A

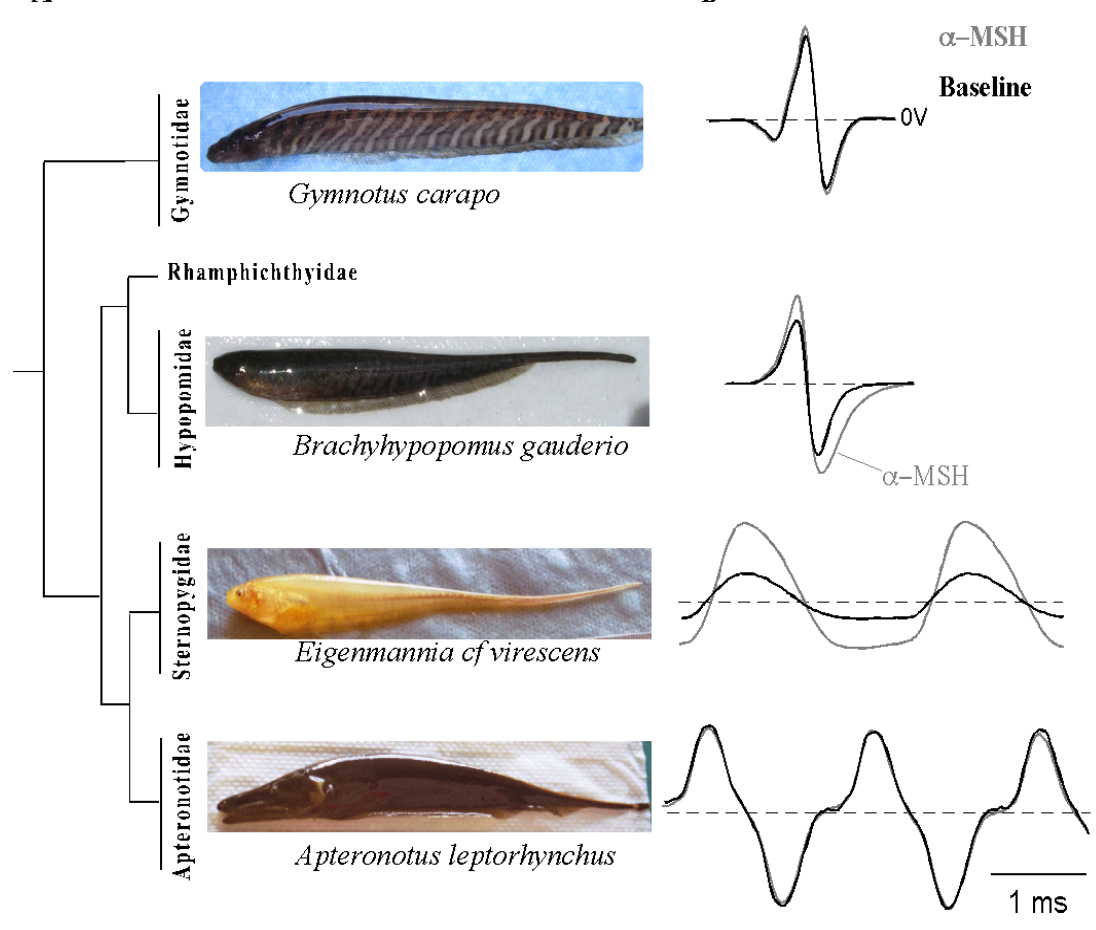

B
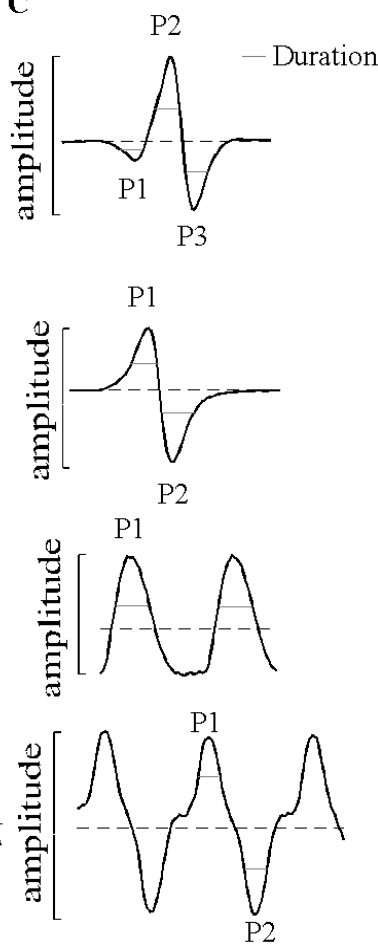

Figure 1. Selected gymnotiform species and their respective EODs. (A) Phylogeny (Crampton, 2011) and photographs of the four species we chose for this study, (B) their respective waveforms (black) and response to $\alpha-\mathrm{MSH}$ injections (gray). (C) In each species we measured total peak-to peak amplitude and duration of each phase. In $G$. carapo, we named phases $\mathrm{V} 2, \mathrm{~V} 3$, and $\mathrm{V} 4$ as $\mathrm{P} 1, \mathrm{P} 2$, and $\mathrm{P} 3$, to maintain consistent nomenclature with the other species (Pereira et al., 2007). 
A. Gymnotus carapo

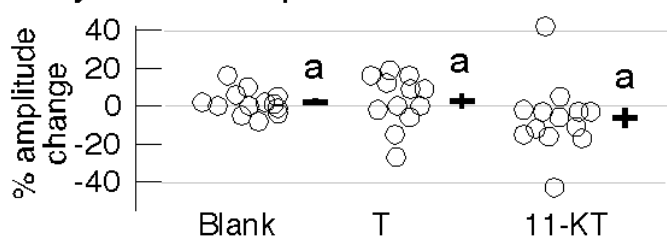

C. Brachyhypopomus gauderio

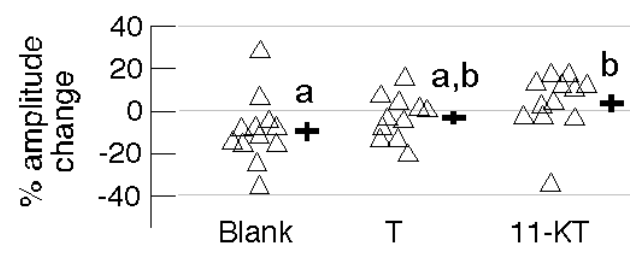

E. Eigenmannia c.f. virescens

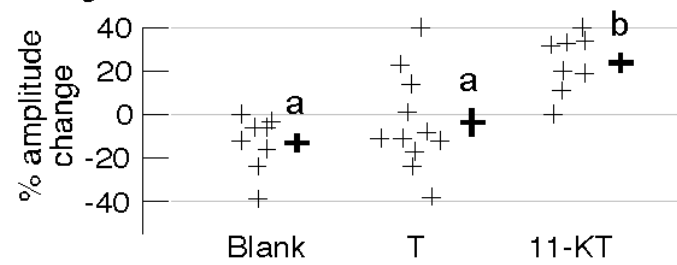

G. Apteronotus leptorhynchus

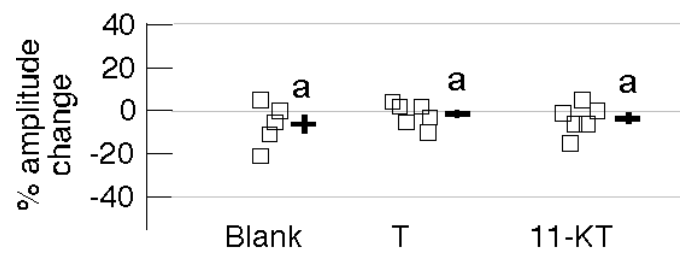

B. Gymnotus carapo

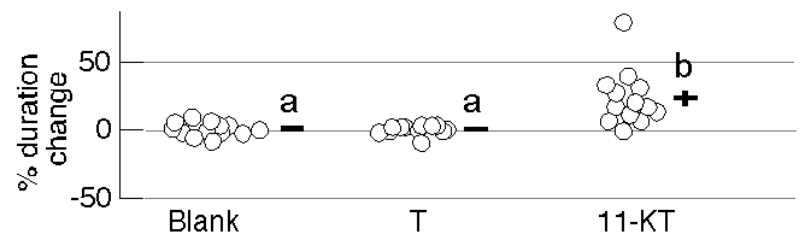

D. Brachyhypopomus gauderio

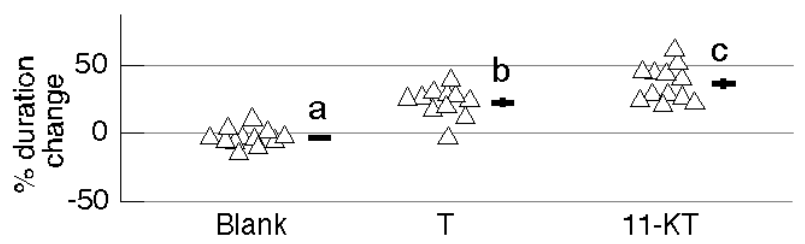

F. Eigenmannia c.f. virescens

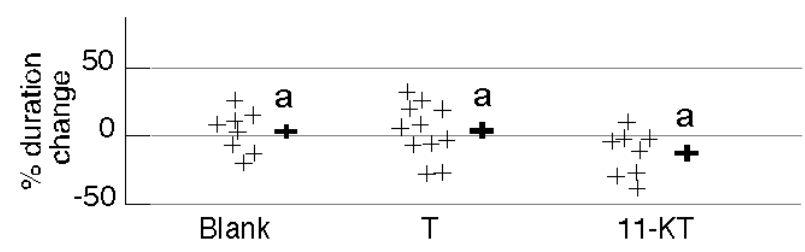

H. Apteronotus leptorhynchus

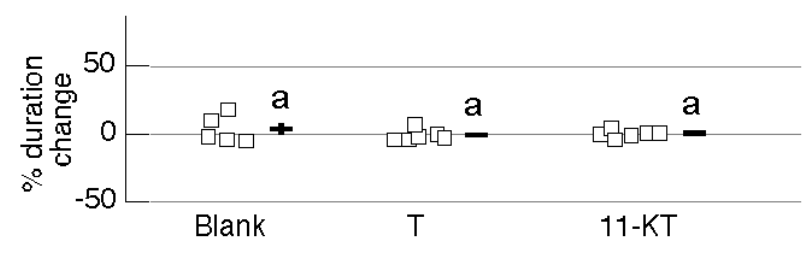

Figure 2. Effect of androgen implants on EOD amplitude and duration. 11-KT elevated EOD amplitude of $B$. gauderio (C. 11-KT p=0.02; T p=0.23), and E.cf. virescens $(\mathbf{E}$. 11$\mathrm{KT} \mathrm{p}<0.01 ; \mathrm{T} \mathrm{p}=0.24)$, but neither $11-\mathrm{KT}$ nor $\mathrm{T}$ affected amplitude of the G. carapo (A) or A. leptorhynchus (G). 11-KT increased total EOD duration of $G$. carapo (B: $\mathrm{p}<0.01$ for $11-\mathrm{KT}$; $\mathrm{p}=0.21$ for $\mathrm{T})$. In B. gauderio $11-\mathrm{KT}$ caused higher elevation of duration than $\mathrm{T}(\mathbf{D}: \mathrm{p}<0.01$ for $11-\mathrm{KT} ; \mathrm{p}<0.01$ for $\mathrm{T})$. Neither androgen implant had a significant effect on EOD duration of E. virescens (F) or A. leptorhynchus (H). Symbols represent individual data points represented as relative change, while horizontal and vertical bars depict mean and SEM, respectively. Different letters represent significant differences between treatments $(\mathrm{p}<0.05)$, based on LSD pairwise comparisons. 
A. Gymnotus carapo

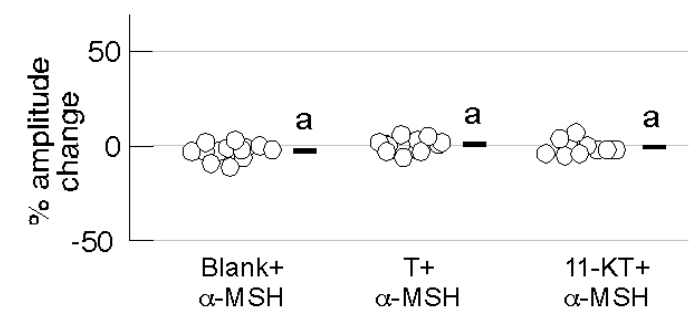

C. Brachyhypopomus gauderio

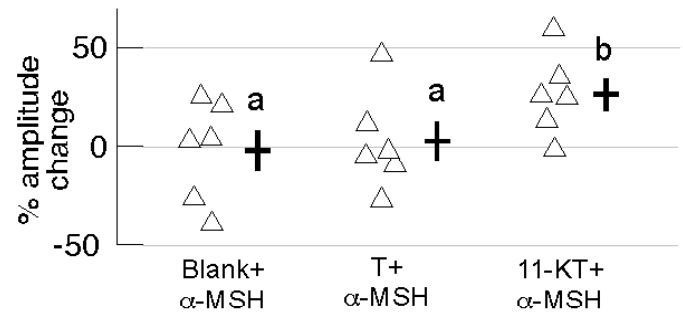

E. Eigenmannia cf. virescens

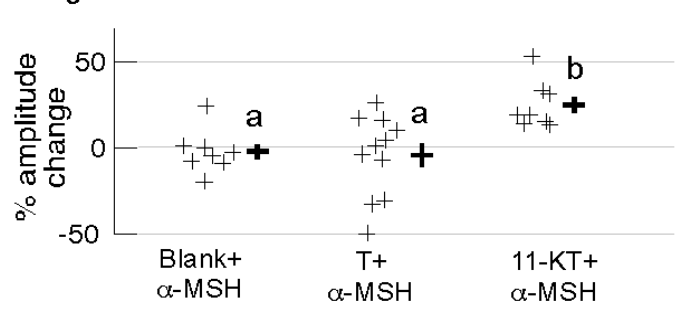

G. Apteronotus leptorhynchus

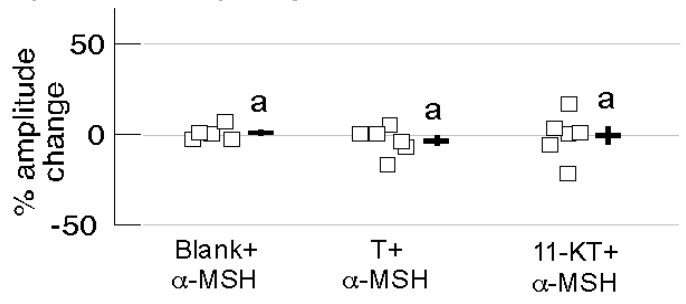

B. Gymnotus carapo

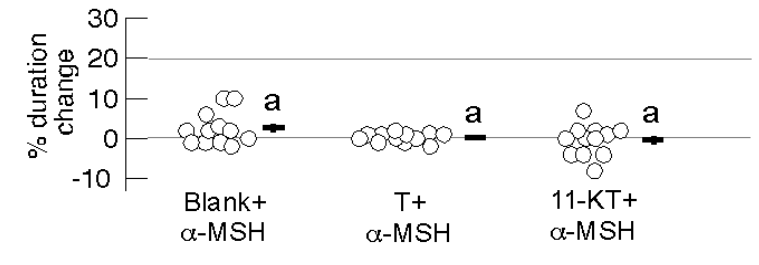

D. Brachyhypopomus gauderio

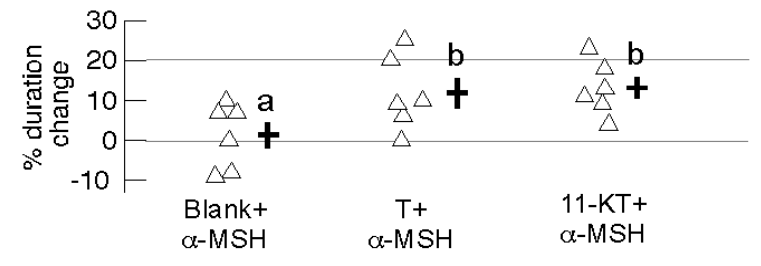

F. Eigenmannia cf. virescens

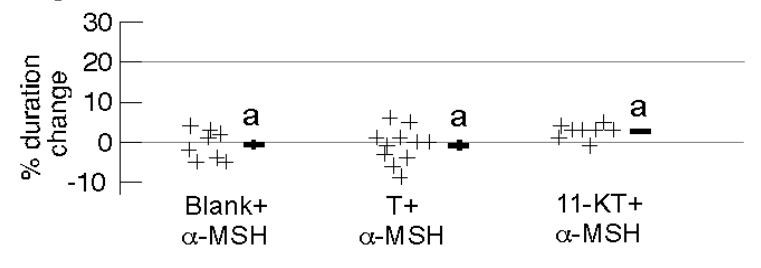

H. Apteronotus leptorhynchus

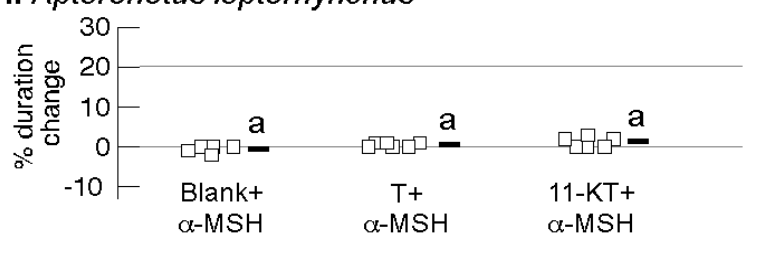

Figure 3. Effect of androgen implants on responsiveness of EOD amplitude to

melanocortins. Only 11-KT increased amplitude responsiveness to $\alpha-\mathrm{MSH}$ injections in B. gauderio $(\mathbf{C} .11-\mathrm{KT} \mathrm{p}=0.02 ; \mathrm{T} \mathrm{p}=0.78)$ and $E$. $c$. virescens $(\mathbf{E} .11-\mathrm{KT} \mathrm{p}=0.03 ; \mathrm{T}$ $\mathrm{p}=0.23)$, but neither androgen had any affect on $G$. carapo $(\mathbf{A})$ or A. leptorhynchus $(\mathbf{G})$ amplitude response. In B. gauderio $11-\mathrm{KT}$ and $\mathrm{T}$ implants increased the $\tau_{\mathrm{p} 2}$ of the $\mathrm{MSH}$ response relative to blank implants (D: $\mathrm{p}<0.01$ for $11-\mathrm{KT}, \mathrm{p}<0.01$ for T). Androgens had no effect on the total EOD duration response to MSH injections in the other three species. 
A.

\begin{tabular}{|c|c|c|c|c|c|c|c|}
\hline & & \multicolumn{6}{|c|}{ AMPLITUDE } \\
\hline \multicolumn{2}{|c|}{ Stereotypy } & $\begin{array}{c}\text { Treatment } \\
\text { Species }\end{array}$ & $\mathbf{T}$ & 11-KT & $\alpha$-MSH & $\begin{array}{c}\alpha \text {-MSH } \\
\text { (T) }\end{array}$ & $\begin{array}{l}\alpha-\text { MSH } \\
(11-K T)\end{array}$ \\
\hline \multirow{4}{*}{ 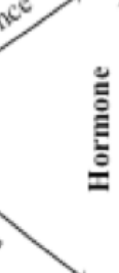 } & Insensitivity & A. leptorhynchus & & & & & \\
\hline & & G. carapo & & & + & & \\
\hline & Partial & E. virescens & & + & + & & + \\
\hline & Sensitivity & B. gauderio & & + & + & & + \\
\hline
\end{tabular}

B.

\begin{tabular}{|c|c|c|c|c|c|c|c|}
\hline & & \multicolumn{6}{|c|}{ DURATION } \\
\hline \multicolumn{2}{|c|}{ Stereotypy } & $\begin{array}{c}\text { Treatment } \\
\text { Species }\end{array}$ & $\mathrm{T}$ & 11-KT & a-MSH & $\begin{array}{c}\alpha \text {-MSH } \\
\text { (T) }\end{array}$ & $\begin{array}{c}\alpha-M S H \\
(11-K T)\end{array}$ \\
\hline \multirow{4}{*}{ 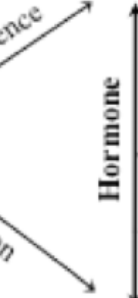 } & Insensitivity & A. leptorhynchus & & & & & \\
\hline & & E. virescens & & & & & \\
\hline & Partial & G. carapo & & + & + & & \\
\hline & Sensitivity & B. gauderio & + & + & + & + & + \\
\hline
\end{tabular}

Figure 4. EOD plasticity and stereotypy reflect endocrine integration and independence in gymnotiforms. EODs of gymnotiform species with static, stereotyped signals, as seen in amplitude of A. leptorhynchus and amplitude and duration of E. virescens are insensitive to androgens and melanocortin hormones. G. carapo, E. virescens (amplitude) and B. gauderio exhibit varying levels of hormone sensitivity and EOD plasticity, suggesting integration between communication signal and hormonal modulator. Gymnotiform species are placed in order of increasing sensitivity to hormone treatments (left column) of their waveforms. Waveform responses are separated into two tables, amplitude (A) and duration $(\mathbf{B})$. Pluses indicate a presence of a response. 


\section{CHAPTER V}

CONCLUSION 
The ability to adjust signals to reflect changes in motivation, body condition and social status may serve as a substrate for the evolution of complex communication systems and sociality. The physiological ability to adjust signals occurs through the interplay between peptide and steroid hormones. Understanding this interplay can allow researchers to advance testable models for evolution of neural and genetic mechanisms that regulate sociality.

In my dissertation I examined the extent of dynamic communication signals within the electric fish order Gymnotiformes. I investigated how closely related species of weakly electric fish modify different parameters of their EOD waveforms. I showed that signal plasticity is not an all-or-none event, but rather a continuum that is differentially mediated by androgen and peptide hormones and tracks species-specific sociality levels. Social strategies facilitate or inhibit dynamic signaling, whereby species that maintain stable social groups sacrifice short-term signal plasticity for stable, easily identifiable signature signals, while species that maintain loose social associations have the most plastic signals. Consequently, the electric organs of species that dynamically alter their signal structure to adjust to changes in the social environment are most sensitive and responsive to steroids, peptide hormones, and neuromodulators. Species that maintain stable social groups, on the other hand, exhibit insensitivity to such hormone changes. In gymnotiforms, the electrocytes of the most gregarious species $(B$. gauderio and E. virescens) were most responsive to androgen and melanocortin manipulations, while the most aggressive and territorial species (A. leptorhynchus and $G$. carapo) were insensitive to hormone manipulations. 
Furthermore, I showed that the androgens testosterone and the fish specific 11ketotestosterone regulate different aspects of the EOD. This differential androgen regulation may serve as a basis for independent regulation of distinct signal traits and possibly, set the stage for the evolution of increased plasticity. Thus, communication plasticity is driven by differential responsiveness patterns to hormones that are correlated to behavioral phenotypes.

Much research has focused on understanding the neural circuitry of electrocommunication and the mechanisms of EOD modulations within the nervous system. My dissertation elucidated some of the proximate mechanisms that modulate dynamic signaling in gymnotiforms; however, still many questions need to be addressed. Currently, we know very little about the natural history of gymnotiforms. To understand the selection pressures that led to the evolution of differential dynamic signaling in this order, we need to know how these animals behave in their natural habitats. For instance, are the highly territorial and aggressive species equally aggressive in the wild as they are in the laboratory, where they cannot escape their opponents? How often do territorial and aggressive individuals come in contact with each other? Is individual recognition more prevalent in the shoaling than territorial species? Furthermore, while I have shown different forms of signal plasticity in gymnotiforms, it is not know what these signal modulations mean to the fish in their natural habitats. Studies examining the role of EOD modulations in behavior are sorely lacking in the electric fish literature.

Furthermore, more studies are needed to understand the proximate mechanisms driving species differences in dynamic signaling. Currently, it is not known whether the observed melanocortin sensitivities result from the same melanocortin receptor type 
being differentially expressed within the electric organ and or between species, or if different melanocortin receptors are expressed in species with different sociality levels. Finally, the same questions can be addressed towards androgen regulation of the waveform.

By combining the existing knowledge of the mechanisms of signal modulation in gymnotiforms with experiments designed in a contextually relevant manner to the fish, we can further understand the factors that drive evolution of dynamic communication signals, which are likely conserved across vertebrates. 
VITA

\section{ANNA GOLDINA}

Born

2005

2003

2010-2011

$2008-2010$

2007-2009

2003-2007

2002-2003
October 1, 1980, Kiev, Ukraine

Doctoral Candidate in Biological Sciences

Florida International University

Miami, Florida

B.S. with honors, Biology

Florida International University

Miami, Florida

Instructor for the QBIC program

General Bio I Laboratory and Science Café

Department of Biological Sciences

Miami, FL

Curriculum development for General Biology laboratories

Department of Biological Sciences

Florida International University

Miami, FL

Laboratory Instructor - Co-Head TA

General Bio I \& II Laboratories

Department of Biological Sciences

Florida International University

Miami, FL

MBRS RISE Graduate Fellow

Research assistant in the lab of Philip Stoddard

Florida International University

Miami, Florida

MBRS RISE Undergraduate Fellow

Research assistant in the lab of Ophelia Weeks

Florida International University

Miami, Florida 


\section{PUBLICATIONS}

Goldina A, Gavassa S, Stoddard PK. (2011) Testosterone and 11-ketotestosteone have different regulatory effects on electric communication signals of Brachyhypopomus gauderio. Hormones and Behavior 60(2): 139-147.

Goldina A, Simms TM, Pitzer T. (2011) Once a loser always a loser? Using crayfish to teach behavioral endocrinology. Pages 355-360, in Tested Studies for Laboratory

Teaching, Volume 32 (K. McMahon, Editor). Proceedings of the $32^{\text {nd }}$ Conference of the Association for Biology Laboratory Education (ABLE), 446 pages.

http://www.ableweb.org/volumes/vol-32/v32reprint.php?ch=35

Simms TM*, Goldina A*, Pitzer T. 2010 General Biology I Laboratory Manual. McGraw-Hill, New York. * Both authors contributed equally to the production of this manual.

Goldina A*, Simms TM*, Pitzer T. 2010. General Biology II Laboratory Manual. McGraw-Hill, New York. * Both authors contributed equally to the production of this manual.

Markham MR, Allee SJ, Goldina A, Stoddard PK. 2009. Melanocortins regulate the electric waveforms of gymnotiform electric fish. Hormones and Behavior. 55: 306-313. 